Nevada

Environmental

Restoration

Project

\title{
Corrective Action Investigation Plan for Corrective Action Unit 371: Johnnie Boy Crater and Pin Stripe Nevada Test Site, Nevada
}

Controlled Copy No::

Revision No.: 0

February 2009

Approved for public release; further dissemination unlimited.

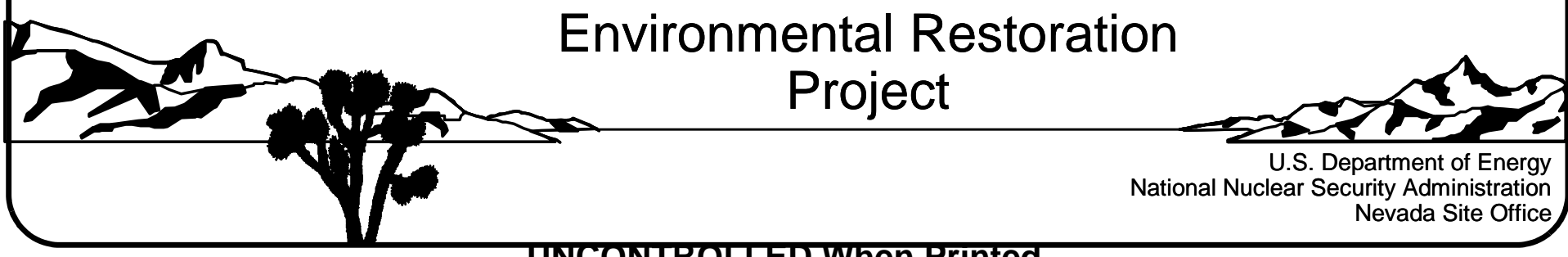


Available for sale to the public from:

U.S. Department of Commerce

National Technical Information Service

5285 Port Royal Road

Springfield, VA 22161

Phone: 800.553 .6847

Fax: 703.605.6900

Email: orders@ntis.gov

Online ordering: http://www.ntis.gov/ordering.htm

Available electronically at http://www.osti.gov/bridge

Available for a processing fee to U.S. Department of Energy and its contractors, in paper, from:

U.S. Department of Energy

Office of Scientific and Technical Information

P.O. Box 62

Oak Ridge, TN 37831-0062

Phone: 865.576.8401

Fax: 865.576.5728

Email: reports@adonis.osti.gov

Reference herein to any specific commercial product, process, or service by trade name, trademark, manufacturer, or otherwise, does not necessarily constitute or imply its endorsement, recommendation, or favoring by the United States Government or any agency thereof or its contractors or subcontractors. 


\title{
CORRECTIVE ACTION INVESTIGATION PLAN FOR CORRECTIVE ACTION UNIT 371: JOHNNIE BOY CRATER AND PIN STRIPE NEVADA TEST SITE, NEVADA
}

\author{
U.S. Department of Energy \\ National Nuclear Security Administration \\ Nevada Site Office \\ Las Vegas, Nevada
}

Controlled Copy No.:

Revision No.: 0

February 2009

Approved for public release; further dissemination unlimited.

Reviewed and determined to be UNCLASSIFIED.
Derivative Classifier: $\frac{\text { Joseph Johnston, SNJV Classification Officer }}{\text { (Name/personal identifier and position title) }}$
Signature: $\frac{1 \mathrm{~s} / \text { Joseph Johnston }}{02 / 19 / 09}$
Date:




\section{CORRECTIVE ACTION INVESTIGATION PLAN FOR}

CORRECTIVE ACTION UNIT 371:

JOHNNIE BOY CRATER AND PIN STRIPE

NEVADA TEST SITE, NEVADA

Approved by: /s/ Kevin J. Cabble

Date: 02/27/2009

Kevin J. Cabble

Acting Federal Sub-Project Director

Soils Sub-Project

Approved by: /s/ Robert F. Boehlecke

Date: 02/27/2009

Robert F. Boehlecke

Federal Project Director

Environmental Restoration Project 


\section{Table of Contents}

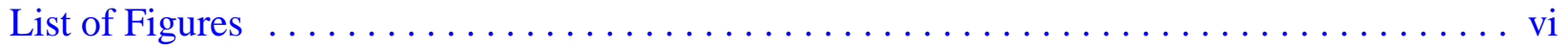

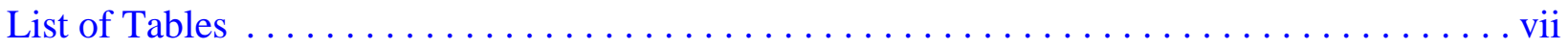

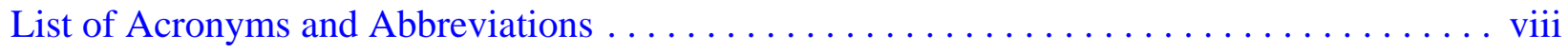

Executive Summary . . . . . . . . . . . . . . . . . . . . . . ES-1

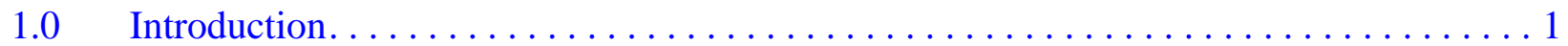

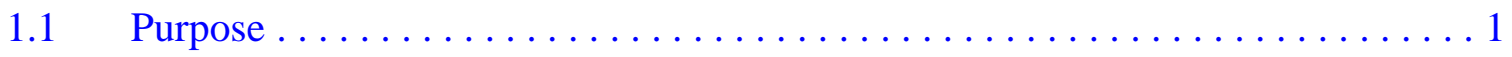

1.1.1 Corrective Action Unit 371 History and Description. . . . . . . . . . 1

1.1.2 Data Quality Objective Summary ..................... 4

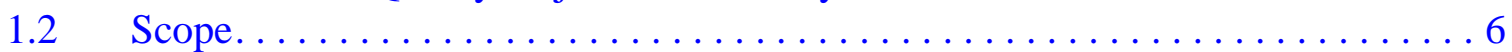

1.3 Corrective Action Investigation Plan Contents $\ldots \ldots \ldots \ldots \ldots \ldots \ldots$

$2.0 \quad$ Facility Description. . . . . . . . . . . . . . . . $8 \ldots \ldots \ldots \ldots$

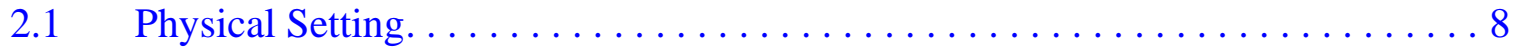

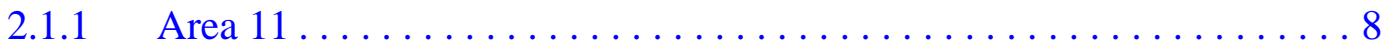

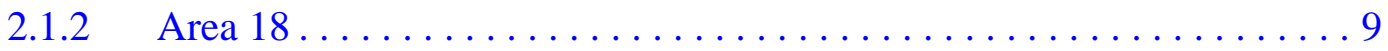

2.2 Operational History. . . . . . . . . . . . . . . . . . . 10

2.2.1 Corrective Action Site 11-23-05, Pin Stripe Contamination Area . . . . 10

2.2.2 Corrective Action Site 18-45-01, U-18j-2 Crater (Johnnie Boy) . . . . . 10

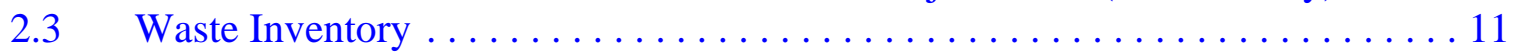

2.3.1 Corrective Action Site 11-23-05, Pin Stripe Contamination Area . . . . 11

2.3.2 Corrective Action Site 18-45-01, U-18j-2 Crater (Johnnie Boy) . . . . . 11

2.4 Release Information . . . . . . . . . . . . . . . . . . . . 11

2.4.1 Corrective Action Site 11-23-05, Pin Stripe Contamination Area . . . . 11

2.4.2 Corrective Action Site 18-45-01, U-18j-2 Crater (Johnnie Boy) . . . . . 12

2.5 Investigative Background . . . . . . . . . . . . . . . . 12

2.5.1 Corrective Action Site 11-23-05, Pin Stripe Contamination Area . . . . . 12

2.5.2 Corrective Action Site 18-45-01, U-18j-2 Crater (Johnnie Boy) . . . . . 12

2.5.3 National Environmental Policy Act . . . . . . . . . . . . 13

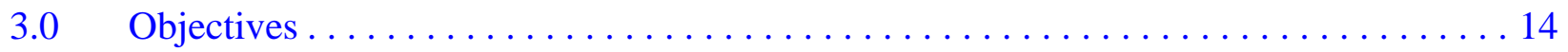

$3.1 \quad$ Conceptual Site Model . . . . . . . . . . . . . . . . . . . . . . 14

3.1.1 Land-Use and Exposure Scenarios. . . . . . . . . . . . . . 17

3.1.2 Contaminant Sources . . . . . . . . . . . . . . . . . . . 17

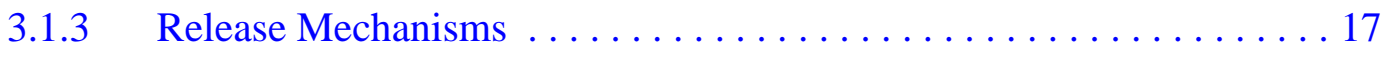

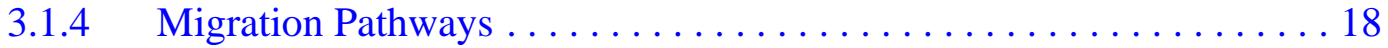

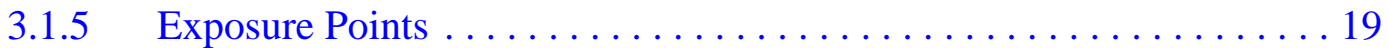

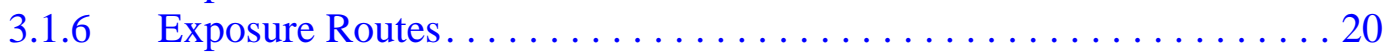

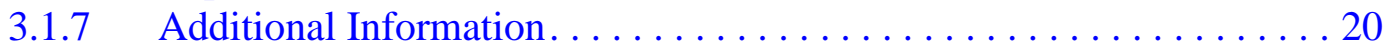

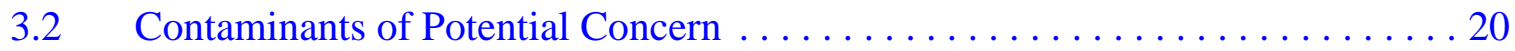

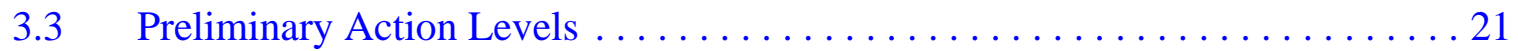




\section{Table of Contents (Continued)}

3.3.1 Chemical PALs............................ 24

3.3.2 Total Petroleum Hydrocarbon PALs $\ldots \ldots \ldots \ldots \ldots \ldots \ldots \ldots \ldots$

3.3.3 Radionuclide PALs........................... 25

3.4 Data Quality Objective Process Discussion .................. 25

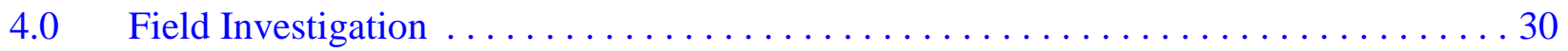

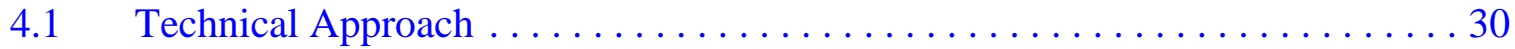

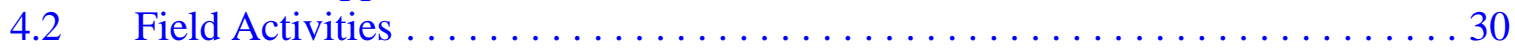

4.2.1 Site Preparation Activities . . . . . . . . . . . . . . . . 30

4.2.2 Sample Location Selection....................... 31

4.2.3 Sample Collection ........................... 32

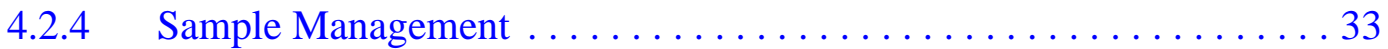

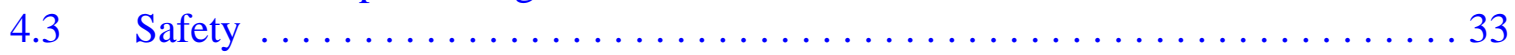

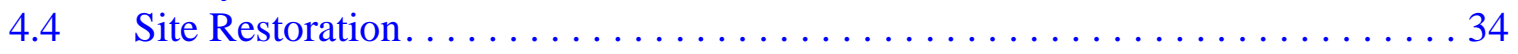

$5.0 \quad$ Waste Management......................................... 35

$5.1 \quad$ Waste Minimization .................................... 35

$5.2 \quad$ Potential Waste Streams . . . . . . . . . . . . . . . . . . . . . . 36

$5.3 \quad$ Investigation-Derived Waste Management $\ldots \ldots \ldots \ldots \ldots \ldots \ldots \ldots \ldots \ldots$

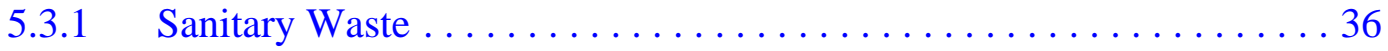

5.3.2 Low-Level Radioactive Waste......................... 37

5.3 .3 Hazardous Waste . . . . . . . . . . . . . . . . . . . . 38

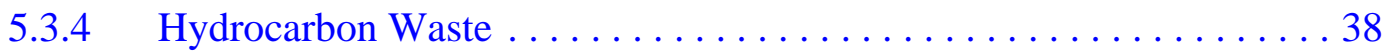

5.3.5 Mixed Low-Level Waste . . . . . . . . . . . . . . . . . . . . 38

5.3.6 Polychlorinated Biphenyls ........................... 39

5.4 Management of Specific Waste Streams . . . . . . . . . . . . . . . . . 39

5.4.1 Personal Protective Equipment. ...................... 39

5.4.2 Management of Decontamination Rinsate .................. 39

5.4 .3 Management of Soil ............................ 40

5.4 .4 Management of Debris ......................... 40

6.0 Quality Assurance/Quality Control $\ldots \ldots \ldots \ldots \ldots \ldots \ldots \ldots \ldots \ldots \ldots \ldots \ldots \ldots \ldots$

6.1 Quality Control Sampling Activities $\ldots \ldots \ldots \ldots \ldots \ldots \ldots \ldots \ldots \ldots . \ldots \ldots 1$

$6.2 \quad$ Laboratory/Analytical Quality Assurance ...................... 42

6.2.1 Data Validation............................... 42

6.2 .2 Data Quality Indicators. . . . . . . . . . . . . . . . . 42

$6.2 .3 \quad$ Precision ................................... 44

$6.2 .4 \quad$ Accuracy................................. 45

6.2.5 Representativeness........................... 46

6.2 .6 Comparability ............................ 47

6.2.7 Completeness ........................... 47 


\section{Table of Contents (Continued)}

6.2.8 Sensitivity......................... 47

$7.0 \quad$ Duration and Records Availability . ........................... 49

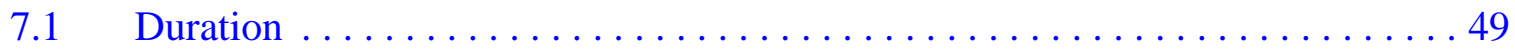

$7.2 \quad$ Records Availability .............................. 49

$8.0 \quad$ References........................................ 50

\section{Appendix A - Data Quality Objectives}

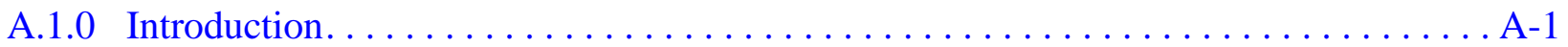

A.2.0 Background Information. $\ldots \ldots \ldots \ldots \ldots \ldots \ldots \ldots \ldots \ldots \ldots \ldots \ldots \ldots \ldots \ldots \ldots \ldots \ldots \ldots$

A.2.1 Corrective Action Site 11-23-05, Pin Stripe Contamination Area .......... A-3

A.2.2 Corrective Action Site 18-45-01, U-18j-2 Crater (Johnnie Boy) . . . . . . . . . A-6

A.3.0 Step 1 - State the Problem............................. A

A.3.1 Planning Team Members $\ldots \ldots \ldots \ldots \ldots \ldots \ldots \ldots \ldots \ldots \ldots \ldots \ldots$ A -10

A.3.2 Conceptual Site Model . ............................ A-10

A.3.2.1 Contaminant Release .......................... A-11

A.3.2.2 Potential Contaminants.......................... A-14

A.3.2.3 Contaminant Characteristics. . . . . . . . . . . . . . A-16

A.3.2.4 Site Characteristics....................... A-16

A.3.2.5 Migration Pathways and Transport Mechanisms............ A-16

A.3.2.6 Exposure Scenarios .......................... A-18

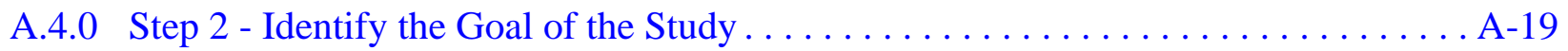

A.4.1 Decision Statements . . . . . . . . . . . . . . . . . . . . . . A-19

A.4.1.1 Primary Releases $\ldots \ldots \ldots \ldots \ldots \ldots \ldots \ldots \ldots \ldots \ldots$. A-19

A.4.1.2 Other Releases ............................ A-19

A.4.2 Alternative Actions to the Decisions $\ldots \ldots \ldots \ldots \ldots \ldots \ldots \ldots \ldots \ldots$ A-20

A.4.2.1 Alternative Actions to Decision I. . . . . . . . . . . . . A-20

A.4.2.2 Alternative Actions to Decision II . . . . . . . . . . . . . A-20

A.5.0 Step 3 - Identify Information Inputs . . . . . . . . . . . . . . . . . . . . A-21

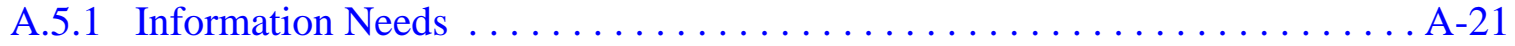

A.5.1.1 Primary Releases $\ldots \ldots \ldots \ldots \ldots \ldots \ldots \ldots \ldots \ldots \ldots \ldots$ A-21

A.5.1.2 Other Releases ............................ A-21

A.5.2 Sources of Information . ............................... A-22

A.5.2.1 Sample Locations ........................... A-22

A.5.2.1.1 Primary Releases ...................... A-23

A.5.2.1.2 Other Releases . . . . . . . . . . . . . . . . . A-26 


\section{Table of Contents (Continued)}

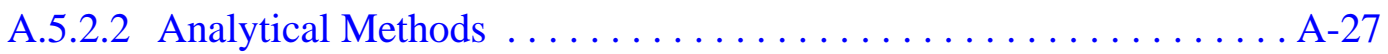

A.6.0 Step 4 - Define the Boundaries of the Study $\ldots \ldots \ldots \ldots \ldots \ldots \ldots \ldots \ldots \ldots \ldots \ldots \ldots$

A.6.1 Target Populations of Interest. . . . . . . . . . . . . . . . . . . A-28

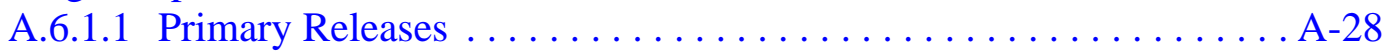

A.6.1.2 Other Releases........................... A-28

A.6.2 Spatial Boundaries . . . . . . . . . . . . . . . . . . . . . . . A-28

A.6.3 Practical Constraints ............................... A-29

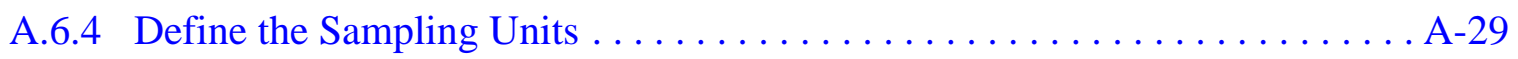

A.7.0 Step 5 - Develop the Analytic Approach ...................... A-30

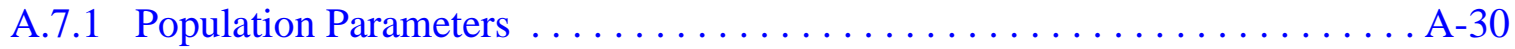

A.7.1.1 Primary Releases $\ldots \ldots \ldots \ldots \ldots \ldots \ldots \ldots \ldots \ldots \ldots \ldots \ldots$ A-30

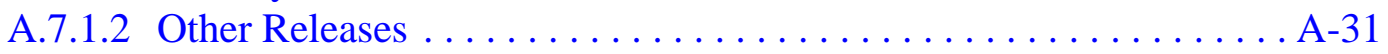

A.7.2 Action Levels . .............................. A-31

A.7.2.1 Chemical PALs.......................... A-32

A.7.2.2 Total Petroleum Hydrocarbon PALs $\ldots \ldots \ldots \ldots \ldots \ldots \ldots \ldots$ A-32

A.7.2.3 Radionuclide PALs. . . . . . . . . . . . . . . . . . A-32

A.7.3 Decision Rules . ............................. A-33

A.8.0 Step 6 - Specify Performance or Acceptance Criteria $\ldots \ldots \ldots \ldots \ldots \ldots \ldots \ldots$ A-34

A.8.1 Decision Hypotheses. . . . . . . . . . . . . . . . . . . . . . . A 34

A.8.2 False Negative Decision Error $\ldots \ldots \ldots \ldots \ldots \ldots \ldots \ldots \ldots \ldots \ldots$ A-34

A.8.2.1 False Negative Decision Error for Judgmental Sampling . . . . . . . A A-35

A.8.2.2 False Negative Decision Error for Probabilistic Sampling ........ A-37

A.8.3 False Positive Decision Error . . . . . . . . . . . . . . . . . . . A-37

A.9.0 Step 7 - Develop the Plan for Obtaining Data $\ldots \ldots \ldots \ldots \ldots \ldots \ldots \ldots \ldots$ A-39

A.9.1 Sampling of Primary Releases . . . . . . . . . . . . . . . . . . A-39

A.9.1.1 Decision I Sampling . . . . . . . . . . . . .

A.9.1.2 Decision II Sampling $\ldots \ldots \ldots \ldots \ldots \ldots \ldots \ldots \ldots \ldots \ldots \ldots \ldots \ldots \ldots \ldots$

A.9.2 Other Releases .................................... A-45

A.9.2.1 Decision I . . . . . . . . . . . . . . . . . . . . . . . .

A.9.2.2 Decision II ............................. A 47

A.10.0 References. .................................... A-49

\section{Appendix B - Project Organization}

B.1.0 Project Organization . . . . . . . . . . . . . . . . . . . .

\section{Appendix C - Nevada Division of Environmental Protection Comment Responses}




\section{List of Figures}

Number

Title

Page

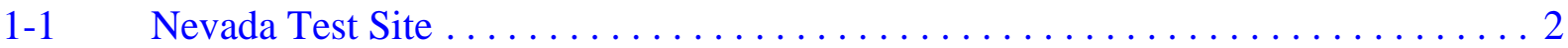

1-2 Corrective Action Unit 371, CAS Location Map ...................... 3

3-1 Conceptual Site Model Diagram .......................... 15

3-2 Corrective Action Unit 371 Conceptual Site Model ................... 16

3-3 Risk-Based Corrective Action Decision Process $\ldots \ldots \ldots \ldots \ldots \ldots \ldots \ldots$

A.2-1 Corrective Action Unit 371, CAS Location Map ................... A-4

A.2-2 Location of CAS 11-23-05, Pin Stripe Contamination Area. ............ A-5

A.2-3 Location of CAS 18-45-01, U-18j-2 Crater (Johnnie Boy) . . . . . . . . . . . A-7

A.3-1 Conceptual Site Model for CAU $371 \ldots \ldots \ldots \ldots \ldots \ldots \ldots \ldots \ldots$ A-13

A.9-1 Proposed Sample Locations at CAS $11-23-05 \ldots \ldots \ldots \ldots \ldots \ldots \ldots . . . . . .41$

A.9-2 Proposed Decision I Sampling for CAS $18-45-01 \ldots \ldots \ldots \ldots \ldots \ldots$ A-42

A.9-3 Sample Plot Example for CASs $11-23-05$ and $18-45-01 \ldots \ldots \ldots \ldots$. . . . . A-44

A.9-4 Proposed Decision II Sampling for CAS $18-45-01 \ldots \ldots \ldots \ldots \ldots \ldots \ldots$ A-46 


\section{List of Tables}

Number

Title

Page

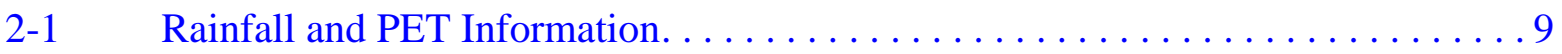

3-1 Constituents Reported by Analytical Methods . . . . . . . . . . . . . . . . 22

3-2 Analytical Requirements for Radionuclides for CAU $371 \ldots \ldots \ldots \ldots . \ldots 28$

3-3 Analytical Requirements for Chemical COPCs for CAU $371 \ldots \ldots \ldots \ldots$

5-1 Waste Management Regulations and Requirements . . . . . . . . . 37

6-1 Laboratory and Analytical Performance Criteria for CAU 371

Data Quality Indicators. . . . . . . . . . . . . . . . . . . 43

7-1 Corrective Action Investigation Activity Durations . . . . . . . . . . . . . . 49

A.3-1 Conceptual Site Model Description of Elements for CASs in CAU $371 \ldots$. . . A-12

A.3-2 Analytical Program. ............................ A-15

A.3-3 Targeted Contaminants for CAU $371 \ldots \ldots \ldots \ldots \ldots \ldots \ldots \ldots \ldots$. . . . . . . .

A.3-4 Land-Use and Exposure Scenarios . . . . . . . . . . . . . A-18

A.5-1 Characteristics of Composite and Simple Random Sampling . . . . . . . . A-25

A.6-1 Spatial Boundaries of CAU 371 CASs . . . . . . . . . . . . . . . . A-29

A.9-1 Placement of Random Composite Sample Locations. . . . . . . . . . . . . . . . . A-45 


\section{List of Acronyms and Abbreviations}

Ac

Am

ASTM

bgs

CADD

CAI

CAIP

CAS

CAU

CERCLA

CFR

$\mathrm{cm}$

Co

COC

COPC

Cs

CSM

DoD

DOE

DOT

DQI

DQO

DRO

EPA
Actinium

Americium

American Society for Testing and Materials

Below ground surface

Corrective action decision document

Corrective action investigation

Corrective action investigation plan

Corrective action site

Corrective action unit

Comprehensive Environmental Response, Compensation, and Liability Act

Code of Federal Regulations

Centimeter

Cobalt

Contaminant of concern

Contaminant of potential concern

Cesium

Conceptual site model

U.S. Department of Defense

U.S. Department of Energy

U.S. Department of Transportation

Data quality indicator

Data quality objective

Diesel-range organics

U.S. Environmental Protection Agency 


\section{List of Acronyms and Abbreviations (Continued)}

\begin{tabular}{|c|c|}
\hline $\mathrm{Eu}$ & Europium \\
\hline FAL & Final action level \\
\hline FFACO & Federal Facility Agreement and Consent Order \\
\hline FLQC & Full laboratory quality control \\
\hline FSR & Field-screening result \\
\hline $\mathrm{ft}$ & Foot \\
\hline GPS & Global Positioning System \\
\hline GRO & Gasoline-range organics \\
\hline GZ & Ground zero \\
\hline I & Iodine \\
\hline IDW & Investigation-derived waste \\
\hline in. & Inch \\
\hline $\mathrm{K}$ & Potassium \\
\hline LCS & Laboratory control sample \\
\hline $\mathrm{m}$ & Meter \\
\hline $\mathrm{m}^{2}$ & Square meter \\
\hline MDC & Minimum detectable concentration \\
\hline $\mathrm{mg} / \mathrm{kg}$ & Milligrams per kilogram \\
\hline $\mathrm{mrem} / \mathrm{yr}$ & Millirem per year \\
\hline N/A & Not applicable \\
\hline NAC & Nevada Administrative Code \\
\hline NAD & North American Datum \\
\hline NCRP & National Council on Radiation Protection and Measurement \\
\hline ND & Normalized difference \\
\hline
\end{tabular}




\section{List of Acronyms and Abbreviations (Continued)}

\begin{tabular}{|c|c|}
\hline NDEP & Nevada Division of Environmental Protection \\
\hline NEPA & National Environmental Policy Act \\
\hline $\mathrm{Ni}$ & Niobium \\
\hline NNSA/NSO & $\begin{array}{l}\text { U.S. Department of Energy, National Nuclear Security Administration } \\
\text { Nevada Site Office }\end{array}$ \\
\hline NRS & Nevada Revised Statutes \\
\hline NSTec & National Security Technologies, LLC \\
\hline NTS & Nevada Test Site \\
\hline NTSWAC & Nevada Test Site Waste Acceptance Criteria \\
\hline NV/YMP & Nevada Yucca Mountain Project \\
\hline OR & Other release \\
\hline PAL & Preliminary action level \\
\hline $\mathrm{Pb}$ & Lead \\
\hline PCB & Polychlorinated biphenyl \\
\hline PET & Potential evapotranspiration \\
\hline POC & Performance Objective for the Certification of Nonradioactive Hazardous Waste \\
\hline PPE & Personal protective equipment \\
\hline PR & Primary release \\
\hline PRG & Preliminary remediation goal \\
\hline $\mathrm{Pu}$ & Plutonium \\
\hline QA & Quality assurance \\
\hline QAPP & Quality Assurance Project Plan \\
\hline QC & Quality control \\
\hline RadCon & Radiological control \\
\hline
\end{tabular}




\section{List of Acronyms and Abbreviations (Continued)}

\begin{tabular}{|c|c|}
\hline RBCA & Risk-based corrective action \\
\hline RBSL & Risk-based screening level \\
\hline RCA & Radiologically controlled area \\
\hline RCRA & Resource Conservation and Recovery Act \\
\hline RESRAD & Residual Radioactive \\
\hline RIDP & Radionuclide Inventory and Distribution Program \\
\hline RL & Reporting limit \\
\hline RMA & Radioactive material area \\
\hline RPD & Relative percent difference \\
\hline RWMS & Radioactive Waste Material Site \\
\hline SDWS & Safe Drinking Water Standards \\
\hline SNJV & Stoller-Navarro Joint Venture \\
\hline $\mathrm{Sr}$ & Strontium \\
\hline SSTL & Site-specific target level \\
\hline SVOC & Semivolatile organic compound \\
\hline TCLP & Toxicity Characteristic Leaching Procedure \\
\hline TED & Total effective dose \\
\hline Th & Thorium \\
\hline $\mathrm{Tl}$ & Thallium \\
\hline TLD & Thermoluminescent dosimeter \\
\hline $\mathrm{TPH}$ & Total petroleum hydrocarbons \\
\hline TSCA & Toxic Substances Control Act \\
\hline $\mathrm{U}$ & Uranium \\
\hline UCL & Upper confidence limit \\
\hline
\end{tabular}




\section{List of Acronyms and Abbreviations (Continued)}

$\begin{array}{ll}\text { USGS } & \text { U.S. Geological Survey } \\ \text { UTM } & \text { Universal Transverse Mercator } \\ \text { VOC } & \text { Volatile organic compound } \\ \mu \mathrm{R} / \mathrm{hr} & \text { Microroentgens per hour } \\ \% \mathrm{R} & \text { Percent recovery }\end{array}$




\section{Executive Summary}

Corrective Action Unit (CAU) 371 is located in Areas 11 and 18 of the Nevada Test Site, which is approximately 65 miles northwest of Las Vegas, Nevada. Corrective Action Unit 371 is comprised of the two corrective action sites (CASs) listed below:

- 11-23-05, Pin Stripe Contamination Area

- 18-45-01, U-18j-2 Crater (Johnnie Boy)

These sites are being investigated because existing information on the nature and extent of potential contamination is insufficient to evaluate and recommend corrective action alternatives. Additional information will be obtained by conducting a corrective action investigation before evaluating corrective action alternatives and selecting the appropriate corrective action for each CAS. The results of the field investigation will support a defensible evaluation of viable corrective action alternatives that will be presented in the Corrective Action Decision Document.

The sites will be investigated based on the data quality objectives (DQOs) developed on November 19, 2008, by representatives of the Nevada Division of Environmental Protection; U.S. Department of Energy, National Nuclear Security Administration Nevada Site Office; Stoller-Navarro Joint Venture; and National Security Technologies, LLC. The DQO process was used to identify and define the type, amount, and quality of data needed to develop and evaluate appropriate corrective actions for CAU 371.

Appendix A provides a detailed discussion of the DQO methodology and the DQOs specific to each CAS.

The scope of the corrective action investigation for CAU 371 includes the following activities:

- Move surface debris and/or materials, as needed, to facilitate sampling.

- Conduct radiological surveys.

- Measure in situ external dose rates using thermoluminescent dosimeters or other dose measurement devices.

- Collect and submit environmental samples for laboratory analysis to determine internal dose rates. 
- Combine internal and external dose rates to determine whether total dose rates exceed final action levels (FALs).

- Collect and submit environmental samples for laboratory analysis to determine whether chemical contaminants are present at concentrations exceeding FALs.

- If contamination exceeds FALs, define the extent of the contamination exceeding FALs.

- Investigate waste to determine whether potential source material is present.

This Corrective Action Investigation Plan has been developed in accordance with the Federal Facility Agreement and Consent Order that was agreed to by the State of Nevada; U.S. Department of Energy; and U.S. Department of Defense. Under the Federal Facility Agreement and Consent Order, this Corrective Action Investigation Plan will be submitted to the Nevada Division of Environmental Protection for approval. Fieldwork will be conducted following approval of the plan. 


\subsection{Introduction}

This Corrective Action Investigation Plan (CAIP) contains project-specific information including facility descriptions, environmental sample collection objectives, and criteria for conducting site investigation activities at Corrective Action Unit (CAU) 371: Johnnie Boy Crater and Pin Stripe, Nevada Test Site (NTS), Nevada.

This CAIP has been developed in accordance with the Federal Facility Agreement and Consent Order (FFACO) that was agreed to by the State of Nevada; U.S. Department of Energy (DOE) and U.S. Department of Defense (FFACO, 1996; as amended February 2008).

The corrective action sites (CASs) within CAU 371 are located in Areas 11 and 18 of the NTS, which is approximately 65 miles northwest of Las Vegas, Nevada (Figure 1-1). Corrective Action Unit 371 is comprised of the two CASs shown on Figure 1-2 and listed below:

- 11-23-05, Pin Stripe Contamination Area

- $\quad$ 18-45-01, U-18j-2 Crater (Johnnie Boy)

The corrective action investigation (CAI) will include field inspections, radiological surveys, sampling of environmental media, analysis of samples, and evaluation of investigation results. Data will be obtained to support corrective action alternative evaluations and waste management decisions.

\subsection{Purpose}

The CASs in CAU 371 are being investigated because hazardous and/or radioactive contaminants may be present in concentrations that could potentially pose a threat to human health and the environment. Existing information on the nature and extent of potential contamination is insufficient to evaluate and recommend corrective actions for the CASs. Additional information will be generated by conducting a CAI before evaluating and selecting corrective action alternatives.

\subsubsection{Corrective Action Unit 371 History and Description}

Corrective Action Unit 371, Johnnie Boy Crater and Pin Stripe, consists of two inactive CASs located in the central portion of Area 18 and the southeastern corner of Area 11, respectively. The two 


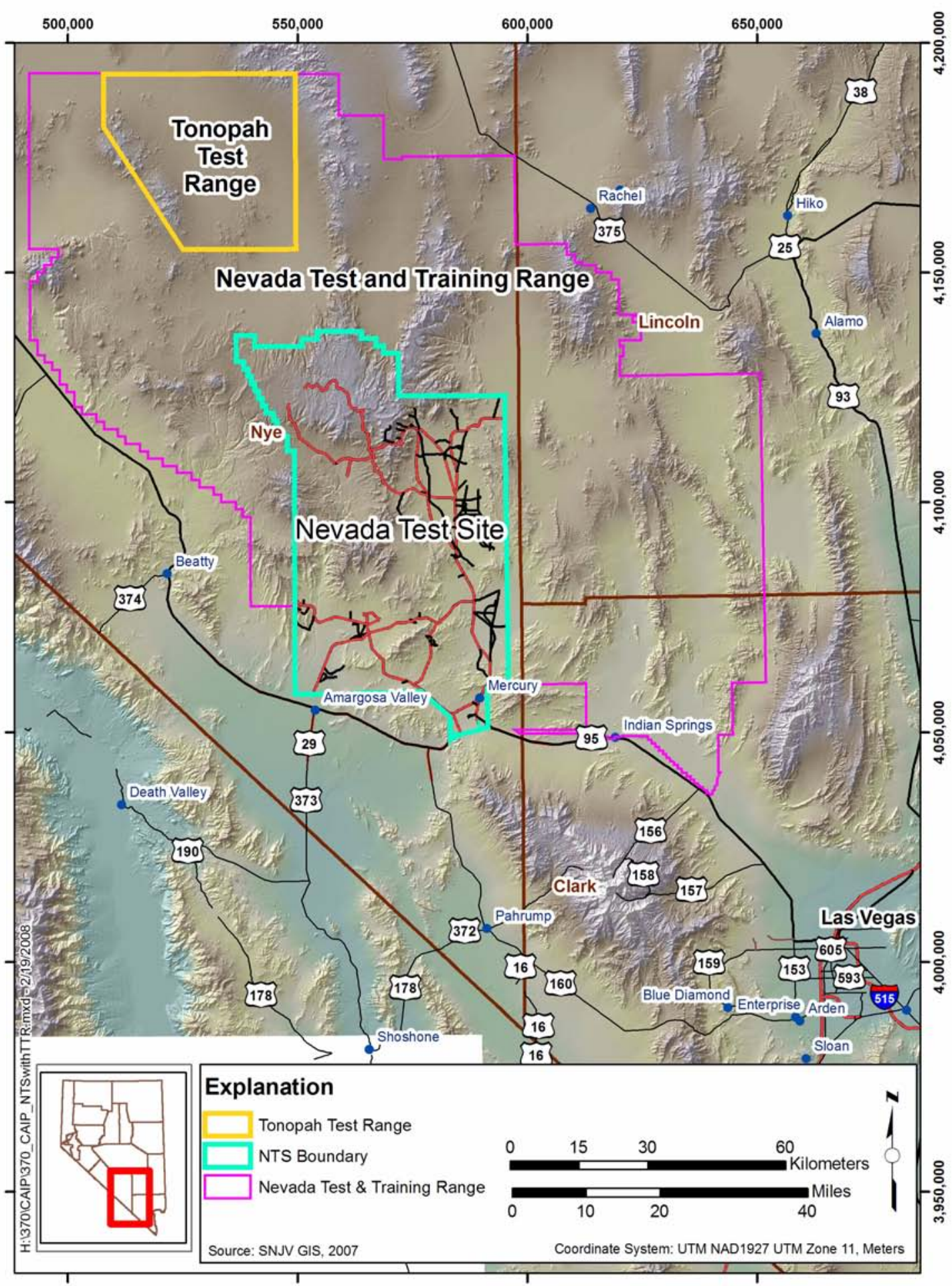

Figure 1-1

Nevada Test Site 


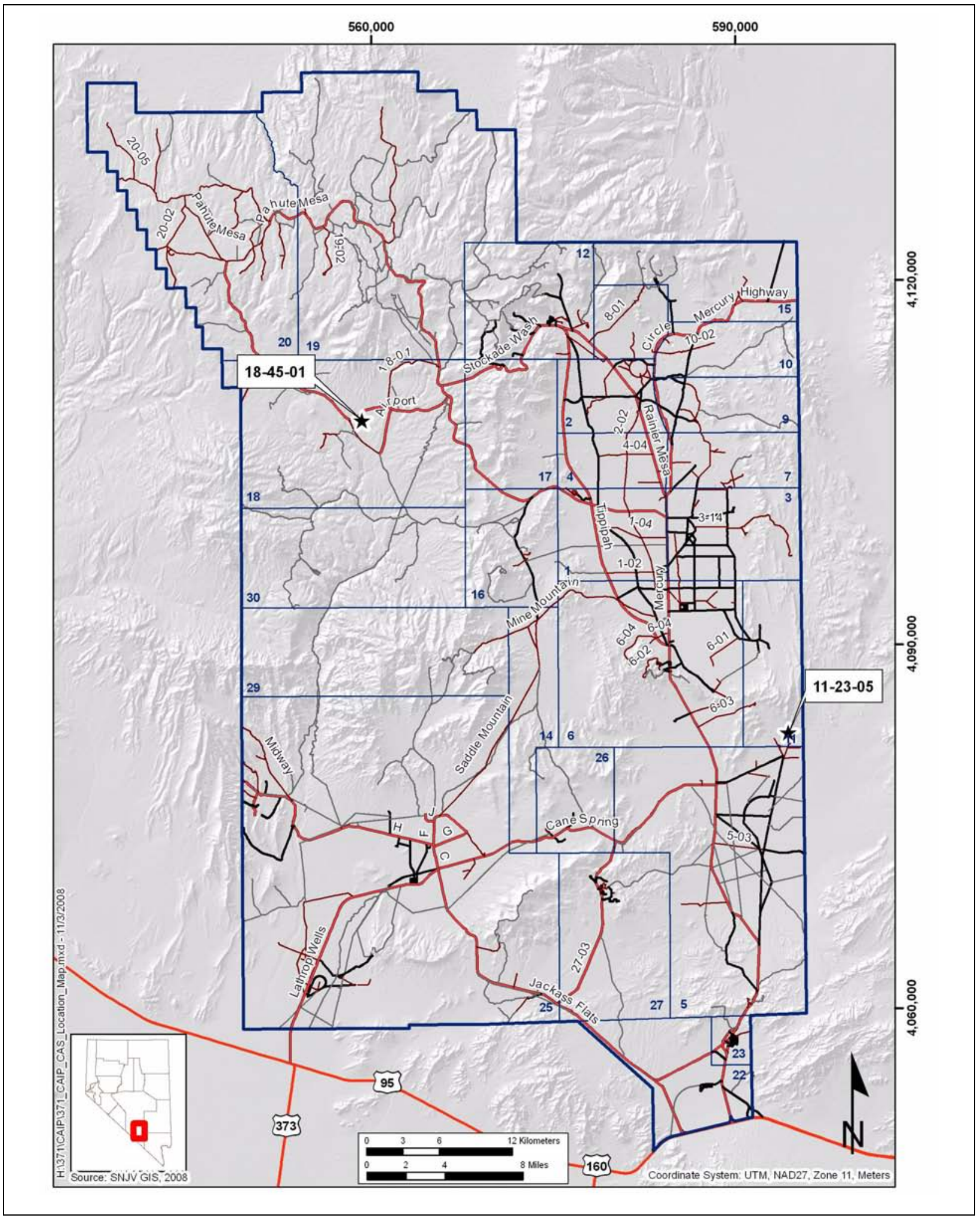

Figure 1-2

Corrective Action Unit 371, CAS Location Map 
CAU 371 sites consist of the following surface releases from nuclear tests (defined as primary releases) conducted in the 1960s:

- Corrective Action Site 11-23-05, also identified as U11b, consists of a release of radioactive material to the soil surface as a result of the venting of radiological debris from a fissure during the Pin Stripe weapons-effects test.

- Corrective Action Site 18-45-01 consists of a release of radioactive material to the soil surface resulting from atmospheric deposition as a result of the weapons-effects test, Johnnie Boy (U-18j-2).

Also to be included in the CAS investigation will be:

- $\quad$ Other releases (e.g., lead bricks, batteries) that may also be present at either CAS 11-23-05 or 18-45-01 (defined as other releases).

Operational histories for both CAU 371 CASs are detailed in Section 2.2.

\subsubsection{Data Quality Objective Summary}

The sites will be investigated based on data quality objectives (DQOs) developed by representatives of the Nevada Division of Environmental Protection (NDEP); DOE, National Nuclear Security Administration Nevada Site Office (NNSA/NSO); Stoller-Navarro Joint Venture (SNJV); and National Security Technologies, LLC (NSTec). The DQOs are used to identify and define the type, amount, and quality of data needed to develop and evaluate appropriate corrective actions for CAU 371. This CAIP describes the investigative approach developed to collect the data needs identified in the DQO process. While a detailed discussion of the DQO methodology and the DQOs specific to each CAS are presented in Appendix A, a summary of the DQO process is provided below.

The DQO problem statement for CAU 371 is: "Existing information on the nature and extent of potential contaminants is insufficient to evaluate and recommend corrective action alternatives for the CASs in CAU 371.” To address this question, the resolution of the decisions statements is required:

- Decision I: "Is any contaminant of concern (COC) associated with the CAS present in environmental media?” For judgmental sampling, any contaminant of potential concern (COPC) associated with a CAS activity that is present at concentrations exceeding its corresponding final action level (FAL) will be defined as a COC. For probabilistic sampling, any COPC for which 95 percent upper confidence limit (UCL) of the mean exceeds its 
corresponding FAL will be defined as a COC. A COC may also be defined as a contaminant that, in combination with other like contaminants, is determined to jointly pose an unacceptable risk based on a multiple contaminant analysis (NNSA/NSO, 2006). If a COC is detected, then Decision II must be resolved. If a COC is not detected, the investigation for that CAS is complete.

- Decision II for primary releases: "Is the extent of the area that provides a dose exceeding 25 millirem per year (mrem/yr) defined?” Sufficient information is defined as identifying the area of media (where the total effective dose [TED] exceeds $25 \mathrm{mrem} / \mathrm{yr}$ ). Total effective dose is defined as the sum of the effective dose (for external exposures) and the committed effective dose (for internal exposures).

- Decision II for other releases: "If a COC is present, is sufficient information available to evaluate potential corrective action alternatives?” Sufficient information is defined to include the:

- Lateral and vertical extent of COC contamination.

- Information needed to determine potential remediation waste types.

- Information needed to evaluate the feasibility of remediation alternatives.

The informational inputs and data needs to resolve the problem statement and the decision statements were generated as part of the DQO process for this CAU and are documented in Appendix A. The information necessary to resolve the DQO decisions will be generated for each CAU 371 CAS by collecting and analyzing samples generated during a field investigation. The presence of contamination at each CAS will be determined by collecting and analyzing samples following these two criteria:

- For judgmental sampling, samples must be collected in areas most likely to contain a COC.

- For probabilistic sampling, samples must be collected from random locations that represent contamination within the CAS.

The DQOs for CAU 371 have been divided into two strategies to appropriately address the two types of releases at the CASs in CAU 371:

- Primary Release strategy will be used for the releases of radiological contaminants from nuclear tests. The primary release is observed as an annular (ring-like) geometric pattern of contamination (i.e., soil particle activation and initial fallout), represented as isopleths, generally decreasing with distances from ground zero (GZ). 
- Other Releases include potential releases of nonradiological contaminants (e.g., lead bricks, batteries) that may have occurred during the pre- and post-test activities.

\subsection{Scope}

To generate information needed to resolve the decision statements identified in the DQO process, the scope of the CAI for CAU 371 includes the following activities:

- Move surface debris and/or materials, as needed, to facilitate sampling.

- Conduct radiological surveys.

- Measure in situ external dose rates using thermoluminescent dosimeters (TLDs) or other dose measurement devices.

- Collect and submit environmental samples for laboratory analysis to determine internal dose rates.

- Combine internal and external dose rates to determine whether total dose rates exceed FALs.

- Collect and submit environmental samples for laboratory analysis to determine whether chemical contaminants are present at concentrations exceeding FALs.

- If contamination exceeds FALs, define the extent of the contamination exceeding FALs.

- Investigate waste to determine whether potential source material is present.

Contamination of environmental media originating from activities not identified in the conceptual site model (CSM) of any CAS will not be considered as part of this CAU unless the CSM and the DQOs are modified to include the release.

\subsection{Corrective Action Investigation Plan Contents}

Section 1.0 presents the purpose and scope of this CAIP, while Section 2.0 provides background information about CAU 371. Objectives of the investigation, including the CSM, are presented in Section 3.0. Field investigation and sampling activities are discussed in Section 4.0, and waste management issues for this project are discussed in Section 5.0. General field and laboratory quality assurance (QA) (including collection of QA samples) are presented in Section 6.0 and in the 
Industrial Sites Quality Assurance Project Plan (QAPP) (NNSA/NV, 2002). The project schedule and records availability are discussed in Section 7.0. Section 8.0 provides a list of references.

Appendix A provides a detailed discussion of the DQO methodology and the DQOs specific to each CAS, and Appendix B contains information on the project organization. 


\subsection{Facility Description}

Corrective Action Unit 371 is comprised of two CASs that were grouped together to assist in the validation of the Soils Site Investigation Strategy. Addressing these two CASs that contain variable levels of radioactive contamination under one CAU allows the opportunity to validate the effectiveness of this investigation strategy in determining the presence and extent of radiological contamination. Furthermore, this validation will aid in the investigation and closure of future Soils CAUs. The CASs are located in Areas 11 and 18 of the NTS.

\subsection{Physical Setting}

The following sections describe the general physical settings of Areas 11 and 18 of the NTS. General background information pertaining to topography, geology, hydrogeology, and climatology are provided for these specific areas of the NTS region in the Geologic Map of the Nevada Test Site, Southern Nevada (USGS, 1990); CERCLA Preliminary Assessment of DOE's Nevada Operations Office Nuclear Weapons Testing Areas (DRI, 1988); Final Environmental Impact Statement, Nevada Test Site, Nye County, Nevada (ERDA, 1977); and the Final Environmental Impact Statement for the Nevada Test Site and Off-Site Locations in the State of Nevada (DOE/NV, 1996a).

Geological and hydrological setting descriptions for each CAS are detailed in the following subsections based on the hydrogeographic area in which they are located.

\subsubsection{Area 11}

Corrective Action Site 11-23-05, Pin Stripe Contamination Area, lies in the southeastern portion of Area 11, north of the Area 5 Radioactive Waste Material Site (RWMS). The area surrounding Pin Stripe increases in elevation from the south to the north; however, the Pin Stripe area was graded to support the instrumentation for the project. An additional graded area is present north and upgradient of the Pin Stripe GZ area, which was used for pre-test drilling operations. Vegetation is denser in the area surrounding the site than in the graded areas of the site. 
The general groundwater flow in Area 11 is from the northeast to southwest. Precipitation at the nearest rain gauge, Area 6 (South) (A06), indicates an average annual rainfall of 18.59 centimeters (cm) (7.32 [in.]) (ARL/SORD, 2009). Data are presented from 2003 to 2008. Average annual potential evapotranspiration (PET) has been estimated for the Area 3 RWMS as $157 \mathrm{~cm}$ (61.81 in.). Additional rainfall and PET information is presented in Table 2-1. Corrective Action Site 11-23-05 is located in the Ash Meadows Subbasin (NNSA/NSO, 2008b). It is expected that vertical migration of contaminants would be very limited due to the low annual rate of precipitation and high annual PET rate at the site.

Table 2-1

Rainfall and PET Information

\begin{tabular}{|c|c|c|c|}
\hline & $\begin{array}{l}\text { PET } \\
\mathbf{( c m )}\end{array}$ & $\begin{array}{c}\text { Area 6 South } \\
\text { Precipitation } \\
\mathbf{( c m )}\end{array}$ & $\begin{array}{c}\text { Little Feller II } \\
\text { Precipitation } \\
\text { (cm) }\end{array}$ \\
\hline \hline Minimum & 150.2 & 12.06 & 9.02 \\
\hline Maximum & 160.8 & 28.98 & 24.61 \\
\hline Mean & 157.0 & 18.59 & 16.26 \\
\hline $95 \%$ UCL & 160.2 & 24.23 & 21.74 \\
\hline
\end{tabular}

Based on information from well UE-11b, located approximately 7.5 meters (m) (24.6 feet [ft]) east of the Pin Stripe GZ, the depth to groundwater as of 1965 was approximately $358 \mathrm{~m}$ (1,174.5 ft). This well was drilled to a depth of $397 \mathrm{~m}$ (1,302 ft) and completed in the volcanic rocks local aquifer (USGS, 2008). Documentation states that Pin Stripe was detonated within the tuff unit of the Volcanic Aquifer (DOE/NV, 1999).

\subsubsection{Area 18}

Corrective Action Site 18-45-01 is located in the central area of Area 18 approximately $500 \mathrm{~m}$ (1,640 ft) south of the 18-03 Road. The CAS is located east of Buckboard Mesa in a valley area near Airport Road. The area of the CAS is gently sloping, and surrounded by small hills. The vegetation is sporadic around the site due to grading for instrumentation staging.

Precipitation at the nearest rain gauge, Little Feller II, indicates an average annual rainfall of 16.26 centimeters (6.4 in.) (ARL/SORD, 2009). Data are presented from 2003 to 2008. The site is 
located within the Alkali Flat-Furnace Creek Ranch Sub-basin. Average annual PET has been estimated for the Area 3 RWMS as 157 cm (61.81 in.) (NNSA/NSO, 2008b; Laczniak et al., 1996). Additional rainfall and PET information is presented in Table 2-1. It is expected that vertical migration of contaminants would be very limited at this site due to the low annual rate of precipitation and high annual PET rate.

Corrective Action Site 18-45-01 is located within the caldera moat-filling sediments geologic unit, and no faults are present within a 1-kilometer radius (Slate et al., 1999; USGS, 2007). The nearest well, UE-18t, is in the northeastern part of the Timber Mountain caldera moat, approximately $735 \mathrm{~m}$ $(2,400 \mathrm{ft})$ northwest of CAS 18-45-01. The well was drilled to a depth of $792.5 \mathrm{~m}(2,600 \mathrm{ft})$ and completed within the volcanic rocks aquifer. The thickness of tuffaceous alluvium at UE-18t is

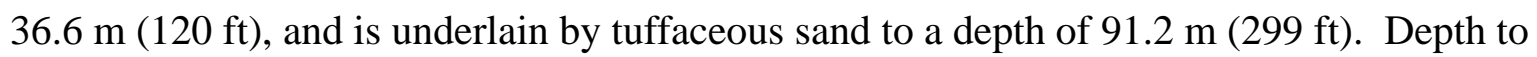
groundwater averages approximately 278 m (912 ft) (USGS, 1981; USGS and DOE, 2007).

\subsection{Operational History}

The following subsections provide a description of the use and history of each CAS in CAU 371 that may have resulted in potential releases to the environment. The CAS-specific summaries are designed to describe the current definition of each CAS and illustrate significant, known activities.

\subsubsection{Corrective Action Site 11-23-05, Pin Stripe Contamination Area}

This CAS consists of the release of radiological contamination to the soil surface as a result of the massive venting of radioactive debris from a fissure during the Pin Stripe (U11b) test. Venting occurred from a fissure approximately 30 to $46 \mathrm{~m}$ southwest of GZ. Pin Stripe was a weapons-effects shaft test with a yield of less than 20 kilotons, conducted on April 25, 1966, at a depth of 296 m below ground surface (bgs) (DOE/NV, 1996b; DOE/NV, 2000b). A subsidence crater measuring $67 \mathrm{~m}$ in diameter and $4.6 \mathrm{~m}$ deep was formed from this test. Although Pin Stripe was designed for containment, a release occurred from a fissure southwest of GZ (Sandia, 1966).

\subsubsection{Corrective Action Site 18-45-01, U-18j-2 Crater (Johnnie Boy)}

This CAS consists of an atmospheric release of radioactive contaminants to the surrounding soil from the U-18j-2 Johnnie Boy crater test. Johnnie Boy was a weapons-effects test conducted at U-18j-2 on 
July 11, 1962. Johnnie Boy was detonated slightly below ground surface $(58.4 \mathrm{~cm})$ and had a yield of 500 tons (DOE/NV, 2000b).

\subsection{Waste Inventory}

Available documentation, interviews with former site employees, site visits, process knowledge, and general historical NTS practices were used to identify wastes that may be present.

\subsubsection{Corrective Action Site 11-23-05, Pin Stripe Contamination Area}

Debris identified at CAS 11-23-05 include abandoned cables from the tests, pieces of wood, metal debris, and concrete blocks scattered around the site. Potential waste types include sanitary and radioactive waste. All waste types may be comprised of debris, investigation-derived waste (IDW), decontamination liquids, and soils.

\subsubsection{Corrective Action Site 18-45-01, U-18j-2 Crater (Johnnie Boy)}

Debris identified at CAS 18-45-01 include materials used during testing such as concrete and piping. Potential waste types include sanitary and radioactive waste. All waste types may be comprised of debris, IDW, decontamination liquids, and soils.

\subsection{Release Information}

Known or suspected releases, including potential release mechanisms, and migration routes associated with each CAS are described in this section. Exposure routes to site workers include ingestion, inhalation, and/or dermal contact (absorption) from disturbance of contaminated soils and/or debris. The following subsections contain CAS-specific descriptions of known or suspected releases associated with CAU 371.

\subsubsection{Corrective Action Site 11-23-05, Pin Stripe Contamination Area}

Corrective Action Site 11-23-05 consists of a release of radiological contamination to soil surface as a result of the massive venting of radioactive debris from a fissure during the Pin Stripe (U11b) test. The release was significant and consisted of relatively unfractionated fission products, suggesting that the venting path may have extended directly into the initial cavity. The primary COPCs at 
CAS 11-23-05 include: cobalt (Co)-60; cesium (Cs)-137; strontium (Sr)-90; europium (Eu)-152, -153, and -154; uranium (U)-234, -235, and -238; and plutonium (Pu)-238 and -239/240. Other potential releases (e.g., batteries or lead bricks) may have been released to the surface and/or subsurface soils at the site.

\subsubsection{Corrective Action Site 18-45-01, U-18j-2 Crater (Johnnie Boy)}

Corrective Action Site 18-45-01 consists of a release of radiological contamination to the atmosphere and soil surface as a result of the Johnnie Boy weapons test. The primary COPCs at CAS 18-45-01 include: Co-60; Cs-137; Sr-90; Eu-152, -153, and -154; U-234, -235, and -238; and Pu-238 and -239/240. Other potential releases (e.g., batteries or lead bricks) may have been released to the surface and/or subsurface soils at the site.

\subsection{Investigative Background}

The following subsections summarize the investigations conducted at the CAU 371 sites. More detailed discussions of these investigations are in Appendix A.

\subsubsection{Corrective Action Site 11-23-05, Pin Stripe Contamination Area}

During an aerial radiological survey conducted at the NTS in 1994, Cs-137 was detected in the area surrounding Pin Stripe. The exposure rate at Pin Stripe ranged from 18 to 24 microroentgens per hour $(\mu \mathrm{R} / \mathrm{hr})(\mathrm{BN}, 1999)$. Isotopes identified the time of release were: krypton, xenon (one of which decays into Cs-137), iodine (I)-131, -133, and -135 (DOE/NV, 1996b).

A Radionuclide Inventory and Distribution Program (RIDP) investigation was conducted in Area 11 in January and February of 1985. This effort estimated the inventory of man-made radionuclides at the NTS through in situ soil measurements, and some (limited) soil sampling (DRI, 1985; Gray et al., 2007). While several radionuclides were detected, only Cs-137 and Sr-90 were present at CAS 11-23-05 at sufficient levels to make an estimate of the radionuclide inventory.

\subsubsection{Corrective Action Site 18-45-01, U-18j-2 Crater (Johnnie Boy)}

An aerial radiological survey was conducted in 1994 at an altitude of $60 \mathrm{~m}$ over the area of CAS 18-45-01. The exposure rate at Johnnie Boy ranged from 39 to $50 \mu \mathrm{R} / \mathrm{hr}$. The survey identified 
the presence of Cs-137, Eu-152, and possibly Co-60 (BN, 1999). These isotopes are a result of fallout and neutron activation of soil and surrounding structures.

A RIDP investigation was conducted in Area 18 between November 1983 and June of 1984. This effort estimated the inventory of man-made radionuclides at the NTS through in situ soil measurements and some (limited) soil sampling (DRI, 1985; Gray et al., 2007). Area 18 contains the location of the Johnnie Boy test, as well as Little Feller I, Little Feller II, Danny Boy, and Sulky. Americium (Am)-241, Pu-238, and -239/240, Co-60, Cs-137, Sr-90, and Eu-152, -154, and -155 were present at sufficient levels in Area 18 to estimate the radionuclide inventory (Note: plutonium and americium are not expected as a result of the test at Johnnie Boy but could be present at low levels as the result of tests nearby).

The Johnnie Boy location was included in the Nevada Test Site Contaminated Land Areas Report (DOE/NV, 2000a) as a posted only (no fencing) radioactive material area (RMA) measuring approximately 33,300 square meters $\left(\mathrm{m}^{2}\right)$.

\subsubsection{National Environmental Policy Act}

The Final Environmental Impact Statement for the Nevada Test Site and Off-Site Locations in the State of Nevada (DOE/NV, 1996a) includes site investigation activities such as those proposed for CAU 371.

In accordance with the NNSA/NSO National Environmental Policy Act (NEPA) Compliance Program, a NEPA checklist will be completed before beginning site investigation activities at CAU 371. This checklist requires NNSA/NSO project personnel to evaluate their proposed project activities against a list of potential impacts that include, but are not limited to: air quality, chemical use, waste generation, noise level, and land use. Completion of the checklist results in a determination of the appropriate level of NEPA documentation by the NNSA/NSO NEPA Compliance Officer. This will be accomplished before mobilization for the field investigation. 


\subsection{Objectives}

This section presents an overview of the DQOs for CAU 371 and formulation of the CSM. Also presented is a summary listing the COPCs, the preliminary action levels (PALs) for the investigation, and the process used to establish FALs. Additional details and figures depicting the CSM are located in Appendix A.

\subsection{Conceptual Site Model}

The CSM describes the most probable scenario for current conditions at the site and defines the assumptions that are the basis for identifying appropriate sampling strategy and data collection methods. An accurate CSM is important, because it serves as the basis for all subsequent inputs and decisions throughout the DQO process.

The CSM was developed for CAU 371 using information from the physical setting, potential contaminant sources, release information, historical background information, knowledge from similar sites, and physical and chemical properties of the potentially affected media and COPCs. Figure 3-1 depicts the conceptual pathways to receptors from CAU 371 sources. Figure 3-2 is a graphical representation of the CSM.

If evidence of contamination associated with these CASs that is not consistent with the presented CSM is identified during investigation activities, the situation will be reviewed, the CSM will be revised, the DQOs will be reassessed, and a recommendation will be made as to how to best proceed. In such cases, decision-makers listed in Section A.3.1 will be notified and given the opportunity to comment on and/or concur with the recommendation.

The following sections discuss future land use and the identification of exposure pathways (i.e., combination of source, release, migration, exposure point, and receptor exposure route) for CAU 371. 


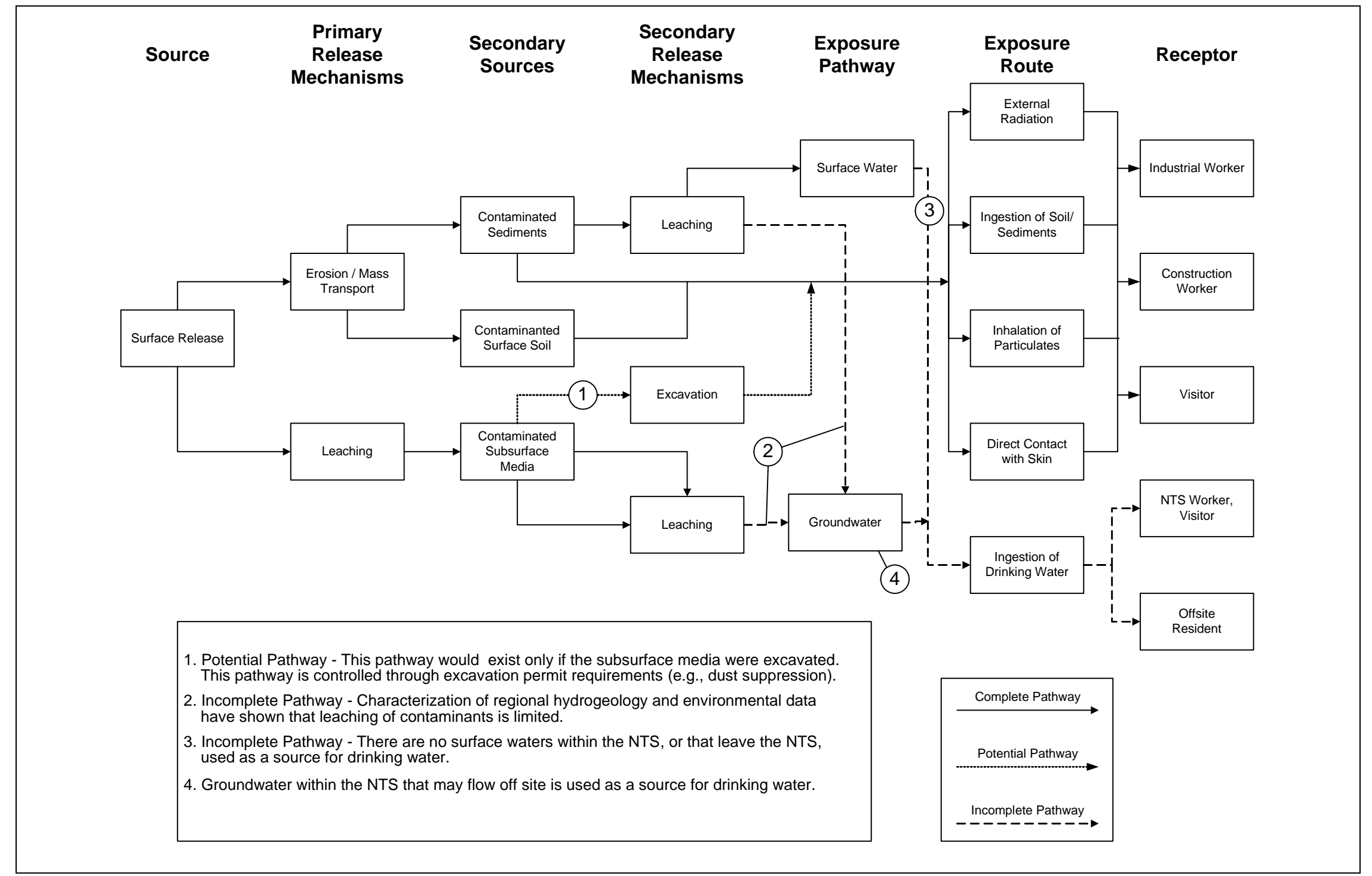

Figure 3-1

Conceptual Site Model Diagram

\section{UNCONTROLLED When Printed}


K.Doo-prod'Soils!371 Figures'Working Files:371_CAIP_CSM_L.ai
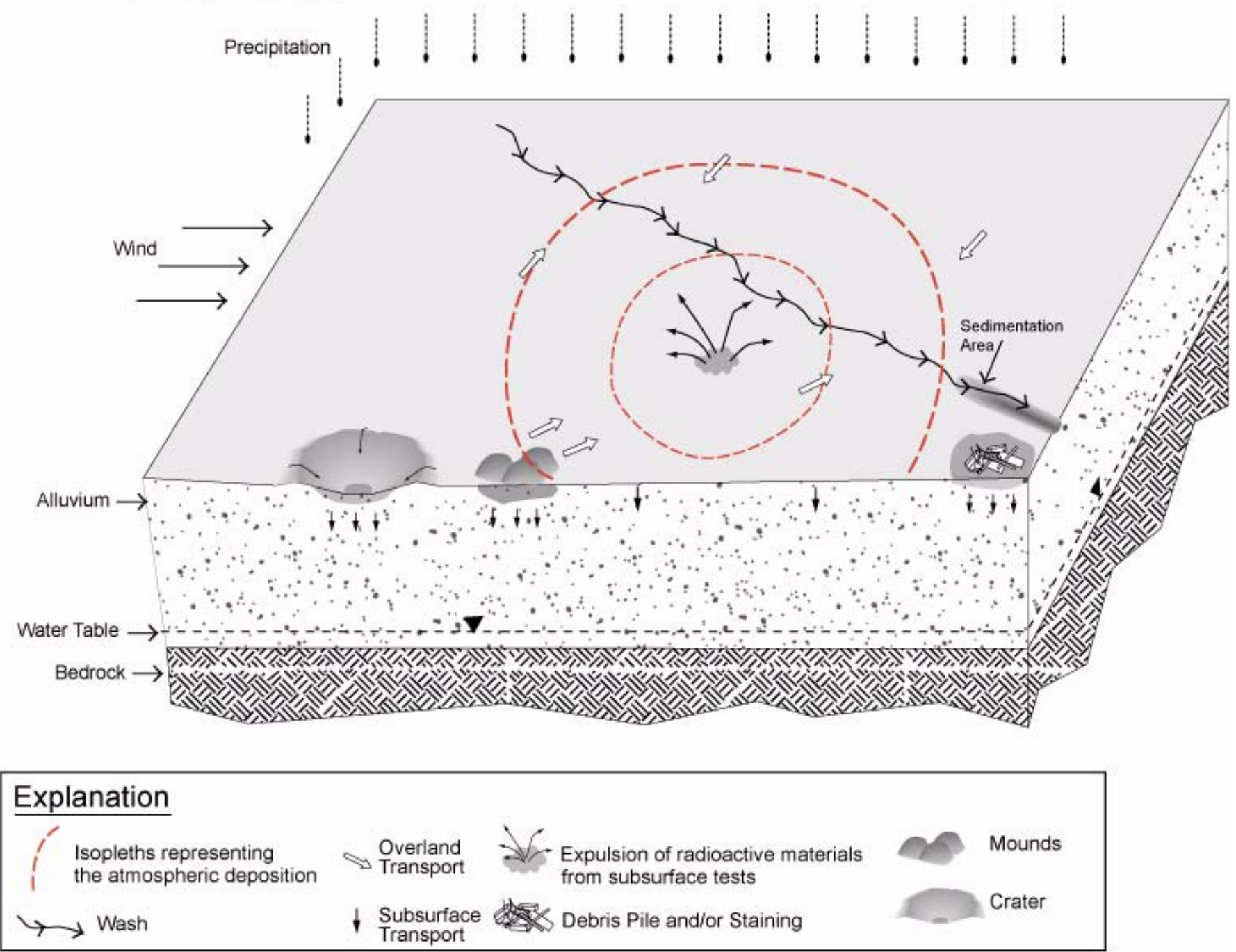

Figure 3-2

Corrective Action Unit 371 Conceptual Site Model 


\subsubsection{Land-Use and Exposure Scenarios}

Land-use zones where the CAU 371 CASs are located dictate future land use and restrict current and future land use to nonresidential (i.e., industrial) activities.

Corrective Action Sites 11-23-05 and 18-45-01 are located in the land-use zone described as "Reserved Zone" within the NTS. This area includes land and facilities that provide widespread flexible support for diverse short-term testing and experimentation. The reserved zone is also used for short-duration exercises and training such as nuclear emergency response, Federal Radiological Monitoring and Assessment Center training, and U.S. Department of Defense (DoD) exercises and training (DOE/NV, 1998).

The exposure scenario for CAU 371 is an Occasional Use Area. This exposure scenario assumes exposure to industrial workers who are not assigned to the area as a regular work site but may use the site occasionally for intermittent or short-term activities. Site workers under this scenario are assumed to be on the site for an equivalent of 10 hours per day, 10 days per year, for 5 years.

\subsubsection{Contaminant Sources}

The identified contamination source for CAS 11-23-05 is a release of radiological contamination to the atmosphere as a result of the massive venting of radiological debris from a fissure that developed during the U11b Pin Stripe test. The plume from the accidental release of radioactivity moved northeasterly from the test location and was detected off the NTS.

The identified contamination source for CAS 18-45-01 is a release of radiological contamination to the atmosphere and soil surface as a result of the Johnnie Boy weapons test.

Other contamination sources may include batteries, lead bricks, and other wastes that may be present at either CAS in CAU 371. Other wastes (e.g., batteries, lead bricks, or spills) may have been used during the testing or left at the sites during activities related to the testing program.

\subsubsection{Release Mechanisms}

Release mechanisms for both CASs include neutron activation of soil and structural components, release of fission products, and release of unburned nuclear fuel from the detonation of nuclear tests. 
At CAS 11-23-05, radioactive debris accidentally vented into the atmosphere through a fissure in the ground shortly after the detonation. The release was significant and consisted of relatively unfractionated fission products, suggesting that the venting path may have extended directly into the initial cavity. At CAS 18-45-01, the detonation irradiated the surrounding soil with neutrons, causing the activation of some elements in the soil (primarily Eu-152 and -154). Fission fragments were released in an annular pattern around GZ with a bias toward the prevailing wind direction at the time of detona3tion (to the north). Radionuclides with a low melting point (e.g., iodine) traveled significant distances before condensing and falling out of the plume, while those with higher melting points (e.g., cesium) condensed earlier and were deposited closer to GZ. The nuclear fuel that did not fission (e.g., U-235) has a very high melting point and is generally found very near to GZ. The radioactive contamination in soil at Johnnie Boy can be seen as a distributed contamination in the soil surface and regions where Trinitite fell out of the fireball in discrete areas around GZ.

\subsubsection{Migration Pathways}

Migration pathways include the lateral migration of contaminants across soil surface and accumulating in drainages, and vertical migration of potential contaminants through subsurface soils.

The surface migration pathways for CAU 371 include lateral movement of potential contaminants into washes transecting the site since the original distribution. Lateral migration of contaminants at the CASs during stormwater runoff events occurs infrequently, but may be significant, due to the nature of precipitation events. Other migration pathways of contamination from the site includes wind-borne material and material pushed along dirt roads within the depositional areas in the area (e.g., moved during road maintenance).

Contaminants released into the unnamed intermittent washes within the site are potentially subject to much higher transport rates than contaminants released to areas outside the natural or man-made drainages. The washes entering and leaving these areas are generally dry but are subject to infrequent, potentially intense, stormwater flows. These stormwater flow events provide an intermittent mechanism for both vertical and horizontal transport of contaminants. Contaminated sediments entrained by these stormwater events would be carried by the streamflow to locations where the flowing water loses energy, and the sediments drop out. These locations are readily 
identified as sedimentation areas. For CAS 11-23-05, washes drain into Frenchman Lake. For CAS 18-45-01, washes drain into Forty Mile Wash, off site, and ultimately to Death Valley.

If other releases are observed at the site (i.e., hydrocarbon spills), subsurface migration pathways at the CASs are expected to be predominately vertical although potential spills or leaks at the ground surface may also have limited lateral migration. The depth of infiltration (shape of the subsurface contaminant plume) will be dependent upon the type, volume, and duration of the discharge; as well as the presence of relatively impermeable layers that could modify vertical or horizontal transport pathways both on the ground surface (e.g., concrete) and in the subsurface (e.g., caliche layers).

Migration is influenced by physical and chemical characteristics of the contaminants and media. Contaminant characteristics include, but are not limited to: solubility, density, and adsorption potential. Media characteristics include permeability, porosity, water saturation, sorting, chemical composition, and organic content. In general, contaminants with low solubility, high affinity for media, and high density can be expected to be found relatively close to release points. Contaminants with high solubility, low affinity for media, and low density can be expected to be found further from release points. These factors affect the migration pathways and potential exposure points for the contaminants in the various media under consideration.

Infiltration and percolation of precipitation serves as a driving force for downward migration of contaminants. However, due to high PET (average annual PET at the Area 3 RWMS has been estimated at $157 \mathrm{~cm}$ [61.81 in.] [NNSA/NSO, 2008b]) and limited annual precipitation for this region (7.32 in. [Area 11] and 6.4 in. [Area 18] [ARL/SORD, 2009]), percolation of infiltrated precipitation at the NTS does not provide a significant mechanism for vertical migration of contaminants to groundwater (DOE/NV, 1992).

\subsubsection{Exposure Points}

Exposure points for the CSM are expected to be areas of surface contamination where visitors and site workers may come in contact with contaminated soil. Subsurface exposure points may also exist if construction workers come in contact with contaminated media during excavation activities. 


\subsubsection{Exposure Routes}

Exposure routes to site workers include ingestion, inhalation, and/or dermal contact (absorption) from disturbance of, or direct contact with, contaminated media. Site workers may also be exposed to ionizing radiation by performing activities in proximity to radiologically contaminated materials.

\subsubsection{Additional Information}

Information concerning topography, geology, climatic conditions, hydrogeology, floodplains, and infrastructure at the CAU 371 CASs is presented in Section 2.1 as it pertains to the investigation. This information has been addressed in the CSM and will be considered during the evaluation of corrective action alternatives, as applicable. Climatic and site conditions (e.g., surface and subsurface soil descriptions), as well as specific structure descriptions, will be recorded during the CAI. Areas of erosion and deposition within washes will be evaluated qualitatively to provide additional information on potential offsite migration of contaminants. Movement of the active ephemeral stream channels may be identified based on a comparison of historical photographs and visual observations where erosion and deposition have occurred within the washes.

\subsection{Contaminants of Potential Concern}

Based on the identified releases at CAS 11-23-05 and CAS 18-45-01 (see Section 2.4), the contaminants of potential concern (COPCs) for CAU 371 that are applicable to Decision I environmental samples are defined as the analytes reported from the following analyses:

- Gamma spectroscopy

- Isotopic U

- Isotopic Pu

- Isotopic Am

- Strontium-90

If a biasing factor is encountered that indicates possible presence of chemical contamination, samples will be submitted for analysis based on the nature of the biasing factors (e.g., lead bricks, stains). These may include the analyte(s) reported from the following analyses:

- Total petroleum hydrocarbons-diesel-range organics

- Total petroleum hydrocarbons-gasoline-range-organics 
- Polychlorinated biphenyls

- Semivolatile organic compounds

- Volatile organic compounds

- Resource Conservation and Recovery Act metals

The analytes reported for each analytical method are listed in Table 3-1. The list of COPCs is intended to encompass all of the contaminants that could potentially be present at the CAS. These COPCs were identified during the planning process through the review of site history, process knowledge, past investigation efforts (where available), and inferred activities associated with the CAS.

\subsection{Preliminary Action Levels}

The PALs presented in this section are to be used for site screening purposes. They are not necessarily intended to be used as cleanup action levels or FALs. However, they are useful in screening out contaminants that are not present in sufficient concentrations to warrant further evaluation, therefore streamlining the consideration of remedial alternatives. The risk-based corrective action (RBCA) process used to establish FALs is described in the Industrial Sites Project Establishment of Final Action Levels (NNSA/NSO, 2006). This process conforms with Nevada Administrative Code (NAC) Section 445A.227, which lists the requirements for sites with soil contamination (NAC, 2006b). For the evaluation of corrective actions, NAC Section 445A.22705 (NAC, 2006c) requires the use of American Society for Testing and Materials (ASTM) Method E 1739-95 (ASTM, 1995) to “conduct an evaluation of the site, based on the risk it poses to public health and the environment, to determine the necessary remediation standards (i.e., FALs) or to establish that corrective action is not necessary.”

This RBCA process, summarized in Figure 3-3, defines three tiers (or levels) of evaluation involving increasingly sophisticated analyses:

- Tier 1 evaluation - Sample results from source areas (highest concentrations) are compared to action levels based on generic (non-site-specific) conditions (i.e., the PALs established in the CAIP). The FALs may then be established as the Tier 1 action levels, or the FALs may be calculated using a Tier 2 evaluation. 
Table 3-1

Constituents Reported by Analytical Methods

\begin{tabular}{|c|c|c|c|c|c|c|c|}
\hline \multicolumn{2}{|c|}{ VOCs } & \multicolumn{2}{|c|}{ SVOCs } & TPH & PCBS & Metals & Radionuclides \\
\hline $\begin{array}{l}\text { 1,1,1,2-Tetrachloroethane } \\
\text { 1,1,1-Trichloroethane } \\
\text { 1,1,2,2-Tetrachloroethane } \\
\text { 1,1,2-Trichloroethane } \\
\text { 1,1-Dichloroethane } \\
\text { 1,1-Dichloroethene } \\
\text { 1,2,4-Trichlorobenzene } \\
\text { 1,2,4-Trimethylbenzene } \\
\text { 1,2-Dibromo-3-chloropropane } \\
\text { 1,2-Dichlorobenzene } \\
\text { 1,2-Dichloroethane } \\
\text { 1,2-Dichloropropane } \\
\text { 1,3,5-Trimethylbenzene } \\
\text { 1,3-Dichlorobenzene } \\
\text { 1,4-Dichlorobenzene } \\
\text { 1,4-Dioxane } \\
\text { 2-Butanone } \\
\text { 2-Chlorotoluene } \\
\text { 2-Hexanone } \\
\text { 4-Isopropyltoluene } \\
\text { 4-Methyl-2-pentanone } \\
\text { Acetone } \\
\text { Acetonitrile } \\
\text { Allyl chloride } \\
\text { Benzene } \\
\text { Bromodichloromethane } \\
\text { Bromoform } \\
\text { Bromomethane } \\
\text { Carbon disulfide }\end{array}$ & $\begin{array}{l}\text { Carbon tetrachloride } \\
\text { Chlorobenzene } \\
\text { Chloroethane } \\
\text { Chloroform } \\
\text { Chloromethane } \\
\text { Chloroprene } \\
\text { cis-1,2-Dichloroethene } \\
\text { Dibromochloromethane } \\
\text { Dichlorodifluoromethane } \\
\text { Ethyl methacrylate } \\
\text { Ethylbenzene } \\
\text { Isobutyl alcohol } \\
\text { Isopropylbenzene } \\
\text { Methacrylonitrile } \\
\text { Methyl methacrylate } \\
\text { Methylene chloride } \\
\text { n-Butylbenzene } \\
\text { n-Propylbenzene } \\
\text { sec-Butylbenzene } \\
\text { Styrene } \\
\text { tert-Butylbenzene } \\
\text { Tetrachloroethene } \\
\text { Toluene } \\
\text { Total Xylenes } \\
\text { Trichloroethene } \\
\text { Trichlorofluoromethane } \\
\text { Vinyl acetate } \\
\text { Vinyl chloride }\end{array}$ & $\begin{array}{l}\text { 2,3,4,6-Tetrachlorophenol } \\
\text { 2,4,5-Trichlorophenol } \\
\text { 2,4,6-Trichlorophenol } \\
\text { 2,4-Dimethylphenol } \\
\text { 2,4-Dinitrotoluene } \\
\text { 2-Chlorophenol } \\
\text { 2-Methylnaphthalene } \\
\text { 2-Methylphenol } \\
\text { 2-Nitrophenol } \\
\text { 3-Methylphenol }{ }^{\text {a }} \text { (m-cresol) } \\
\text { 4-Methylphenol }{ }^{\text {(p-cresol) }} \\
\text { 4-Chloroaniline } \\
\text { 4-Nitrophenol } \\
\text { Acenaphthene } \\
\text { Acenaphthylene } \\
\text { Aniline } \\
\text { Anthracene } \\
\text { Benzo(a)anthracene } \\
\text { Benzo(a)pyrene } \\
\text { Benzo(b)fluoranthene } \\
\text { Benzo(g,h,i)perylene } \\
\text { Benzo(k)fluoranthene } \\
\text { Benzoic Acid } \\
\text { Benzyl Alcohol } \\
\text { Bis(2-ethylhexyl) phthalate } \\
\text { Butyl benzyl phthalate } \\
\text { Carbazole } \\
\text { Chrysene } \\
\text { Di-n-butyl Phthalate }\end{array}$ & $\begin{array}{l}\text { Di-n-octyl Phthalate } \\
\text { Dibenzo(a,h)anthracene } \\
\text { Dibenzofuran } \\
\text { Diethyl Phthalate } \\
\text { Dimethyl Phthalate } \\
\text { Fluoranthene } \\
\text { Fluorene } \\
\text { Hexachlorobenzene } \\
\text { Hexachlorobutadiene } \\
\text { Hexachloroethane } \\
\text { Indeno(1,2,3-cd)pyrene } \\
\text { n-Nitroso-di-n-propylamine } \\
\text { Naphthalene } \\
\text { Nitrobenzene } \\
\text { Pentachlorophenol } \\
\text { Phenanthrene } \\
\text { Phenol } \\
\text { Pyrene } \\
\text { Pyridine }\end{array}$ & $\begin{array}{l}\text { DRO } \\
\text { GRO }\end{array}$ & \begin{tabular}{|l} 
Aroclor 1016 \\
Aroclor 1221 \\
Aroclor 1232 \\
Aroclor 1242 \\
Aroclor 1248 \\
Aroclor 1254 \\
Aroclor 1260 \\
Aroclor 1268
\end{tabular} & $\begin{array}{l}\text { Arsenic } \\
\text { Barium } \\
\text { Beryllium } \\
\text { Cadmium } \\
\text { Chromium } \\
\text { Lead } \\
\text { Mercury } \\
\text { Selenium } \\
\text { Silver }\end{array}$ & $\begin{array}{l}\text { Gross Alpha/Beta } \\
\text { Am-241 } \\
\text { Pu-238 } \\
\text { Pu-239/240 } \\
\text { Sr-90 } \\
\text { U-234 } \\
\text { U-235 } \\
\text { U-238 } \\
\text { Tritium } \\
\\
\text { Gamma-Emitting } \\
\text { Ac-228 } \\
\text { Am-241 } \\
\text { Co-60 } \\
\text { Cs-137 } \\
\text { Eu-152 } \\
\text { Eu-154 } \\
\text { Eu-155 } \\
\text { K-40 } \\
\text { Nb-94 } \\
\text { Pb-212 } \\
\text { Pb-214 } \\
\text { Tl-208 } \\
\text { Th-234 } \\
\text { U-235 }\end{array}$ \\
\hline
\end{tabular}

aMay be reported as 3,4-Methylphenol or m,p-cresol.

$\mathrm{Ac}=$ Actinium

$\mathrm{GRO}=$ Gasoline-range organics

$\mathrm{K}=$ Potassium

$\mathrm{Ni}=$ Niobium
$\mathrm{Pb}=$ Lead

$\mathrm{PCB}=$ Polychlorinated bipheny

Th = Thorium

$\mathrm{Tl}=$ Thallium 


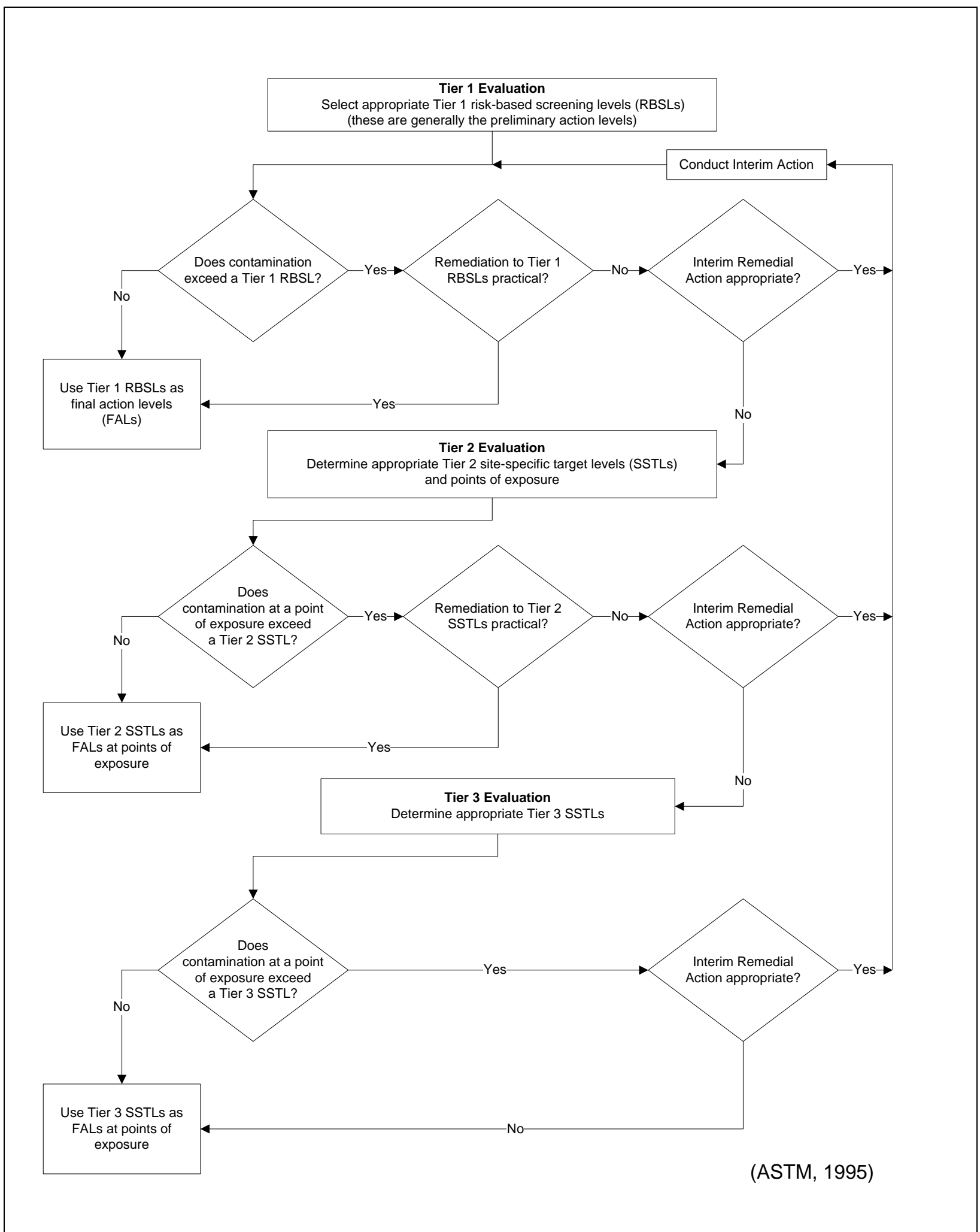

Figure 3-3

Risk-Based Corrective Action Decision Process 
- Tier 2 evaluation - Conducted by calculating Tier 2 Site-Specific Target Levels (SSTLs) using site-specific information as inputs to the same or similar methodology used to calculate Tier 1 action levels. The Tier 2 SSTLs are then compared to individual sample results from reasonable points of exposure (as opposed to the source areas as is done in Tier 1) on a point-by-point basis. Total petroleum hydrocarbons concentrations will not be used for risk-based decisions under Tier 2 or Tier 3. Rather, the individual chemicals of concern will be compared to the SSTLs.

- Tier 3 evaluation - Conducted by calculating Tier 3 SSTLs on the basis of more sophisticated risk analyses using methodologies described in ASTM Method E 1739-95 that consider site-, pathway-, and receptor-specific parameters.

The RBCA process includes a provision for conducting an interim remedial action if necessary and appropriate. The decision to conduct an interim action may be made at any time during the investigation and at any level (tier) of analysis. Concurrence of the decision-makers listed in Section A.3.1 will be obtained before any interim action is implemented. Evaluation of DQO decisions will be based on conditions at the site following completion of any interim actions. Any interim actions conducted will be reported in the Corrective Action Decision Document (CADD).

The FALs (along with the basis for their selection) will be proposed in the CADD and compared to laboratory results in the evaluation of potential corrective actions.

\subsubsection{Chemical PALs}

Except as noted herein, the chemical PALs are defined as the U.S. Environmental Protection Agency (EPA) Region 9 Preliminary Remediation Goals (PRGs) for contaminants in industrial soils (EPA, 2008a). Background concentrations for Resource Conservation and Recovery Act (RCRA) metals will be used instead of PRGs when natural background concentrations exceed the PRG, as is often the case with arsenic on the NTS. Background is considered the mean plus two standard deviations for sediment samples collected by the Nevada Bureau of Mines and Geology throughout the Nevada Test and Training Range (formerly the Nellis Air Force Range) (NBMG, 1998; Moore, 1999). For detected chemical COPCs without established PRGs, the protocol used by the EPA Region 9 in establishing PRGs (or similar) will be used to establish PALs. If used, this process will be documented in the CADD. 


\subsubsection{Total Petroleum Hydrocarbon PALs}

The PAL for TPH is 100 milligrams per kilogram $(\mathrm{mg} / \mathrm{kg})$ as listed in NAC 445A.2272 (NAC, 2006d).

\subsubsection{Radionuclide PALs}

For primary releases, the PAL will be $25 \mathrm{mrem} / \mathrm{yr}$ total effective dose based on the Industrial Area Scenario.

For other releases, the PALs for radiological contaminants (other than tritium) are based on the National Council on Radiation Protection and Measurement (NCRP) Report No. 129 recommended screening limits for construction, commercial, industrial land-use scenarios (NCRP, 1999) using a 25-mrem/yr dose constraint (Murphy, 2004), and the generic guidelines for residual concentration of radionuclides in DOE Order 5400.5 (DOE, 1993). The NCRP-based PALs are based on the construction, commercial, and industrial land-use scenario provided in the guidance and are appropriate for the NTS based on future land-use scenarios as presented in Section 3.1.1.

\subsection{Data Quality Objective Process Discussion}

This section contains a summary of the DQO process that is presented in Appendix A. The DQO process is a strategic planning approach based on the scientific method that is designed to ensure that the data collected will provide sufficient and reliable information to identify, evaluate, and technically defend the recommendation of viable corrective actions (e.g., no further action, clean closure, or closure in place).

During the development of the DQOs, the participants identified the presence of two types of potential contaminant releases at the site:

- Primary releases of contaminants are defined as releases of radionuclides from nuclear tests. For CAS 11-23-05, the primary release of contaminants is from the venting of radioactive debris from a fissure. For CAS 18-45-01, the primary release of contaminants is from the atmospheric deposition of radionuclides.

- Other releases of contamination include potential releases (e.g., drums, batteries) that may have occurred during the pre- and post-test activities. 
The DQO participants agreed to investigate the primary releases through a combination of probabilistic and judgmental sampling, and to investigate the other releases through judgmental sampling only. Therefore, discussions related to these investigations are presented separately.

The DQO strategy for CAU 371 was developed at a meeting on November 19, 2008. The DQOs were developed to identify data needs, clearly define the intended use of the environmental data, and to design a data collection program that will satisfy these purposes. During the DQO discussions for this CAU, the informational inputs or data needs to resolve problem statements and decision statements were documented.

The problem statement for CAU 371 is: "Existing information on the nature and extent of potential contamination is insufficient to evaluate corrective action alternatives for the CASs in CAU 371.” To address this problem statement, the resolution of the decisions statements is required:

- Decision I: “Is any COC associated with the CAS present in environmental media?” If a COC is detected, then Decision II must be resolved. Otherwise, the investigation for that CAS is complete. Resolution of this decision statement is discussed in Section A.4.1.

- Decision II for primary releases: "Is the extent of the area that provides a dose exceeding 25 millirem per year (mrem/yr) defined?” Sufficient information is defined as identifying the area of media (where the TED exceeds $25 \mathrm{mrem} / \mathrm{yr}$ ).

- Decision II for other releases: "If a COC is present, is sufficient information available to evaluate potential corrective action alternatives?” Sufficient information is defined to include the:

- Lateral and vertical extent of COC contamination.

- Information needed to determine potential remediation waste types.

- Information needed to evaluate the feasibility of remediation alternatives.

The presence of a COC would require a corrective action. A corrective action may also be necessary if there is a potential for wastes that are present at a site to result in the introduction of COCs into site environmental media. To evaluate the potential for wastes to result in the introduction of a COC to the surrounding environmental media, the following conservative assumptions were made:

- That any containment of wastes would fail at some point, and the waste would be released to the surrounding soil. 
- For nonliquid wastes, the resulting concentration of contaminants in the surrounding soil would be equal to the concentration of contaminants in the wastes.

- For liquid wastes, the resulting concentration of contaminants in the surrounding soil would be calculated based on the concentration of contaminants in the wastes, and the liquid holding capacity of the soil.

Decision I samples will be submitted to analytical laboratories for the analyses listed in Section 3.2. Decision II samples will be submitted for the analysis of all unbounded COCs. In addition, samples will be submitted for analyses as needed to support waste management or health and safety decisions.

The data quality indicators (DQIs) of precision, accuracy, representativeness, completeness, comparability, and sensitivity needed to satisfy DQO requirements are discussed in Section 6.2. Laboratory data will be assessed in the CADD to confirm or refute the CSM and determine whether the DQO data needs were met.

To satisfy the DQI of sensitivity (presented in Section 6.2.8), the analytical methods must be sufficient to detect contamination that is present in the samples at concentrations less than or equal to the corresponding FALs. Analytical methods and target minimum detectable concentrations (MDCs) for each CAU 371 COPC are provided in Tables 3-2 and 3-3. The MDC is the lowest concentration of a chemical or radionuclide parameter that can be detected in a sample within an acceptable level of error. Due to changes in analytical methodology and changes in analytical laboratory contracts, information in Tables 3-2 and 3-3 that varies from corresponding information in the QAPP will supersede the QAPP (NNSA/NV, 2002). 
Table 3-2

Analytical Requirements for Radionuclides for CAU 371

\begin{tabular}{|c|c|c|c|c|c|}
\hline Analysis $^{a}$ & $\begin{array}{l}\text { Medium or } \\
\text { Matrix }\end{array}$ & $\begin{array}{c}\text { Analytical } \\
\text { Method }\end{array}$ & $\mathrm{MDC}^{\mathrm{b}}$ & $\begin{array}{l}\text { Laboratory } \\
\text { Precision }\end{array}$ & $\begin{array}{l}\text { Laboratory } \\
\text { Accuracy }\end{array}$ \\
\hline \multicolumn{6}{|c|}{ Gamma-Emitting Radionuclides } \\
\hline \multirow[t]{2}{*}{$\begin{array}{c}\text { Gamma } \\
\text { Spectroscopy }\end{array}$} & Aqueous & EPA $901.1^{c}$ & \multirow[t]{2}{*}{$\begin{array}{c}<\text { PALs } \\
\text { (Other Releases) }\end{array}$} & $\begin{array}{c}\text { RPD } \\
35 \% \text { (nonaqueous) }^{d} \\
20 \% \text { (aqueous) }^{d}\end{array}$ & \multirow{2}{*}{$\begin{array}{c}\text { LCS Recovery } \\
(\% \mathrm{R}) \\
80-120^{\mathrm{f}}\end{array}$} \\
\hline & Nonaqueous & GA-01-R & & $\begin{array}{c}N D \\
-2<N D<2^{e}\end{array}$ & \\
\hline \multicolumn{6}{|c|}{ Other Radionuclides } \\
\hline Isotopic U & All & $\mathrm{U}-02-\mathrm{RC}^{\mathrm{g}}$ & \multirow{9}{*}{$\begin{array}{c}<\text { PALs } \\
\text { (Other Releases) }\end{array}$} & \multirow{5}{*}{$\begin{array}{c}\text { RPD } \\
35 \% \text { (nonaqueous) }^{d} \\
20 \% \text { (aqueous) }^{d}\end{array}$} & \multirow{5}{*}{$\begin{array}{c}\text { Chemical Yield } \\
\text { Recovery (\%R) } \\
30-105^{\mathrm{h}}\end{array}$} \\
\hline \multirow{2}{*}{ Isotopic Pu } & Aqueous & Pu-10-RC & & & \\
\hline & Nonaqueous & $\mathrm{Pu}-02-\mathrm{RC}^{\mathrm{g}}$ & & & \\
\hline \multirow{2}{*}{ Isotopic Am } & Aqueous & Am-03-RC & & & \\
\hline & Nonaqueous & Am-01-RC & & & \\
\hline \multirow{2}{*}{ Pu-241 } & Aqueous & Pu-10-RC & & \multirow{4}{*}{$\begin{array}{c}N D \\
-2<N D<2^{e}\end{array}$} & \multirow{4}{*}{$\begin{array}{c}\text { LCS Recovery } \\
\qquad(\% \mathrm{R}) \\
80-120^{\mathrm{h}}\end{array}$} \\
\hline & Nonaqueous & $\mathrm{Pu}-02-\mathrm{RC}^{\mathrm{g}}$ & & & \\
\hline \multirow{2}{*}{ Sr-90 } & Aqueous & EPA $905.0^{c}$ & & & \\
\hline & Nonaqueous & Sr-02-RC ${ }^{g}$ & & & \\
\hline \multirow{2}{*}{ Gross Alpha/Beta } & Aqueous & EPA $900.0^{c}$ & \multirow{4}{*}{$\begin{array}{c}<\text { PALs } \\
\text { (Other Releases) }\end{array}$} & \multirow{3}{*}{$\begin{array}{c}\text { RPD } \\
35 \% \text { (nonaqueous) }^{d} \\
20 \% \text { (aqueous) }^{d}\end{array}$} & \multirow{4}{*}{$\begin{array}{c}\text { FLQC Recovery } \\
(\% \mathrm{R}) \\
\text { Lab-specific }^{\mathrm{j}}\end{array}$} \\
\hline & Nonaqueous & SM $7110 B^{i}$ & & & \\
\hline \multirow{2}{*}{ Tritium } & Aqueous & EPA $906.0^{c}$ & & & \\
\hline & Nonaqueous & $\begin{array}{l}\text { Laboratory } \\
\text { Procedure }^{k}\end{array}$ & & $\begin{array}{c}N D \\
-2<N D<2^{e}\end{array}$ & \\
\hline
\end{tabular}

${ }^{\text {aA }} \mathrm{A}$ list of analytes reported for each method is provided in Table 3-1.

${ }^{\mathrm{b}} \mathrm{The} \mathrm{MDC}$ is the minimum concentration of a analyte that can be measured and reported with 95\% confidence (Standard Methods). 'Prescribed Procedures for Measurement of Radioactivity in Drinking Water (EPA, 1980).

${ }^{\mathrm{d}}$ Sampling and Analysis Plan Guidance and Template (EPA, 2000).

eEvaluation of Radiochemical Data Usability (Paar and Porterfield, 1997).

${ }^{\mathrm{f}}$ Test Methods for Evaluating Solid Waste, Physical/Chemical Methods (EPA, 2008b).

${ }^{9}$ The Procedures Manual of the Environmental Measurements Laboratory (DOE, 1997).

hProfessional judgment and other industry acceptance criteria are used.

iStandard Methods for the Examination of Water and Wastewater (Clesceri, et al., 1998).

'Accuracy criteria are developed in-house using approved laboratory standard operating procedures in accordance with industry standards and the SNJV Statement of Work requirements.

kLaboratory standard operating procedures in accordance with industry standards and the SNJV Statement of Work requirements.

LCS = Laboratory control sample

FLQC = Full laboratory quality control

$N D=$ Normalized difference

$\mathrm{RPD}=$ Relative percent difference

$\% \mathrm{R}=$ Percent recovery 
Table 3-3

Analytical Requirements for Chemical COPCs for CAU 371

\begin{tabular}{|c|c|c|c|c|c|}
\hline Analysis $^{a}$ & $\begin{array}{l}\text { Medium or } \\
\text { Matrix }\end{array}$ & $\begin{array}{c}\text { Analytical } \\
\text { Method }\end{array}$ & $\mathrm{MDC}^{\mathrm{b}}$ & $\begin{array}{l}\text { Laboratory } \\
\text { Precision }\end{array}$ & $\begin{array}{l}\text { Laboratory } \\
\text { Accuracy }\end{array}$ \\
\hline \multicolumn{6}{|c|}{ Organics } \\
\hline VOCs & All & $8260^{c}$ & $<$ PALS & Lab-specific $^{d}$ & Lab-specific $^{d}$ \\
\hline TCLP VOCs & Leachate & $1311 / 8260^{c}$ & $\begin{array}{c}<\text { Regulatory } \\
\text { Levels }\end{array}$ & Lab-specific $^{d}$ & Lab-specific $^{d}$ \\
\hline SVOCs & All & $8270^{c}$ & $<$ PALS & Lab-specific $^{d}$ & Lab-specific $^{d}$ \\
\hline TCLP SVOCS & Leachate & $1311 / 8270^{c}$ & $\begin{array}{c}<\text { Regulatory } \\
\text { Levels }\end{array}$ & Lab-specific $^{d}$ & Lab-specific $^{d}$ \\
\hline PCBs & All & $8082^{c}$ & \multirow{3}{*}{$<$ PALs } & Lab-specific $^{d}$ & Lab-specific $^{d}$ \\
\hline TPH-GRO & All & 8015 Modified $^{c}$ & & Lab-specific $^{d}$ & Lab-specific $^{d}$ \\
\hline TPH-DRO & All & 8015 Modified $^{c}$ & & Lab-specific $^{d}$ & Lab-specific $^{d}$ \\
\hline \multicolumn{6}{|c|}{ Inorganics } \\
\hline Metals & All & $6010 / 6020^{c}$ & \multirow{3}{*}{$<$ PALS } & $\begin{array}{c}\text { RPD } \\
35 \% \text { (nonaqueous) }\end{array}$ & $\begin{array}{c}\text { FLQC Recovery } \\
(\% \mathrm{R})\end{array}$ \\
\hline \multirow{2}{*}{ Mercury } & Aqueous & $7470^{c}$ & & $20 \%$ (aqueous) & 75- \\
\hline & Nonaqueous & $7471^{c}$ & & \multirow{2}{*}{$\begin{array}{l}\text { Absolute Difference } \\
\pm 2 \times R L \text { (nonaqueous) }^{f} \\
\pm 1 \times \text { RL (aqueous) }\end{array}$} & \multirow{2}{*}{$\begin{array}{c}\text { LCS Recovery } \\
(\% \mathrm{R}) \\
80-120^{\mathrm{c}}\end{array}$} \\
\hline TCLP Metals & Leachate & $1311 / 6010 / 7470^{c}$ & $\begin{array}{c}<\text { Regulatory } \\
\text { Levels }\end{array}$ & & \\
\hline
\end{tabular}

${ }^{\mathrm{a} A}$ list of analytes reported for each method is provided in Table 3-1.

${ }^{\mathrm{b}}$ The MDC is the minimum concentration of a analyte that can be measured and reported with $99 \%$ confidence (SW-846).

${ }^{\mathrm{c}}$ Test Methods for Evaluating Solid Waste, Physical/Chemical Methods (EPA, 2008b).

${ }^{\mathrm{d} P}$ Precision and accuracy criteria are developed in-house using approved laboratory standard operating procedures in accordance with industry standards and the SNJV Statement of Work requirements.

'Sampling and Analysis Plan Guidance and Template (EPA, 2000).

${ }^{\dagger}$ Contract Laboratory Program National Functional Guidelines for Inorganic Data Review (EPA, 2004). 


\subsection{Field Investigation}

This section contains a description of the activities to be conducted to gather and document information from the CAU 371 field investigation.

\subsection{Technical Approach}

The information necessary to satisfy the DQO data needs will be generated for each CAU 371 CAS by collecting and analyzing samples generated during a field investigation. The presence and nature of contamination at both CAS 11-23-05 and CAS 18-45-01 will be evaluated using a combination of judgmental and probabilistic sampling approaches. The presence and nature of contamination that is not part of the radiological releases (e.g., spills, lead bricks) will be evaluated using a judgmental approach. The sampling strategy is presented in Appendix A.

If it is determined that a COC is present at any CAS, that CAS will be addressed further by determining the extent of contamination before evaluating corrective action alternatives. The number, location, and spacing of step-outs may be modified by the Task Manager or Site Supervisor, as warranted by site conditions, to achieve DQO criteria stipulated in Appendix A. Where sampling locations are modified by the Task Manager or Site Supervisor, the justification for these modifications will be documented in the field logbook, and in the CADD. Significant modifications shall be agreed to by NDEP before implementation. If an unexpected condition indicates that conditions are significantly different than the CSM, the activity will be rescoped, and the identified decision-makers notified for concurrence.

\subsection{Field Activities}

Field activities at CAU 371 include site preparation, sample location selection, and sample collection activities.

\subsubsection{Site Preparation Activities}

Site preparation activities to be conducted before environmental sampling include: relocation or removal of surface debris or instrument support structures; construction of hazardous waste accumulation areas and site exclusion zones; provision of sanitary facilities; performing radiological 
surveys and visual surveys at both CAU 371 CASs to identify any staining, discoloration, disturbance of native soils, or other indications of potential contamination.

\subsubsection{Sample Location Selection}

For the primary releases at both CASs, the Decision I sample plot locations will be determined judgmentally based on the results of the radiological survey. One sample plot will be established at each CAS in the location with the highest reading detected in the radiological survey. Four composite samples will be collected from each plot. Data collected will be used to estimate the TED for each sample. The TED will be determined for each sample by summing the internal and external dose components. Sample results for individual radionuclides will be used to calculate internal dose using Residual Radioactive (RESRAD) computer code. External dose will be determined by collecting in situ measurements using a dose measurement device (e.g., TLDs). These dose measurements will be taken at the approximate center of the sample plot at a height of $1 \mathrm{~m}$. Decision criteria is based on the 95 percent UCL of the average TED estimates from the four samples for each plot.

A probabilistic sampling approach will be implemented for the selection of sample locations within sample plots at both CASs. At each plot, each composite sample will consist of soil collected from nine random sample locations within the plot. For each composite sample, the first location will be selected randomly; the remaining eight sample locations will be established on a systematic triangular grid (Section A.9.0). Selection of probabilistic sample locations at these CASs, including an example of the predetermined sample locations at one plot (Figure A.9-3), are presented in Sections A.5.2.1.1 and A.9.1. Section A.5.2.1.1 briefly reviews the methodology and computation approach for the probabilistic sampling. In the event that the sample results yield a 95 percent UCL of the TED below $25 \mathrm{mrem} / \mathrm{yr}$ dose, additional sample plots will not be required.

For other releases at both CAU 371 CASs, a judgmental sampling approach will be used to investigate the likelihood of the soil containing a COC. Biasing factors, such as stains, radiological survey results, and wastes suspected of containing hazardous or radiological components are defined in Section A.5.2.1.2 and will be the basis of sample location selection. As biasing factors are identified and used for selection of sampling locations, they will be recorded in the appropriate field documents. 
Decision II sampling will consist of further defining the extent of contamination where COCs have been confirmed. For investigations of other releases at both CASs, step-out (Decision II) sample locations will be arranged in a triangular pattern around areas containing a COC at distances based on site conditions, COC concentrations, process knowledge, and biasing factors. If COCs extend beyond step-out locations, additional Decision II samples will be collected from locations further from the source. If a spatial boundary is reached, the CSM is shown to be inadequate, or the Site Supervisor determines that extent sampling needs to be re-evaluated, then work will be suspended temporarily, NDEP notified, and the investigation strategy re-evaluated. A minimum of one analytical result less than the action level from each lateral and vertical direction will be required to define the extent of COC contamination.

For CAS 11-23-05, if the Decision I sample plot results yield a 95 percent UCL of the TED above 25 mrem/yr dose, a Decision II sampling strategy will be presented and agreed upon by the stakeholders before collecting Decision II samples. For CAS 18-45-01, if the sample results from the Decision I sample plot yield a 95 percent UCL of the TED above $25 \mathrm{mrem} / \mathrm{yr}$ dose, additional sample plots will be required for Decision II. For Decision II, an additional nine sample plot locations will be determined along three sampling vectors, outward from GZ, based upon the 1994 flyover radiological survey. The outermost sample plot on each vector will be placed beyond the 25-millirem-dose boundary.

At both CAU 371 CASs, biasing factors (including field-screening results [FSRs]) will be used to select the most appropriate samples from a particular location for submittal to the analytical laboratory.

\subsubsection{Sample Collection}

The CAU 371 sampling program will consist of the following activities:

- Collect and analyze samples from locations as described in Section 4.2.2.

- Collect required QC samples.

- Collect waste management samples (if required). 
- Collect external dose measurements by hanging TLDs at the sample plots or collect instrument dose readings at extent locations.

- Record Global Positioning System (GPS) coordinates for each environmental sample location.

Decision I surface soil samples ( 0 to $5 \mathrm{~cm}$ [2 in.] bgs for primary releases and 0 to $0.5 \mathrm{ft}$ [15.24 cm] bgs for other releases) will be collected. If biasing factors are present in soils below locations where Decision I samples were collected, Decision II sampling will include collecting subsurface soil samples by hand augering, backhoe excavation, or other techniques as appropriate. Subsurface soil samples will be collected at depth intervals selected by the Site Supervisor or Task Manager. Samples will be based on biasing factors to a depth where the biasing factors are no longer obvious.

For the primary release at CAS 11-23-05, it is anticipated that the FAL of $25 \mathrm{mrem} / \mathrm{yr}$ will not be exceeded at the Decision sample plot. Therefore, Decision II sample plots will not be established at CAS 11-23-05 during the initial Decision I sampling field effort. For the primary release at CAS 18-45-01, there is high confidence that the FAL of $25 \mathrm{mrem} / \mathrm{yr}$ will be exceeded at the Decision I sample plot. Therefore, the Decision II sample plots will be located and sampled at CAS 18-45-01 during the initial field effort.

\subsubsection{Sample Management}

The laboratory requirements (i.e., minimum detectable concentrations, precision, and accuracy) to be used when analyzing the COPCs are presented in Tables 3-2 and 3-3. The analytical program for each CAS is presented in Section 3.2. All sampling activities and QC requirements for field and laboratory environmental sampling will be conducted in compliance with the Industrial Sites QAPP (NNSA/NV, 2002) and other applicable, approved procedures.

\subsection{Safety}

A site-specific health and safety document will be prepared and approved before the field effort. This document presents the requirements for protecting the health and safety of the workers. The 
following safety issues will be taken into consideration when evaluating the hazards and associated control procedures for field activities:

- Potential hazards to site personnel and the public include, but are not limited to: radionuclides, chemicals (e.g., heavy metals, VOC, SVOCs, and petroleum hydrocarbons), adverse and rapidly changing weather, remote location, motor vehicle and heavy equipment operations, and work conducted around craters which have not been approved for entry.

- $\quad$ Proper training of all site personnel to recognize and mitigate the anticipated hazards.

- Work controls to reduce or eliminate the hazards including engineering controls, substitution of less hazardous materials, and use of appropriate personal protective equipment (PPE).

- Occupational exposure monitoring to prevent overexposures to hazards such as radionuclides, chemicals, and physical agents (e.g., heat, cold, and high wind).

- Radiological surveying for alpha/beta and gamma emitters to minimize and/or control personnel exposures; use of the "as-low-as-reasonably-achievable” principle when addressing radiological hazards.

- Emergency and contingency planning to include medical care and evacuation, decontamination, spill control measures, and appropriate notification of project management. The same principles apply to emergency communications.

\subsection{Site Restoration}

Upon completion of CAI and waste management activities, all equipment, wastes, debris, and materials associated with the CAI will be removed from the site, and all signage and fencing (unless part of a corrective action) will also be removed from the site. 


\subsection{Waste Management}

Management of investigation-derived waste (IDW) will be based on regulatory requirements, field observations, process knowledge, and laboratory results from CAU 371 investigation samples.

Disposable sampling equipment, PPE, and rinsate are considered potentially contaminated waste only by virtue of contact with potentially contaminated media (e.g., soil) or potentially contaminated debris (e.g., metal and concrete). Therefore, sampling and analysis of IDW, separate from analyses of site investigation samples, may not be necessary for all IDW. However, if associated investigation samples are found to contain contaminants above regulatory levels, conservative estimates of total waste contaminant concentrations may be made based on the mass of the waste, the amount of contaminated media contained in the waste, and the maximum concentration of contamination found in the media. Direct samples of IDW may also be taken to support waste characterization.

Sanitary, hazardous, radioactive, and/or mixed waste, if generated, will be managed and disposed of in accordance with applicable DOE orders, U.S. Department of Transportation (DOT) regulations, state and federal waste regulations, and agreements and permits between DOE and NDEP.

\subsection{Waste Minimization}

Investigation activities are planned to minimize IDW generation. This will be accomplished by incorporating the use of process knowledge, visual examination, and/or radiological survey and swipe results. When possible, disturbed media (e.g., soil removed during subsurface excavation) or debris will be returned to its original location. Contained media (e.g., soil managed as waste) as well as other IDW will be segregated to the greatest extent possible to minimize generation of hazardous, radioactive, or mixed waste. Hazardous material used at the sites will be controlled to limit unnecessary generation of hazardous or mixed waste. Administrative controls, including decontamination procedures and waste characterization strategies, will minimize waste generated during investigations. 


\subsection{Potential Waste Streams}

Page 36 of 55

Waste generated during the investigation activities may include the following potential waste streams:

- Personal protective equipment and disposable sampling equipment (e.g., plastic, paper, sample containers, aluminum foil, spoons, bowls)

- Decontamination rinsate

- Environmental media (e.g., soil)

- $\quad$ Surface debris in investigation area (e.g., metal and concrete)

- $\quad$ Field-screening waste (e.g., disposable sampling equipment, and/or PPE contaminated by field-screening activities)

\subsection{Investigation-Derived Waste Management}

The onsite management and ultimate disposition of IDW will be determined based on a determination of the waste type (e.g., sanitary, low-level, hazardous, hydrocarbon, mixed), or the combination of waste types. A determination of the waste type will be guided by several factors, including, but not limited to: the analytical results of samples either directly or indirectly associated with the waste, historical site knowledge, waste generation process knowledge, field observations, field-monitoring/screening results, and/or radiological survey/swipe results.

Table 4-2 of the NV/YMP RadCon Manual (NNSA/NSO, 2004) is used to determine the radiological release status of such materials. Onsite IDW management requirements by waste type are detailed in the following sections. Applicable waste management regulations and requirements are listed in Table 5-1.

\subsubsection{Sanitary Waste}

Sanitary IDW generated at each CAS will be collected, managed, and disposed of in accordance with the sanitary waste management regulations and the permits for operation of the NTS U10c Industrial Waste Landfill.

Industrial IDW generated at each CAS will be placed in a roll-off box located in Mercury, or other approved roll-off box, for ultimate disposal in the U10c Industrial Waste Landfill. 
Table 5-1

Waste Management Regulations and Requirements

\begin{tabular}{|c|c|c|}
\hline Waste Type & Federal Regulation & Additional Requirements \\
\hline Solid (nonhazardous) & $\mathrm{N} / \mathrm{A}$ & $\begin{array}{c}\text { NRS }^{\mathrm{a}} 444.440-444.620 \\
\text { NAC }^{\mathrm{b}} 444.570-444.7499 \\
\text { NTS Landfill Permit SW13-097-04 }{ }^{\text {c }} \text {, Rev. } 5 \\
\text { NTS Landfill Permit SW13-097-03 }{ }^{\text {, }} \text {, Rev. } 7\end{array}$ \\
\hline Liquid/Rinsate (nonhazardous) & $\mathrm{N} / \mathrm{A}$ & $\begin{array}{l}\text { Water Pollution Control General Permit, } \\
\text { GNEV93001, Rev. iv }\end{array}$ \\
\hline Hazardous & $\begin{array}{c}\mathrm{RCRA}^{\mathrm{f}} \\
40 \text { CFR 260-282 }\end{array}$ & $\begin{array}{c}\text { NRS }^{a} 459.400-459.600 \\
\text { NAC }^{b} 444.850-444.8746 \\
\text { POC }^{g}\end{array}$ \\
\hline Low-Level Radioactive & $\mathrm{N} / \mathrm{A}$ & DOE Orders and NTSWAC \\
\hline Mixed & $\begin{array}{c}\text { RCRA }^{f} \\
40 \text { CFR 260-282 }\end{array}$ & $\begin{array}{l}\text { NTSWAC } \\
\text { POC }^{\mathrm{g}}\end{array}$ \\
\hline Hydrocarbon & $\mathrm{N} / \mathrm{A}$ & $\begin{array}{c}\text { NTS Landfill Permit SW13-097-02', Rev. } 7 \\
\text { NAC }^{\text {b }} \text { 445A.2272 }\end{array}$ \\
\hline Polychlorinated Biphenyls & $\begin{array}{c}\text { TSCA }^{\mathrm{j}} \\
40 \text { CFR } 761\end{array}$ & $\begin{array}{l}N^{N R S^{a}} 459.400-459.600 \\
\text { NAC }^{b} 444.940-444.9555\end{array}$ \\
\hline Asbestos & $\begin{array}{c}\text { TSCA }^{\mathrm{j}} \\
40 \text { CFR } 763\end{array}$ & $\begin{array}{l}N_{R S}^{a} 618.750-618.840 \\
N^{\text {b }} 6 C^{b} 444.965-444.976\end{array}$ \\
\hline
\end{tabular}

${ }^{a}$ Nevada Revised Statutes (NRS, 2007a, b, c)

${ }^{\mathrm{b}}$ Nevada Administrative Code (NAC, 2006a and d)

${ }^{\mathrm{c}}$ Area 23 Class II Solid Waste Disposal Site (NDEP, 2006a)

${ }^{\mathrm{d} A}$ Area 9 Class III Solid Waste Disposal Site (NDEP, 2006c)

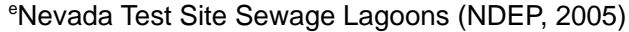

${ }^{\mathrm{f}}$ Resource Conservation and Recovery Act (CFR, 2007a)

${ }^{9}$ Nevada Test Site Performance Objective for the Certification of Nonradioactive Hazardous Waste (BN, 1995)

${ }^{\mathrm{h}}$ Nevada Test Site Waste Acceptance Criteria, Rev. 7 (NNSA/NSO, 2008a)

'Area 6 Class III Solid Waste Disposal Site for hydrocarbon waste (NDEP, 2006b)

'Toxic Substances Control Act (CFR, 2007b and c)

CFR $=$ Code of Federal Regulations

$\mathrm{N} / \mathrm{A}=$ Not applicable

NRS = Nevada Revised Statutes

NTSWAC = Nevada Test Site Waste Acceptance Criteria

$\mathrm{POC}=$ Performance Objective for the Certification of Nonradioactive Hazardous Waste

TSCA = Toxic Substances Control Act

\subsubsection{Low-Level Radioactive Waste}

Radiological swipe surveys and/or direct-scan surveys may be conducted on reusable sampling equipment and the PPE and disposable sampling equipment waste streams exiting a radiologically controlled area (RCA). This allows for the immediate segregation of radioactive waste from waste that may be unrestricted regarding radiological release. Removable contamination limits, as defined in Table 4-2 of the current version of the NV/YMP RadCon Manual (NNSA/NSO, 2004), will be 
used to determine whether such waste may be declared unrestricted regarding radiological release versus being declared radioactive waste. Direct sampling of the waste may be conducted to aid in determining whether a particular waste unit (e.g., drum of soil) contains low-level radioactive waste, as necessary. Waste that is determined to be below the release values, either by direct radiological survey/swipe results or through process knowledge, will not be managed as potential radioactive waste. Wastes with values in excess of release criteria will be managed as potential radioactive waste and managed in accordance with this section.

Low-level radioactive waste, if generated, will be managed in accordance with the contractor-specific waste certification program plan, DOE orders, and the requirements of the current version of the Nevada Test Site Waste Acceptance Criteria (NNSA/NSO, 2008a). Potential radioactive waste drums containing soil, PPE, disposable sampling equipment, and/or rinsate may be staged and managed at a designated RMA or RCA when full or at the end of an investigation phase.

\subsubsection{Hazardous Waste}

Suspected hazardous wastes will be placed in DOT-compliant containers. All containerized hazardous waste will be handled, inspected, and managed in accordance with Title 40 CFR 265 Subpart I (CFR, 2007a).

\subsubsection{Hydrocarbon Waste}

Hydrocarbon soil waste containing more than $100 \mathrm{mg} / \mathrm{kg}$ of TPH will be managed on site in a drum or other appropriate container until fully characterized. Hydrocarbon waste may be disposed of at a designated hydrocarbon landfill, an appropriate hydrocarbon waste management facility (e.g., recycling facility), or other method in accordance with the State of Nevada regulations (see Table 5-1).

\subsubsection{Mixed Low-Level Waste}

Mixed waste, if generated, shall be managed and dispositioned according to the requirements of RCRA (CFR, 2007a) or subject to agreements between NNSA/NSO and the State of Nevada, as well as DOE requirements for radioactive waste. 


\subsubsection{Polychlorinated Biphenyls}

If any type of polychlorinated biphenyl waste is generated, it will be managed according to 40 CFR 761 (CFR, 2007b) as well as State of Nevada requirements (NAC, 2006a), guidance, and agreements with NNSA/NSO.

\subsection{Management of Specific Waste Streams}

\subsubsection{Personal Protective Equipment}

Personal protective equipment and disposable sampling equipment will be visually inspected for stains, discoloration, and gross contamination as the waste is generated, and also evaluated for radiological contamination. Staining and discoloration will be assumed to be the result of contact with potentially contaminated media such as soil, sludge, or liquid. Gross contamination is the visible contamination of an item (e.g., clumps of soil/sludge on a sampling spoon or free liquid smeared on a glove). While gross contamination can often be removed through decontamination methods, removal from small items, such as gloves or booties, is not typically conducted. Investigation-derived waste that meets this description will be segregated and managed as potentially characteristic hazardous waste. This segregated population of waste will either: (1) be assigned the characterization of the soil/sludge that was sampled, (2) be sampled directly, or (3) undergo further evaluation using the soil/sludge sample results to determine how much soil/sludge would need to be present in the waste to exceed regulatory levels. Waste that is determined to be hazardous will be entered into an approved waste management system where it will be managed and dispositioned according to RCRA requirements or subject to agreements between NNSA/NSO and the State of Nevada (see Table 5-1). The PPE and equipment that is not visibly stained, discolored, or grossly contaminated, and is within the radiological free-release criteria, will be managed as nonhazardous industrial waste.

\subsubsection{Management of Decontamination Rinsate}

Rinsate at CAU 371 will not be considered hazardous waste unless there is evidence that the rinsate may display a RCRA characteristic. Evidence may include such things as the presence of a visible sheen, $\mathrm{pH}(>12.5$ or $<2.0)$, or association with equipment/materials used to respond to a release/spill of a hazardous waste/substance. Decontamination rinsate that is potentially hazardous (using associated sample results and/or process knowledge) will be managed as characteristic 
hazardous waste (CFR, 2007a). The regulatory status of the potentially hazardous rinsate will be determined through the application of associated sample results or through direct sampling. If the associated samples do not indicate the presence of hazardous contaminants, then the rinsate will be considered nonhazardous.

The disposal of nonhazardous rinsate will be consistent with guidance established in current NNSA/NSO Fluid Management Plans for the NTS as follows:

- $\quad$ Rinsate that is determined to be nonhazardous and contaminated to less than 5x Safe Drinking Water Standards (SDWS) is not restricted for disposal. Nonhazardous rinsate that is contaminated at 5x to 10x SDWS will be disposed of in an established infiltration basin or solidified and disposed of as sanitary waste or low-level waste.

- Nonhazardous rinsate that is contaminated at greater than 10x SDWS will be disposed of in a lined basin or solidified and disposed of as sanitary waste or low-level waste.

\subsubsection{Management of Soil}

This waste stream consists of soil removed for disposal during soil sampling. This waste stream will be characterized based on laboratory analytical results from representative locations. If the soil is determined to potentially contain COCs, the material will be managed on site or containerized for transportation to an appropriate disposal site. Soils placed into the location from which it originated are not considered waste.

\subsubsection{Management of Debris}

This waste stream can vary depending on site conditions. Debris that requires removal for the investigation activities (soil sampling) must be characterized for proper management and disposition. Historical site knowledge, knowledge of the waste generation process, field observations, field-monitoring/screening results, radiological survey/swipe results, and/or the analytical results of samples either directly or indirectly associated with the waste may be used to characterize the debris. 


\subsection{Quality Assurance/Quality Control}

The overall objective of the characterization activities described in this CAIP is to collect accurate and defensible data to support the selection and implementation of a closure alternative for each CAU 371 CAS. Sections 6.1 and 6.2 discuss the collection of required QC samples in the field and QA requirements for laboratory/analytical data to achieve closure. Unless otherwise stated in this CAIP or required by the results of the DQO process (see Appendix A), this investigation will adhere to the Industrial Sites QAPP (NNSA/NV, 2002).

\subsection{Quality Control Sampling Activities}

Field QC samples will be collected in accordance with established procedures. Field QC samples are collected and analyzed to aid in determining the validity of environmental sample results. The number of required QC samples depends on the types and number of environmental samples collected. The minimum frequency of collecting and analyzing QC samples for this investigation, as determined in the DQO process, include:

For radiological samples:

- Field duplicates (1 per 20 environmental samples or 1 per CAS per matrix, if less than 20 collected)

- Laboratory QC samples (1 per 20 environmental samples or 1 per CAS per matrix, if less than 20 collected)

For chemical samples (if collected):

- $\quad$ Trip blanks (1 per cooler containing samples for VOC analysis)

- Equipment rinsate blanks (1 per sampling event for each type of decontamination procedure)

- Source blanks (1 per lot of uncharacterized source material that contacts sampled media)

- Field duplicates (1 per 20 environmental samples or 1 per CAS per matrix, if less than 20 collected) 
- Field blanks (1 per CAS depending on site conditions)

- Laboratory QC samples (1 per 20 environmental samples or 1 per CAS per matrix, if less than 20 collected)

Additional QC samples may be submitted based on site conditions at the discretion of the Task Manager or Site Supervisor. Field QC samples shall be analyzed using the same analytical procedures implemented for associated environmental samples. Additional details regarding field QC samples are available in the Industrial Sites QAPP (NNSA/NV, 2002).

\subsection{Laboratory/Analytical Quality Assurance}

Criteria for the investigation, as stated in the DQOs (Appendix A), and except where noted, require laboratory analytical quality data be used for making critical decisions. Rigorous QA/QC will be implemented for all laboratory samples including documentation, data verification and validation of analytical results, and an assessment of DQIs as they relate to laboratory analysis.

\subsubsection{Data Validation}

Data verification and validation will be performed in accordance with the Industrial Sites QAPP (NNSA/NV, 2002), except where otherwise stipulated in this CAIP. Chemical and radiological laboratory data from samples that are collected and analyzed will be evaluated for data quality according to company-specific procedures. The data will be reviewed to ensure that all required samples were appropriately collected, analyzed, and the results met data validation criteria. Validated data, including estimated data (i.e., J-qualified), will be assessed to determine whether they meet the DQO requirements of the investigation and the performance criteria for the DQIs. The results of this assessment will be documented in the CADD. If the DQOs were not met, corrective actions will be evaluated, selected, and implemented (e.g., refine CSM or resample to fill data gaps).

\subsubsection{Data Quality Indicators}

The DQIs are qualitative and quantitative descriptors used in interpreting the degree of acceptability or utility of data. Data quality indicators are used to evaluate the entire measurement system and laboratory measurement processes (i.e., analytical method performance) as well as to evaluate 
individual analytical results (i.e., parameter performance). The quality and usability of data used to make DQO decisions will be assessed based on the following DQIs:

- Precision

- Accuracy/bias

- Representativeness

- Comparability

- Completeness

- Sensitivity

Table 6-1 provides the established analytical method/measurement system performance criteria for each of the DQIs and the potential impacts to the decision if the criteria are not met. The following subsections discuss each of the DQIs that will be used to assess the quality of laboratory data. Due to changes in analytical methodology and in analytical laboratory contracts, criteria for precision and accuracy in Tables 3-2 and 3-3 that vary from corresponding information in the Industrial Sites QAPP will supersede the Industrial Sites QAPP (NNSA/NV, 2002).

Table 6-1

Laboratory and Analytical Performance Criteria for CAU 371 Data Quality Indicators (Page 1 of 2)

\begin{tabular}{|c|c|c|}
\hline $\begin{array}{l}\text { Data Quality } \\
\text { Indicator }\end{array}$ & Performance Metric & $\begin{array}{l}\text { Potential Impact on Decision } \\
\text { If Performance Metric Not Met }\end{array}$ \\
\hline Precision & $\begin{array}{l}\text { At least } 80 \% \text { of the sample results for each } \\
\text { measured contaminant are not qualified for } \\
\text { precision based on the criteria for each } \\
\text { analytical method-specific and } \\
\text { laboratory-specific criteria presented in } \\
\text { Section } 6.2 .3 \text {. }\end{array}$ & $\begin{array}{l}\text { If the performance metric is not met, the } \\
\text { affected analytical results from each } \\
\text { affected CAS will be assessed to } \\
\text { determine whether there is sufficient } \\
\text { confidence in analytical results to use the } \\
\text { data in making DQO decisions. }\end{array}$ \\
\hline Accuracy & $\begin{array}{l}\text { At least } 80 \% \text { of the sample results for each } \\
\text { measured contaminant are not qualified for } \\
\text { accuracy based on the method-specific and } \\
\text { laboratory-specific criteria presented in } \\
\text { Section } 6.2 .4 \text {. }\end{array}$ & $\begin{array}{l}\text { If the performance metric is not met, the } \\
\text { affected analytical results from each } \\
\text { affected CAS will be assessed to } \\
\text { determine whether there is sufficient } \\
\text { confidence in analytical results to use the } \\
\text { data in making DQO decisions. }\end{array}$ \\
\hline Representativeness & $\begin{array}{l}\text { Samples contain contaminants at } \\
\text { concentrations present in the environmental } \\
\text { media from which they were collected. }\end{array}$ & $\begin{array}{l}\text { Analytical results will not represent true } \\
\text { site conditions. Inability to make } \\
\text { appropriate DQO decisions. }\end{array}$ \\
\hline Completeness & $\begin{array}{l}80 \% \text { of the CAS-specific COPCs } \\
\text { have valid results. } \\
100 \% \text { of CAS-specific targeted contaminants } \\
\text { have valid results. }\end{array}$ & $\begin{array}{l}\text { Cannot support/defend decision on } \\
\text { whether COCs are present. }\end{array}$ \\
\hline
\end{tabular}


Table 6-1

Laboratory and Analytical Performance Criteria for CAU 371 Data Quality Indicators (Page 2 of 2)

\begin{tabular}{||c|l|l||}
\hline $\begin{array}{c}\text { Data Quality } \\
\text { Indicator }\end{array}$ & \multicolumn{1}{|c|}{ Performance Metric } & \multicolumn{1}{|c|}{$\begin{array}{c}\text { Potential Impact on Decision } \\
\text { If Performance Metric Not Met }\end{array}$} \\
\hline \hline Extent Completeness & $\begin{array}{l}100 \% \text { of COCs used to define extent } \\
\text { have valid results. }\end{array}$ & $\begin{array}{l}\text { Extent of contamination cannot be } \\
\text { accurately determined. }\end{array}$ \\
\hline $\begin{array}{l}\text { Clean Closure } \\
\text { Completeness }\end{array}$ & $\begin{array}{l}100 \% \text { of targeted contaminants } \\
\text { have valid results. }\end{array}$ & $\begin{array}{l}\text { Cannot determine whether CoCs remain } \\
\text { in soil. }\end{array}$ \\
\hline Comparability & $\begin{array}{l}\text { Sampling, handling, preparation, analysis, } \\
\text { reporting, and data validation are performed } \\
\text { using standard methods and procedures. }\end{array}$ & $\begin{array}{l}\text { Inability to combine data with data } \\
\text { obtained from other sources and/or } \\
\text { inability to compare data to regulatory } \\
\text { action levels. }\end{array}$ \\
\hline Sensitivity & $\begin{array}{l}\text { Minimum detectable concentrations are less } \\
\text { than or equal to respective FALs. }\end{array}$ & $\begin{array}{l}\text { Cannot determine whether COCs are } \\
\text { present or migrating at levels of concern. }\end{array}$ \\
\hline
\end{tabular}

\subsubsection{Precision}

Precision is a measure of the repeatability of the analysis process from sample collection through analysis results and is used to assess the variability between two equal samples.

Determinations of precision will be made for field duplicate samples and laboratory duplicate samples. Field duplicate samples will be collected simultaneously with samples from the same source under similar conditions in separate containers. The duplicate sample will be treated independently of the original sample in order to assess field impacts and laboratory performance on precision through a comparison of results. Laboratory precision is evaluated as part of the required laboratory internal QC program to assess performance of analytical procedures. The laboratory sample duplicates are an aliquot, or subset, of a field sample generated in the laboratory. They are not a separate sample but a split, or portion, of an existing sample. Typically, laboratory duplicate QC samples may include FLQC and LCS duplicate samples for organic, inorganic, and radiological analyses.

Precision is a quantitative measure used to assess overall analytical method and field-sampling performance as well as to assess the need to "flag” (qualify) individual parameter results when corresponding QC sample results are not within established control limits. 
The criteria used for the assessment of inorganic chemical precision when both results are greater than or equal to $5 x$ RL is 20 percent and 35 percent for aqueous and soil samples, respectively. When either result is less than $5 x$ RL, a control limit of $\pm 1 x$ RL and $\pm 2 x$ RL for aqueous and soil samples, respectively, is applied to the absolute difference.

The criteria used for the assessment of organic chemical precision is based on professional judgment using laboratory derived control limits.

The criteria used for the assessment of radiological precision when both results are greater than or equal to 5x MDC is 20 percent and 35 percent for aqueous and soil samples, respectively. When either result is less than 5x MDC, the ND should be between -2 and +2 for aqueous and soil samples. The parameters to be used for assessment of precision for duplicates are listed in Table 3-2.

Values that are outside the specified criteria do not necessarily result in the qualification of analytical data. It is only one factor in making an overall judgment about the quality of the reported analytical results. The performance metric for assessing the DQI of precision on DQO decisions (see Table 6-1) is that at least 80 percent of sample results for each measured contaminant are not qualified due to duplicates exceeding the criteria. If this performance is not met, an assessment will be conducted in the CADD on the impacts to DQO decisions specific to affected contaminants.

\subsubsection{Accuracy}

Accuracy is a measure of the closeness of an individual measurement to the true value. It is used to assess the performance of laboratory measurement processes.

Accuracy is determined by analyzing a reference material of known parameter concentration or by reanalyzing a sample to which a material of known concentration or amount of parameter has been added (spiked). Accuracy will be evaluated based on results from three types of spiked samples: FLQC, LCS, and surrogates (organics). The LCS sample is analyzed with the field samples using the same sample preparation, reagents, and analytical methods employed for the samples. One LCS will be prepared with each batch of samples for analysis by a specific measurement.

The criteria used for the assessment of inorganic chemical accuracy are 75 to 125 percent for FLQC recoveries and 80 to 120 percent for LCS recoveries. For organic chemical accuracy, FLQC and LCS 
laboratory-specific percent recovery criteria developed and generated in-house by the laboratory according to approved laboratory procedures are applied. The criteria used for the assessment of radiochemical accuracy are 80 to 120 percent for LCS and FLQC recoveries.

Values that are outside the criteria specified do not necessarily result in the qualification of analytical data. It is only one factor in making an overall judgment about the quality of the reported analytical results. Factors beyond laboratory control, such as sample matrix effects, can cause the measured values to be outside of the established criteria. Therefore, the entire sampling and analytical process may be evaluated when determining the usability of the affected data.

The performance metric for assessing the DQI of accuracy on DQO decisions (see Table 6-1) is that at least 80 percent of the sample results for each measured contaminant are not qualified for accuracy. If this performance is not met, an assessment will be conducted in the CADD on the impacts to DQO decisions specific to affected contaminants and CASs.

\subsubsection{Representativeness}

Representativeness is the degree to which sample characteristics accurately and precisely represent a characteristics of a population or an environmental condition (EPA, 2002). Representativeness is assured by carefully developing the sampling strategy during the DQO process such that false negative and false positive decision errors are minimized. The criteria listed in DQO Step 6 - Specify the Tolerable Limits on Decision Errors are:

- For Decision I judgmental sampling, having a high degree of confidence that the sample locations selected will identify COCs if present anywhere within the CAS.

- For Decision I probabilistic sampling, having a high degree of confidence that the sample locations selected will represent contamination of the CAS.

- Having a high degree of confidence that analyses conducted will be sufficient to detect any COCs if present in the samples.

- For Decision II, having a high degree of confidence that the sample locations selected will identify the extent of COCs.

These are qualitative measures that will be used to assess measurement system performance for representativeness. The assessment of this qualitative criterion will be presented in the CADD. 


\subsubsection{Comparability}

Comparability is a qualitative parameter expressing the confidence with which one dataset can be compared to another (EPA, 2002). The criteria for the evaluation of comparability will be that all sampling, handling, preparation, analysis, reporting, and data validation were performed and documented in accordance with approved procedures that are in conformance with standard industry practices. Analytical methods and procedures approved by DOE will be used to analyze, report, and validate the data. These methods and procedures are in conformance with applicable methods used in industry and government practices. An evaluation of comparability will be presented in the CADD.

\subsubsection{Completeness}

Completeness is defined as generating sufficient data of the appropriate quality to satisfy the data needs identified in the DQOs. For judgmental sampling, completeness will be evaluated using both a quantitative measure and a qualitative assessment. The quantitative measurement to be used to evaluate completeness is presented in Table 6-1 and is based on the percentage of measurements made that are judged to be valid.

For the judgmental sampling approach, the completeness goal is 80 percent. If this goal is not achieved, the dataset will be assessed for potential impacts on making DQO decisions. For the probabilistic sampling approach, the completeness goal is a calculated minimum sample size required to produce a valid statistical comparison of the sample mean to the FAL. The methodology for determining minimum required sample size is described in Section A.9.1.

The qualitative assessment of completeness is an evaluation of the sufficiency of information available to make DQO decisions. This assessment will be based on meeting the data needs identified in the DQOs and presented in the CADD. Additional samples will be collected if it is determined that the number of samples do not meet completeness criteria.

\subsubsection{Sensitivity}

Sensitivity is the capability of a method or instrument to discriminate between measurement responses representing different levels of the variable of interest (EPA, 2002). The evaluation criteria for this parameter will be that measurement sensitivity (i.e., MDCs) will be less than or equal to the 
corresponding FALs. If this criterion is not achieved, the affected data will be assessed for usability and potential impacts on meeting site characterization objectives. This assessment will be presented in the CADD. 


\subsection{Duration and Records Availability}

\subsection{Duration}

Table 7-1 is a tentative duration of activities (in calendar days) for CAI activities.

Table 7-1

Corrective Action Investigation Activity Durations

\begin{tabular}{|c|c|}
\hline Duration (days) & Activity \\
\hline \hline 10 & Site Preparation \\
\hline 76 & Fieldwork Preparation and Mobilization \\
\hline 55 & Sampling \\
\hline 160 & Data Assessment \\
\hline 180 & Waste Management \\
\hline
\end{tabular}

\subsection{Records Availability}

Historical information and documents referenced in this plan are retained in the NNSA/NSO project files in Las Vegas, Nevada, and can be obtained through written request to the DOE Federal Sub-Project Director. This document is available in the DOE public reading rooms located in Las Vegas and Carson City, Nevada, or by contacting the DOE Federal Sub-Project Director. The NDEP maintains the official Administrative Record for all activities conducted under the auspices of the FFACO. 


\subsection{References}

ARL/SORD, see Air Resources Laboratory/Special Operations and Research Division.

ASTM, see American Society for Testing and Materials.

Air Resources Laboratory/Special Operations and Research Division. 2009. NTS Climatological Rain Gauge Data. As accessed at http://www.sord.nv.goe/home_climate_rain.htm on 12 February.

American Society for Testing and Materials. 1995. Standard Guide for Risk-Based Corrective Action Applied at Petroleum Release Sites, ASTM E 1739-95 (Reapproved 2002). Philadelphia, PA.

BN, see Bechtel Nevada.

Bechtel Nevada. 1995. Nevada Test Site Performance Objective for Certification of Nonradioactive Hazardous Waste, Rev. 0, G-E11/96.01. Las Vegas, NV.

Bechtel Nevada. 1999. An Aerial Radiological Survey of the Nevada Test Site, DOE/11718-324. Prepared for U.S. Department of Energy, Nevada Operations Office. Las Vegas, NV: Remote Sensing Laboratory.

CFR, see Code of Federal Regulations.

Clesceri, L.S., A.E. Greenberg, and A.D. Eaton, eds. 1998. Standard Methods for the Examination of Water and Wastewater, $20^{\text {th }}$ edition. Published by American Public Health Association, American Water Works Association, and Water Environmental Federation.

Code of Federal Regulations. 2007a. Title 40 CFR, Parts 260-282, "Hazardous Waste Management System: General.” Washington, DC: U.S. Government Printing Office.

Code of Federal Regulations. 2007b. Title 40 CFR, Part 761, "Polychlorinated Biphenyls (PCBs) Manufacturing, Processing, Distribution in Commerce, and Use Prohibitions.” Washington, DC: U.S. Government Printing Office.

Code of Federal Regulations. 2007c. Title 40 CFR, Part 763, “Asbestos.” Washington, DC: U.S. Government Printing Office.

DOE, see U.S. Department of Energy.

DOE/NV, see U.S. Department of Energy, Nevada Operations Office. 
DRI, see Desert Research Institute.

Desert Research Institute. 1985. Nevada Test Site Radionuclide Inventory and Distribution Program Report \#2. Areas 2 and 4, Publication \#45041. Las Vegas, NV.

Desert Research Institute. 1988. CERCLA Preliminary Assessment of DOE's Nevada Operations Office Nuclear Weapons Testing Areas. April. Las Vegas, NV.

EPA, see U.S. Environmental Protection Agency.

ERDA, see Energy Research and Development Administration.

Energy Research and Development Administration. 1977. Final Environmental Impact Statement, Nevada Test Site, Nye County, Nevada, ERDA-1551. Washington, DC.

FFACO, see Federal Facility Agreement and Consent Order.

Federal Facility Agreement and Consent Order. 1996 (as amended February 2008). Agreed to by the State of Nevada; U.S. Department of Energy, Environmental Management; U.S. Department of Defense; and U.S. Department of Energy, Legacy Management.

Gray, K.J., D.S. Shafer, K. Self, C. Martin, and R. McCarthur. 2007. Radionuclide Inventory and Distribution Program (RIDP) Database, Rev. 2. April. Las Vegas, NV.

Laczniak, R.J., J.C. Cole, D.A. Sawyer, and D.A. Trudeau. 1996. Summary of Hydrogeologic Controls Ground-Water flow at the Nevada Test Site, Nye County, Nevada. As accessed at http://water.usgs.geo/pubs/wri/wri964109/report.htm on 30 October.

Moore, J., Science Applications International Corporation. 1999. Memorandum to M. Todd (SAIC) entitled, “Background Concentrations for NTS and TTR Soil Samples,” 3 February. Las Vegas, NV: IT Corporation.

Murphy, T., Bureau of Federal Facilities. 2004. Letter to R. Bangerter (NNSA/NSO) entitled, "Review of Industrial Sites Project Document Guidance for Calculating Industrial Sites Project Remediation Goals for Radionuclides in Soil Using the Residual Radiation (RESRAD) Computer Code.” 19 November. Las Vegas, NV.

NAC, see Nevada Administrative Code.

NBMG, see Nevada Bureau of Mines and Geology.

NCRP, see National Council on Radiation Protection and Measurements.

NDEP, see Nevada Division of Environmental Protection. 
NNSA/NSO, see U.S. Department of Energy, National Nuclear Security Administration Nevada Site Office.

NNSA/NV, see U.S. Department of Energy, National Nuclear Security Administration Nevada Operations Office.

NRS, see Nevada Revised Statutes.

National Council on Radiation Protection and Measurements. 1999. Recommended Screening Limits for Contaminated Surface Soil and Review of Factors Relevant to Site-Specific Studies, NCRP Report No. 129. Bethesda, MD.

Nevada Administrative Code. 2006a. NAC 444, "Sanitation.” Carson City, NV. As accessed at http://www.leg.state.nv.us/nac on 30 October.

Nevada Administrative Code. 2006b. NAC 445A.227, “Contamination of Soil: Order by Director for Corrective Action; Factors To Be Considered in Determining Whether Corrective Action Required.” Carson City, NV. As accessed at http://www.leg.state.nv.us/nac on 30 October.

Nevada Administrative Code. 2006c. NAC 445A.22705, “Contamination of Soil: Evaluation of Site by Owner or Operator; Review of Evaluation by Division.” Carson City, NV. As accessed at http://www.leg.state.nv.us/nac on 30 October.

Nevada Administrative Code. 2006d. NAC 445A.2272, "Contamination of Soil: Establishment of Action Levels.” Carson City, NV. As accessed at http://www.leg.state.nv.us/nac on 30 October.

Nevada Bureau of Mines and Geology. 1998. Mineral and Energy Resource Assessment of the Nellis Air Force Range, Open-File Report 98-1. Reno, NV.

Nevada Division of Environmental Protection. 2005. Water Pollution Control General Permit, No. GNEV93001, Rev. iv. Carson City, NV.

Nevada Division of Environmental Protection. 2006a. Class II Solid Waste Disposal Site for Municipal and Solid Waste, Area 23 of the NTS, Permit SW 13-097-04, Rev. 5. Carson City, NV.

Nevada Division of Environmental Protection. 2006b (as amended in August 2000). Class III Solid Waste Disposal Site for Hydrocarbon Burdened Soils, Area 6 of the NTS, Permit SW 13-097-02, Rev. 7. Carson City, NV.

Nevada Division of Environmental Protection. 2006c (as amended in August 2000). Class III Solid Waste Disposal Site; UIOc, Area 9 of the NTS, Permit SW 13-097-03. Carson City, NV.

Nevada Revised Statutes. 2007a. NRS 444.440 - 444.620, “Collection and Disposal of Solid Waste.” Carson City, NV. 
Nevada Revised Statutes. 2007b. NRS 459.400 - 459.600, “Disposal of Hazardous Waste.” Carson City, NV.

Nevada Revised Statutes. 2007c. NRS 618.750 - 618.840, “Control of Asbestos.” Carson City, NV.

Paar, J.G., and D.R. Porterfield. 1997. Evaluation of Radiochemical Data Usability, ES/ER/MS-5. April. Oak Ridge, TN: U.S. Department of Energy.

SNJV GIS, see Stoller-Navarro Joint Venture Geographic Information Systems.

Sandia Corporation. 1966. Letter to W.W. Allaire (U.S. Atomic Energy Commission) entitled, “Scientific Advisor’s Report of Pin Stripe.” 19 May. Open Net Accession Number 77515. Sandia Base, Albuquerque, NM.

Slate, J.L., M.E. Berry, P.D. Rowley, C.J. Fridrich, K.S. Morgan, J.B. Workman, O.D. Young, G.L. Dixon, V.S. Williams, E.H. McKee, D.A. Ponce, T.G. Hildenbrand, W.C. Swadley, S.C. Lundstrom, E.B. Ekren, R.G. Warren, J.C. Cole, R.J. Fleck, M.A. Lanphere, D.A. Sawyer, S.A. Minor, D.J. Grunwald, R.J. Laczniak, C.M. Menges, J.C. Yount, and A.S. Jayko. 1999. Part A. Digital Geologic Map of the Nevada Test Site and Vicinity, Nye, Lincoln, and Clark Counties, Nevada, and Inyo County, California, Revision 4, Open-File Report 99-554-A, scale 1:120,000. Denver, CO: U.S. Geological Survey.

Stoller-Navarro Joint Venture Geographic Information Systems. 2007. ESRI ArcGIS Software.

Stoller-Navarro Joint Venture Geographic Information Systems. 2008. ESRI ArcGIS Software.

USGS, see U.S. Geological Survey.

USGS and DOE, See U.S. Geological Survey and U.S. Department of Energy.

U.S. Department of Energy. 1993. Radiation Protection of the Public and the Environment, DOE Order 5400.5, Change 2. Washington, DC: U.S. Government Printing Office.

U.S. Department of Energy. 1997. The Procedures Manual of the Environmental Measurements Laboratory, HASL-300, 28th Ed., Vol. I. February. New York, NY.

U.S. Department of Energy, National Nuclear Security Administration Nevada Operations Office. 2002. Industrial Sites Quality Assurance Project Plan, Nevada Test Site, Nevada, Rev. 3, DOE/NV--372. Las Vegas, NV.

U.S. Department of Energy, National Nuclear Security Administration Nevada Site Office. 2004. NV/YMP Radiological Control Manual, Rev. 5, DOE/NV/11718-079, UC-702. Prepared by Bechtel Nevada. Las Vegas, NV. 
U.S. Department of Energy, National Nuclear Security Administration Nevada Site Office. 2006. Industrial Sites Project Establishment of Final Action Levels, Rev. 0, DOE/NV--1107. Las Vegas, NV.

U.S. Department of Energy, National Nuclear Security Administration Nevada Site Office. 2008a. Nevada Test Site Waste Acceptance Criteria, DOE/NV-325-Rev. 7. Las Vegas, NV.

U.S. Department of Energy, National Nuclear Security Administration Nevada Site Office. 2008b. Nevada Test Site 2007 Waste Management Report Area 3 and Area 5 Radioactive Waste Management Sites, DOE/NV/25946-490. June. Las Vegas, NV.

U.S. Department of Energy, Nevada Operations Office. 1992. Remedial Investigation and Feasibility Study for the Plutonium Contaminated Soils at Nevada Test Site, Nellis Air Force Range and Tonopah Test Range, April. Las Vegas, NV.

U.S. Department of Energy, Nevada Operations Office. 1996a. Final Environmental Impact Statement for the Nevada Test Site and Off-Site Locations in the State of Nevada, DOE/EIS 0243. Las Vegas, NV.

U.S. Department of Energy, Nevada Operations Office. 1996b. Radiological Effluents Released From U.S. Continental Tests 1961 Through 1992, DOE/NV-317 (Rev 1) UC-702. August. Las Vegas, NV.

U.S. Department of Energy, Nevada Operations Office. 1998. Nevada Test Site Resource Management Plan, DOE/NV--518. Las Vegas, NV.

U.S. Department of Energy, Nevada Operations Office. 1999. Corrective Action Investigation Plan for Corrective Action Unit 98: Frenchman Flat, Nevada Test Site, Nevada, DOE/NV--478-Rev.1. July. Las Vegas, NV.

U.S. Department of Energy, Nevada Operations Office. 2000a. Nevada Test Site Contaminated Land Areas Report, Volume I, DOE/NV/11718-481-VOL 1. Las Vegas, NV.

U.S. Department of Energy, Nevada Operations Office. 2000b. United States Nuclear Tests, July 1945 through September 1992, DOE/NV--209-Rev 15. Las Vegas, NV.

U.S. Environmental Protection Agency. 1980. Prescribed Procedures for Measurement of Radioactivity in Drinking Water, EPA 600/4-80-032. Cincinnati, OH: Environmental Monitoring and Support Laboratory Office of Research and Development.

U.S. Environmental Protection Agency. 2000. Sampling and Analysis Plan Guidance and Template, R9QA/002.1. As accessed at http://www.epa.gov/region09/qa/projplans.html on 20 November.

U.S. Environmental Protection Agency. 2002. Guidance for Quality Assurance Project Plans, EPA QA/G5. Washington, DC. 
U.S. Environmental Protection Agency. 2004. USEPA Contract Laboratory Program National Functional Guidelines for Inorganic Data Review, OSWER 9240.1-45/EPA 540-R-04-004. October. Washington, DC: Office of Solid Waste and Emergency Response.

U.S. Environmental Protection Agency. 2008a. Region 9: Superfund, Preliminary Remediation Goals, Screening Levels for Chemical Contaminants. As accessed at http://www.epa.gov/region09/waste/sfund/prg/index.html on 5 November. Prepared by EPA Office of Superfund and Oak Ridge National Laboratory.

U.S. Environmental Protection Agency. 2008b. SW-846 On-Line, Test Methods for Evaluating Solid Physical/Chemical Methods. As accessed at http://www.epa.gov/epaoswer/hazwaste/test/main.htm on 20 November.

U.S. Geological Survey. 1981. Geology of Drill Hole UE18t and Area 18, Timber Mountain Caldera Moat, Nevada Test Site, USGS-474-312. October. Prepared for the U.S. Department of Energy, Nevada Operations Office. Las Vegas, NV.

U.S. Geological Survey. 1990. Geologic Map of the Nevada Test Site, Southern Nevada, USGS Map I-2046. Denver, CO.

U.S. Geological Survey. 2008. "National Water Information System: Web Interface” web page. As accessed at http://nwis.waterdata.usgs.gov/nwis/gwlevels?site_no=365315115562701 on 25 November.

U.S. Geological Survey and U.S. Department of Energy. 2007. "USGS/DOE Cooperative Studies in Nevada” web page. As accessed at http://nevada.usgs.gov/doe_nv/ntsmap.htm on 8 October.

Winograd, I.J., and W. Thordarson. 1975. Hydrology and Hydrochemical Framework, South-Central Great Basin, Nevada-California, with Special Reference to the Nevada Test Site, USGS Professional Paper 712-C. Denver, CO. 


\section{Appendix A}

\section{Data Quality Objectives}




\section{A.1.0 Introduction}

The DQO process described in this appendix is a seven-step strategic systematic planning method used to plan data collection activities and define performance criteria for the CAU 371, Johnnie Boy Crater and Pin Stripe, field investigation. The DQOs are designed to ensure that the data collected will provide sufficient and reliable information to identify, evaluate, and technically defend recommended corrective actions (i.e., no further action, closure in place, or clean closure). Existing information about the nature and extent of contamination at the CASs in CAU 371 is insufficient to evaluate and select preferred corrective actions; therefore, a CAI will be conducted.

The CAU 371 investigation will be based on the DQOs presented in this appendix as developed by representatives of the NDEP and the NNSA/NSO. The seven steps of the DQO process presented in Sections A.3.0 through A.9.0 were developed in accordance with Guidance on Systematic Planning Using the Data Quality Objectives Process (EPA, 2006).

The DQO process presents a combination of a judgmental and probabilistic sampling approaches. In general, the procedures used in the DQO process provide:

- A method to establish performance or acceptance criteria, which serve as the basis for designing a plan for collecting data of sufficient quality and quantity to support the goals of a study.

- Criteria that will be used to establish the final data collection design such as:

- The nature of the problem that has initiated the study and a conceptual model of the environmental hazard to be investigated.

- The decisions or estimates that need to be made and the order of priority to resolve them.

- The type of data needed.

- An analytic approach or decision rule that defines the logic for how the data will be used to draw conclusions from the study findings.

- Acceptable quantitative criteria on the quality and quantity of the data to be collected, relative to the ultimate use of the data. 
- A data collection design that will generate data meeting the quantitative and qualitative criteria specified. A data collection design specifies the type, number, location, and physical quantity of samples and data, as well as the QA and QC activities that will ensure that sampling design and measurement errors are managed sufficiently to meet the performance or acceptance criteria specified in the DQOs. 


\section{A.2.0 Background Information}

The following two CASs comprise CAU 371 and are located in Areas 11 and 18 of the NTS, as shown in Figure A.2-1:

- 11-23-05, Pin Stripe Contamination Area

- 18-45-01, U-18j-2 Crater (Johnnie Boy)

Sections A.2.1 and A.2.2 provide a description, physical setting and operational history, release information, and previous investigation results for each CAS.

\section{A.2.1 Corrective Action Site 11-23-05, Pin Stripe Contamination Area}

Corrective Action Site 11-23-05 consists of a release of radiological contamination to the atmosphere as a result of the massive venting of radiological debris from a fissure that developed during the U11b Pin Stripe test. The release was significant and consisted of relatively unfractionated fission products, suggesting that the venting path may have extended directly into the initial cavity. The CAS is located in the southeastern portion of Area 11, north of the Area 5 RWMS. No radiological postings are present at the site. Figure A.2-2 is an aerial photograph showing the location of CAS 11-23-05.

Physical Setting and Operational History - The area surrounding Pin Stripe increases in elevation from the south to the north; however, the Pin Stripe area was graded to support the instrumentation for the project. An additional graded area is present north and upgradient of the Pin Stripe GZ area, which was used for pre-test drilling operations. Vegetation in the area surrounding the site is denser than in the graded areas of the site.

Pin Stripe, part of Operation Flintlock, was a weapons-effects shaft test with a yield of less than 20 kilotons, conducted on April 25, 1966, at a depth of 296 m bgs. Pin Stripe was a stemmed shaft test designed for containment. A crater measuring approximately $67 \mathrm{~m}$ in diameter and $4.6 \mathrm{~m}$ in depth was produced from this test. Venting occurred from a fissure approximately 30 to $46 \mathrm{~m}$ southwest of GZ both at one minute and seven hours after detonation (DOE/NV, 1996b and 2000a; Sandia, 1966; USGS, 1966). 


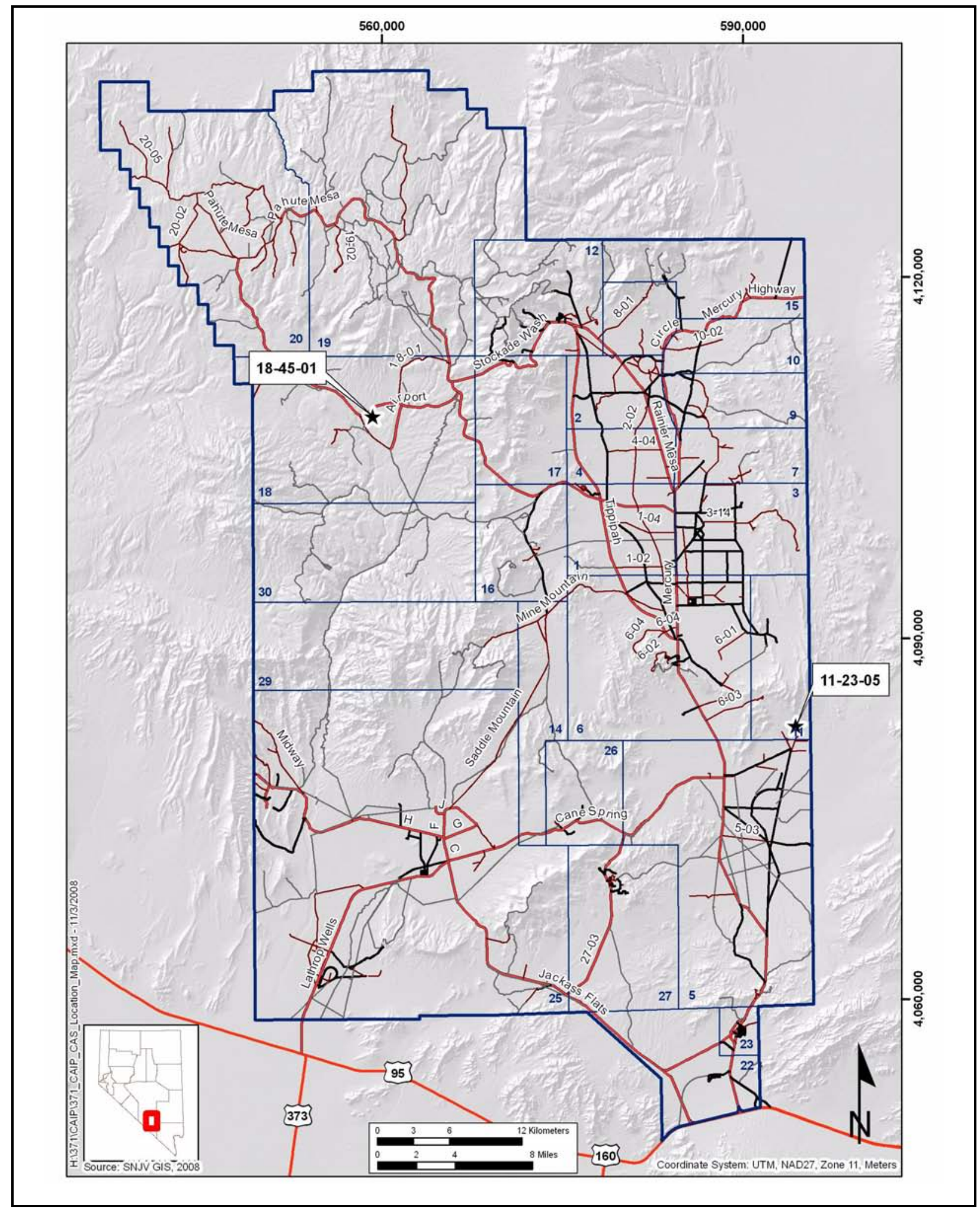

Figure A.2-1

Corrective Action Unit 371, CAS Location Map 


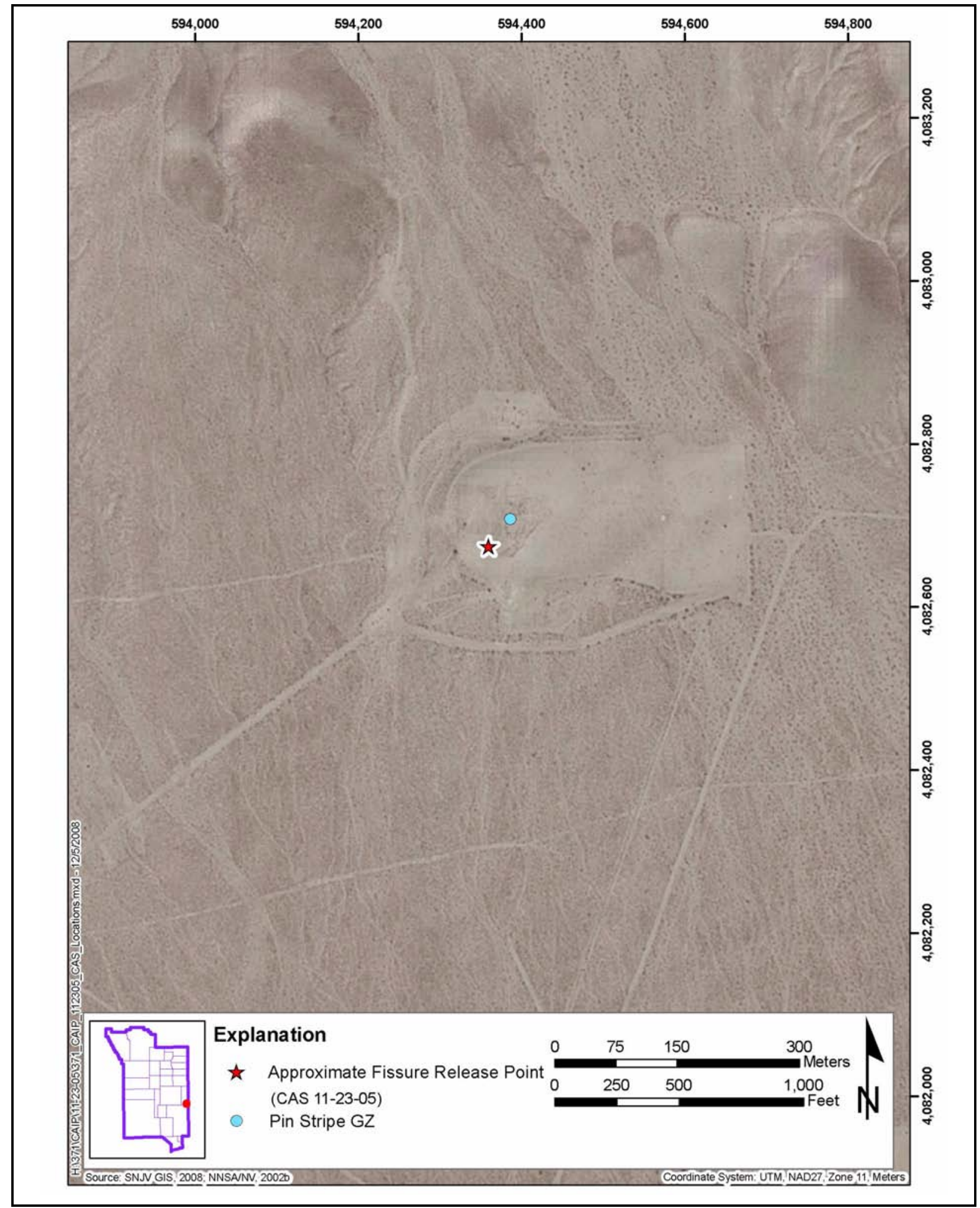

Figure A.2-2

Location of CAS 11-23-05, Pin Stripe Contamination Area 
Release Information - This CAS consists of a release of radiological contamination to the atmosphere as a result of the massive venting of radiological debris from a fissure that developed during the U11b Pin Stripe test. The release was significant and consisted of relatively unfractionated fission products, suggesting that the venting path may have extended directly into the initial cavity. The plume from the accidental release of radioactivity moved northeasterly from the test location, and was detected off the NTS (DOE/NV, 1996b and 2000b; Sandia, 1966). Isotopes of the following elements identified at the time of release were: krypton, xenon (one of which decays into Cs-137), I-131, -133, and -135 (DOE/NV, 1996b).

Previous Investigation Results - During an aerial radiological survey conducted at the NTS in 1994, Cs-137 was detected in the area surrounding Pin Stripe (BN, 1999). The exposure rate at Pin Stripe ranged from 18 to $24 \mu \mathrm{R} / \mathrm{hr}$ (BN, 1999).

A RIDP investigation was conducted in Area 11 in January and February of 1985. This effort estimated the inventory of man-made radionuclides at the NTS through in situ soil measurements, and some (limited) soil sampling (DRI, 1985; Gray et al., 2007). While several radionuclides were detected, only Cs-137 and Sr-90 were present at CAS 11-23-05 at sufficient levels to make an estimate of the radionuclide inventory.

During a site visit in August 2008, concrete and metal debris were observed within the crater boundary. There are T-posts surrounding the area; however, no radiological or crater postings were observed. A ground stability study is in the process of being requested for this CAS.

\section{A.2.2 Corrective Action Site 18-45-01, U-18j-2 Crater (Johnnie Boy)}

Corrective Action Site 18-45-01 consists of the atmospheric deposition of radiological contamination to the soil surface during the Johnnie Boy (U-18j-2) test. The site is located in central Area 18 approximately $500 \mathrm{~m}$ south of the 18-03 Road. Figure A.2-3 is an aerial photograph showing the location of CAS 18-45-01.

Physical Setting and Operational History - Corrective Action Site 18-45-01, U-18j-2 Crater (Johnnie Boy), is located in the central portion of Area 18, east of Buckboard Mesa and is in a valley area near Airport Road. The area of the CAS is gently sloping, and surrounded by small hills. There 


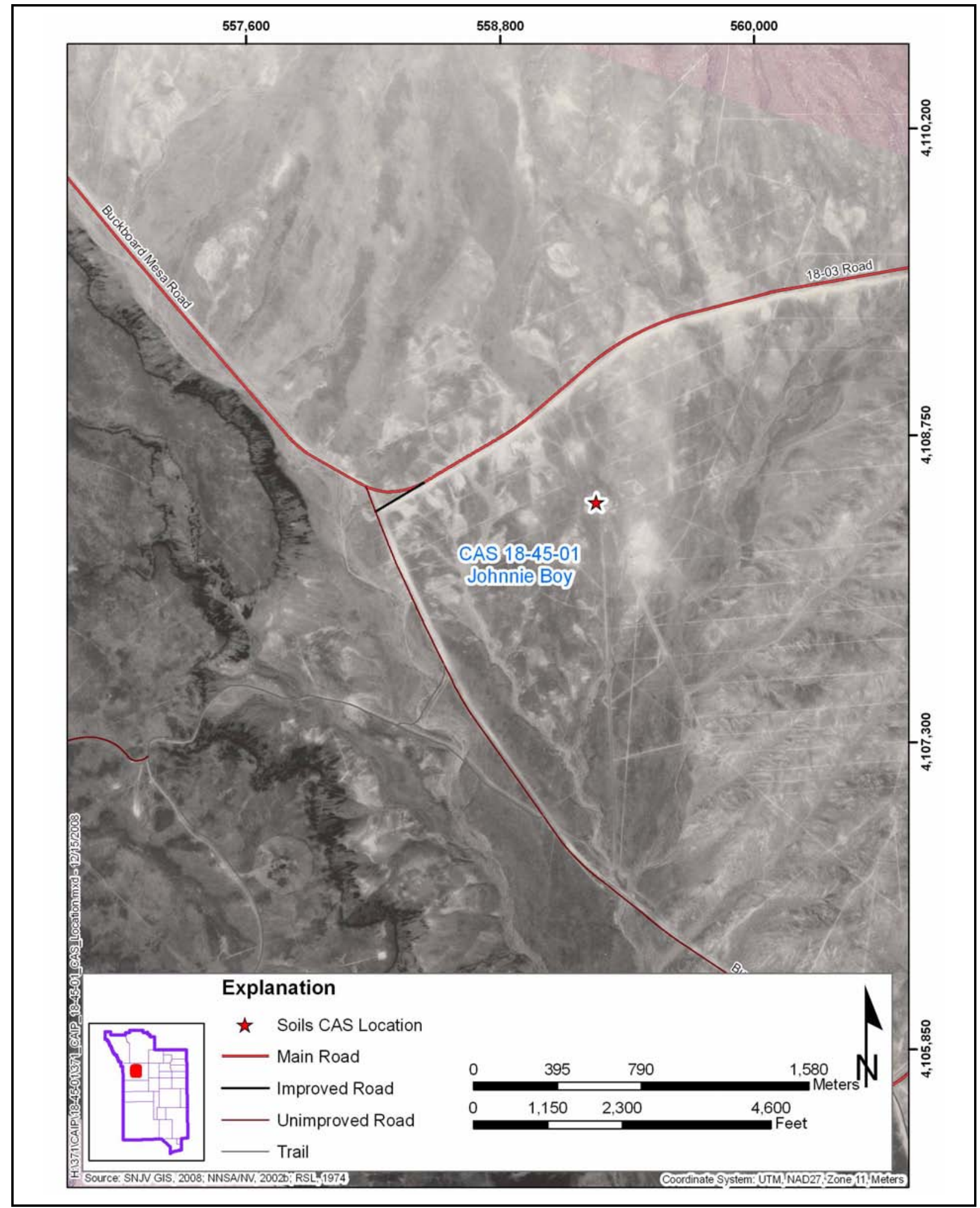

Figure A.2-3

Location of CAS 18-45-01, U-18j-2 Crater (Johnnie Boy) 
are several areas of rill erosion around the site that may carry sediment into the crater area. The vegetation is sporadic around the site.

Johnnie Boy was a weapons-effects test conducted as part of Operation Sunbeam on July 11, 1962. Johnnie Boy was detonated slightly below ground surface $(58.4 \mathrm{~cm})$ with a yield of 500 tons (DOE/NV, 2000b). A surface crater measuring $34 \mathrm{~m}$ in diameter at its widest point and $9 \mathrm{~m}$ deep formed from this test (GE, 1979).

Release Information - The CAS consists of a release of radiological contamination to the atmosphere and soil surface as a result of the Johnnie Boy weapons test. For this test, the primary modes of radioactive contamination are: the neutron activation of man-made structures and the soils near GZ, the release of fission products from the device, and the deposition of unburned fuel from the device.

Atmospheric monitoring during the test identified I-131, -133, -135; tellurium-132; and barium-140/lanthanum-140 in the release (DOE/NV, 1996b). The test resulted in the formation of a plume of radioactive surface contamination (DOE/NV, 1996a).

Previous Investigation Results - An aerial radiological survey was conducted at the NTS in 1994. The exposure rate at Johnnie Boy ranged from 39 to $50 \mu \mathrm{R} / \mathrm{hr}$. The survey identified the presence of Cs-137, Eu-152, and possibly Co-60 (BN, 1999).

A RIDP investigation was conducted in Area 18 between November 1983 and June of 1984. This effort estimated the inventory of man-made radionuclides at the NTS through in situ soil measurements, and some (limited) soil sampling (DRI, 1985; Gray et al., 2007). Area 18 contains the location of the Johnnie Boy test, as well as Little Feller I, Little Feller II, Danny Boy, and Sulky. Am-241, Pu-238, Pu-239/240, Co-60, Cs-137, Sr-90, and Eu-152, -154, and- 155 were present at sufficient levels in Area 18 to estimate the radionuclide inventory (Note: plutonium and americium are not expected as a result of the test at Johnnie Boy but could be present at low levels as the result of tests nearby).

Johnnie Boy is a posted RMA measuring approximately 33,260 $\mathrm{m}^{2}$ (DOE/NV, 2000a), which is located in a larger controlled area surrounding the site. During an August 2008 site visit, mounds of 
soil were observed, and test-related equipment and structures were present on the north and south sides of the site. Trinity glass was also observed north of the crater, and a small amount of cables, wood, and metal debris are located on the ground surface to the north and east of the crater. 


\section{A.3.0 Step 1 - State the Problem}

Step 1 of the DQO process defines the problem that requires study, identifies the planning team, and develops a conceptual model of the environmental hazard to be investigated.

The problem statement for CAU 371 is: "Existing information on the nature and extent of potential contamination is insufficient to evaluate and recommend corrective action alternatives for the CASs in CAU 371.”

\section{A.3.1 Planning Team Members}

The DQO planning team consists of representatives from NDEP, NNSA/NSO, SNJV, and NSTec. The DQO planning team met on November 19, 2008, for the DQO meeting. The primary decision-makers are the NDEP and NNSA/NSO representatives.

\section{A.3.2 Conceptual Site Model}

The CSM is used to organize and communicate information about site characteristics. It reflects the best interpretation of available information at a point in time. The CSM is a primary vehicle for communicating assumptions about release mechanisms, potential migration pathways, or specific constraints. It provides a summary of how and where contaminants are expected to move and what impacts such movement may have. It is the basis for assessing how contaminants could reach receptors both in the present and future. The CSM describes the most probable scenario for current conditions at each site and defines the assumptions that are the basis for identifying appropriate sampling strategy and data collection methods. An accurate CSM is important as it serves as the basis for all subsequent inputs and decisions throughout the DQO process.

The CSM was developed for CAU 371 using information from the physical setting, potential contaminant sources, release information, historical background information, knowledge from similar sites, and physical and chemical properties of the potentially affected media and COPCs. 
The CSM consists of:

- Potential contaminant releases, including media subsequently affected.

- Release mechanisms (the conditions associated with the release).

- Potential contaminant source characteristics, including contaminants suspected to be present and contaminant-specific properties.

- Site characteristics, including physical, topographical, and meteorological information.

- Migration pathways and transport mechanisms that describe the potential for migration and where the contamination may be transported.

- Points of exposure locations where individuals or populations may come in contact with a COC associated with a CAS.

- $\quad$ Routes of exposure where contaminants may enter the receptor.

If additional elements are identified during the investigation that are outside the scope of the CSM, the situation will be reviewed and a recommendation will be made as to how to proceed. In such cases, NDEP will be notified and given the opportunity to comment on, or concur with, the recommendation.

The applicability of the CSM to each CAS is summarized in Table A.3-1 and discussed below. Table A.3-1 provides information on CSM elements that will be used throughout the remaining steps of the DQO process. Figure A.3-1 represents site conditions applicable to the CSM.

\section{A.3.2.1 Contaminant Release}

The releases for CAU 371 have been divided into primary releases and other releases. The primary releases are defined as the venting of radioactive debris at CAS 11-23-05 and the deposition of fission products, activation products, and unburned fuel at CAS 18-45-01. Other releases are defined as all other types of releases such as those resulting from spills or wastes found at the site during the investigation.

At Pin Stripe, radioactive debris vented accidentally into the atmosphere through a fissure in the ground shortly after the detonation. The release was significant and consisted of relatively 
Table A.3-1

Conceptual Site Model Description of Elements for CASs in CAU 371

\begin{tabular}{|c|c|c|}
\hline CAS Identifier & 11-23-05 & 18-45-01 \\
\hline CAS Description & $\begin{array}{c}\text { Pin Stripe } \\
\text { Contamination Area }\end{array}$ & $\begin{array}{l}\text { U-18j-2 Crater } \\
\text { (Johnnie Boy) }\end{array}$ \\
\hline Site Status & \multicolumn{2}{|c|}{ Sites are inactive and/or abandoned } \\
\hline Exposure Scenario & \multicolumn{2}{|c|}{ Occasional Use } \\
\hline $\begin{array}{l}\text { Sources of Potential Soil } \\
\text { Contamination }\end{array}$ & $\begin{array}{l}\text { Accidental release of } \\
\text { radiological contamination } \\
\text { from subsurface nuclear } \\
\text { testing }\end{array}$ & $\begin{array}{l}\text { Atmospheric deposition from } \\
\text { nuclear testing }\end{array}$ \\
\hline $\begin{array}{l}\text { Location of } \\
\text { Contaminationl } \\
\text { Release Point }\end{array}$ & \multicolumn{2}{|c|}{ Interface between subsurface soils/debris and native soil } \\
\hline Amount Released & \multicolumn{2}{|c|}{ Unknown } \\
\hline Affected Media & \multicolumn{2}{|c|}{$\begin{array}{l}\text { Surface and shallow subsurface soils, debris such as metal and } \\
\text { concrete }\end{array}$} \\
\hline Potential Contaminants & \multicolumn{2}{|c|}{ Gamma and isotopic radionuclides } \\
\hline Transport Mechanisms & \multicolumn{2}{|c|}{$\begin{array}{l}\text { Surface water runoff may provide for the transportation of some } \\
\text { contaminants within or outside of the boundaries of the CASs. } \\
\text { Percolation of precipitation through subsurface media serves as } \\
\text { a minor driving force for vertical migration of contaminants. }\end{array}$} \\
\hline Migration Pathways & \multicolumn{2}{|c|}{$\begin{array}{l}\text { Lateral transport expected to dominate over vertical transport } \\
\text { due to limited vertical infiltration. }\end{array}$} \\
\hline $\begin{array}{l}\text { Lateral and Vertical } \\
\text { Extent of Contamination }\end{array}$ & \multicolumn{2}{|c|}{$\begin{array}{l}\text { Contamination, if present, is expected to be contiguous to the } \\
\text { release points. Concentrations are expected to decrease with } \\
\text { distance and depth from the source. Groundwater } \\
\text { contamination is not expected. Lateral and vertical extent of } \\
\text { COC contamination is assumed to be within the spatial } \\
\text { boundaries of the CAS. }\end{array}$} \\
\hline Exposure Pathways & \multicolumn{2}{|c|}{$\begin{array}{l}\text { The potential for contamination exposure is limited to industrial } \\
\text { and construction workers, and military personnel conducting } \\
\text { training. These human receptors may be exposed to COPCs } \\
\text { through oral ingestion or inhalation of soil and/or debris due to } \\
\text { inadvertent disturbance of these materials or irradiation by } \\
\text { radioactive materials. }\end{array}$} \\
\hline
\end{tabular}




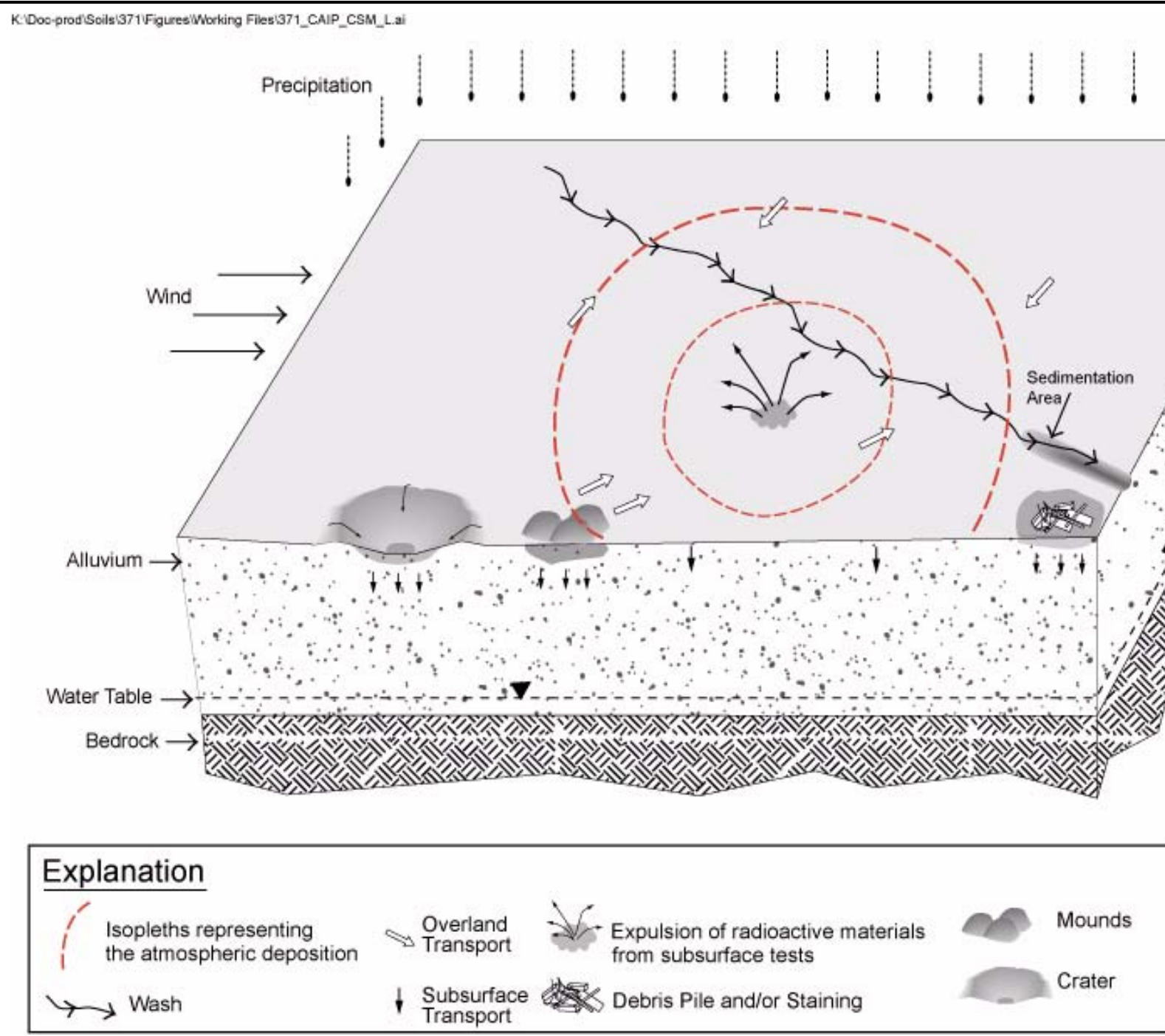

Figure A.3-1

Conceptual Site Model for CAU 371 
unfractionated fission products, suggesting that the venting path may have extended directly into the initial cavity. The pattern of deposition of radioactive contamination can be seen in Figure A.3-1. After 42 years of radioactive decay, the predominant radionuclide contaminant is expected to be Cs-137. Other very low levels of radioactive contaminants may be seen at Pin Stripe as a result of fallout from the massive venting or from other nearby nuclear tests.

At Johnnie Boy, the detonation irradiated the surrounding soil with neutrons, causing the activation of some elements in the soil (primarily Eu-152 and -154). Fission fragments were released in an annular pattern around GZ, with a bias toward the prevailing wind direction at the time of detonation (to the north). Refer to Figure A.3-1. Radionuclides with low melting points (e.g., iodine) traveled significant distances before condensing and falling out of the plume, while those with higher melting points (e.g., cesium) condensed earlier and were deposited closer to GZ. The nuclear fuel that did not fission (e.g., U-235) has a high melting point and is generally found near GZ. The radioactive contamination in soil at Johnnie Boy can be seen as a distributed contamination in the soil surface, and as regions where Trinitite fell out of the fireball in discrete areas around GZ.

Other releases, such as from batteries or lead bricks, may have been released to the surface and/or subsurface soils.

\section{A.3.2.2 Potential Contaminants}

The COPCs were identified during the planning process through the review of site history, process knowledge, personal interviews, past investigation efforts (where available), and inferred activities associated with the CASs. Because complete information regarding activities performed at the CAU 371 sites is not available, contaminants detected at similar NTS sites were included in the contaminant lists to reduce uncertainty. The list of COPCs is intended to encompass all of the significant contaminants that could potentially be present at each CAS. Significant contaminants are defined as COPCs that exceed PAL concentrations.

At CASs 11-23-05 and 18-45-01, the primary COPCs include: Co-60; Cs-137; Sr-90; Eu-152, -154, -155; U-234, -235, U-238; and Pu-238, -239/240. Other radionuclides may be present, at low activity-concentrations, as the result of fallout from other tests nearby. 
The COPCs applicable to Decision I environmental samples from each of the CASs of CAU 371 are defined as the analytes reported from the analytical methods stipulated in Table A.3-2. Targeted contaminants for each CAU 371 CAS are identified in Table A.3-3.

Table A.3-2

Analytical Program ${ }^{\text {a }}$

\begin{tabular}{|c|c|c|c|c|}
\hline \multirow{2}{*}{ Analyses } & \multicolumn{2}{|c|}{ 11-23-05 } & \multicolumn{2}{|c|}{$18-45-01$} \\
\hline & PR & OR & PR & OR \\
\hline \multicolumn{5}{|c|}{ Organic COPCs } \\
\hline Total Petroleum Hydrocarbons-Diesel-Range Organics & $\overline{--}$ & $\mathrm{X}^{\mathrm{b}}$ & - & $\mathrm{X}^{\mathrm{b}}$ \\
\hline Semivolatile Organic Compounds & -- & $x^{b}$ & -- & $X^{b}$ \\
\hline Volatile Organic Compounds & -- & $x^{b}$ & -- & $X^{b}$ \\
\hline Pesticides & -- & $X^{b}$ & -- & $X^{b}$ \\
\hline \multicolumn{5}{|c|}{ Inorganic COPCs } \\
\hline Resource Conservation and Recovery Act Metals & -- & $\mathrm{X}^{\mathrm{b}}$ & -- & $\mathrm{X}^{\mathrm{b}}$ \\
\hline \multicolumn{5}{|c|}{ Radionuclide COPCs } \\
\hline Gamma Spectroscopyc & $\bar{x}$ & $\mathrm{X}^{\mathrm{b}}$ & $\mathrm{X}$ & $\mathrm{X}^{\mathrm{b}}$ \\
\hline Isotopic U & $x$ & $\mathrm{X}^{\mathrm{bc}}$ & $x$ & $\mathrm{X}^{\mathrm{bc}}$ \\
\hline Isotopic $\mathrm{Pu}$ & $\mathrm{X}$ & $\mathrm{X}^{\mathrm{bc}}$ & $\mathrm{X}$ & $\mathrm{X}^{\mathrm{bc}}$ \\
\hline Isotopic Am & $x$ & $\mathrm{X}^{\mathrm{bc}}$ & $x$ & $\mathrm{X}^{\mathrm{bc}}$ \\
\hline Sr-90 & $\mathrm{x}$ & - & $\mathrm{x}$ & $\mathrm{X}^{\mathrm{bc}}$ \\
\hline
\end{tabular}

${ }^{a}$ The COPCs are the analytes reported from the analytical methods listed.

${ }^{b}$ Selection based on type of release, indicators, process knowledge, etc.

${ }^{\mathrm{c}}$ Results of gamma analysis will be used to determine whether further isotopic analysis is warranted.

$\mathrm{OR}=$ Other Release

$\mathrm{PR}=$ Primary Release

$$
\begin{aligned}
& X=\text { Required analytical method } \\
& --=\text { Not required }
\end{aligned}
$$

Table A.3-3

Targeted Contaminants for CAU 371

\begin{tabular}{|c|c|c|}
\hline CAS & Chemical Targeted Contaminant(s) & Radiological Targeted Contaminant(s) \\
\hline \hline $11-23-05$ & None & Cs-137 \\
\hline $18-45-01$ & None & None \\
\hline
\end{tabular}




\section{A.3.2.3 Contaminant Characteristics}

Contaminant characteristics include, but are not limited to: solubility, density, and adsorption potential. In general, contaminants with low solubility, high affinity for media, and high density can be expected to be found relatively close to release points. Contaminants with small particle size, high solubility, low density, and/or low affinity for media are found further from release points or in low areas where evaporation of ponding will concentrate dissolved contaminants.

\section{A.3.2.4 Site Characteristics}

Site characteristics are defined by the interaction of physical, topographical, and meteorological attributes and properties. Physical properties include permeability, porosity, hydraulic conductivity, degree of saturation, sorting, chemical composition, and organic content. Topographical and meteorological properties and attributes include slope stability, precipitation frequency and amounts, precipitation, runoff pathways, drainage channels and ephemeral streams, and evapotranspiration potential.

Corrective Action Site 11-23-05, Pin Stripe Contamination Area, lies in the southeastern portion of Area 11, north of the Area 5 RWMS. A crater (surrounded by T-posts) measuring approximately $67 \mathrm{~m}$ in diameter and $4.6 \mathrm{~m}$ in depth was formed from this test. The elevation in the area surrounding Pin Stripe increases from the south to the north; however, the Pin Stripe area was graded to support the instrumentation for the project.

Corrective Action Site 18-45-01, U-18j-2 Crater (Johnnie Boy), is located in the central area of Area 18, east of Buckboard Mesa in a valley. The area of the CAS is gently sloping, and surrounded by small hills. A crater measuring $34 \mathrm{~m}$ in diameter and $9 \mathrm{~m}$ in depth was formed from this test.

\section{A.3.2.5 Migration Pathways and Transport Mechanisms}

Migration pathways include the lateral migration of potential contaminants across surface soils/sediments and vertical migration of potential contaminants through subsurface soils. The undisturbed atmospheric deposition of radionuclides is limited to the top $5 \mathrm{~cm}$ of soil, while the depth of radiological contamination from depositions other than atmospheric is largely dependent upon its original placement. Radionuclides, with multi-year half-lives, that have been distributed at NTS from 
aboveground nuclear testing have been found to be concentrated in the upper $5 \mathrm{~cm}$ of undisturbed soil (DRI, 1983 and 1985; Gilbert, et al, 1977; Tamura, 1977). Contaminants released into intermittent washes in the vicinity of the tests are subject to much higher potential for migration than contaminants released to other surface areas. These intermittent washes are generally dry but are subject to infrequent, potentially intense, stormwater flows. These stormwater flow events provide an intermittent mechanism for both vertical and horizontal transport of contaminants. Contaminated sediments entrained by these stormwater events would be carried by the streamflow to locations where the flowing water loses energy and the sediments drop out. These locations are readily identifiable as sedimentation areas.

Infiltration and percolation of precipitation serves as a driving force for downward migration of contaminants. For CAS 11-23-05, precipitation at the nearest rain gauge, A06 (South), indicates an average annual rainfall of $18.59 \mathrm{~cm}$ (7.32 in.). For CAS 18-45-01, precipitation at the nearest rain gauge, Little Feller II, indicates an average annual rainfall of 16.26 centimeters (6.4 in.) (ARL/SORD, 2009). Average annual PET has been estimated for the Area 3 RWMS as $157 \mathrm{~cm}$ (61.81 in.). However, due to high PET and limited precipitation for this region, percolation of infiltrated precipitation at the NTS does not provide a significant mechanism for vertical migration of contaminants to groundwater (DOE/NV, 1992). In addition, the depth to groundwater near the CAU 371 CASs is at least $275 \mathrm{~m}$. Based on the depth to groundwater, groundwater contamination is not considered a likely scenario.

Contaminants migrating from a CAS, regardless of physical or chemical characteristics, are generally expected to exist in the soil adjacent to the area of soil-particle activation and fallout deposition in lateral directions. Contamination is expected to be contiguous to the release points and may have been distributed in a plume dictated by the wind direction during the test, unless transported in an intermittent wash. For CAS 11-23-05, intermittent streams in the area flow south, towards Frenchman Lake. For CAS 18-45-01, intermittent streams near the site flow south, through the Fortymile Wash Drainage Basin, towards Jackass Flats. Other potential minor transport of contamination may include wind-borne material and material pushed along dirt roads within the depositional areas in the area (e.g., moved during road maintenance). For CAS 18-45-01, activated soil (including Trinity glass) formed during the nuclear explosion is expected to contain activation products (i.e., Eu and Co isotopes), most concentrated closest to GZ. The activated soil is distributed 
in an annular pattern at the site. Concentrations are generally expected to decrease with horizontal and vertical distance from the source. For both CASs, contamination may have been transported in washes since the original distribution and may not be contiguous to the undisturbed contaminant plume. Surface migration of contaminants at the CASs due to lateral migration during stormwater run-off events occurs infrequently, but may be significant, as drainages are present around the sites.

\section{A.3.2.6 Exposure Scenarios}

Human receptors may be exposed to COPCs through dermal contact, oral ingestion, or inhalation of soil or debris due to inadvertent disturbance of these materials, or irradiation by radioactive materials. The land-use and exposure scenarios for the CAU 371 CASs are listed in Table A.3-4 and are based on NTS current and future land use. All of the CAU 371 CASs are at remote locations without site improvements and where no regular work is performed. There is still the possibility, however, that site workers could occupy these locations on an occasional and temporary basis such as a military exercise. Therefore, these sites are classified as occasional work areas.

Table A.3-4

\section{Land-Use and Exposure Scenarios}

\begin{tabular}{|c|c|c|}
\hline CAS & Record of Decision Land-Use Zone & Exposure Scenario \\
\hline $\begin{array}{l}11-23-05 \\
18-45-01\end{array}$ & $\begin{array}{l}\text { Reserved Zone } \\
\text { This area includes land and facilities that provide } \\
\text { widespread flexible support for diverse short-term } \\
\text { testing and experimentation. The reserved zone is also } \\
\text { used for short duration exercises and training (e.g., } \\
\text { nuclear emergency response and Federal Radiological } \\
\text { Monitoring and Assessment Center training) and DoD } \\
\text { land-navigation exercises and training. }\end{array}$ & $\begin{array}{l}\text { Occasional Use Area } \\
\text { Worker will be exposed to the site occasionally } \\
\text { (up to } 80 \text { hours per year for } 5 \text { years). Site } \\
\text { structures are not present for shelter and } \\
\text { comfort of the worker. }\end{array}$ \\
\hline
\end{tabular}




\section{A.4.0 Step 2 - Identify the Goal of the Study}

Step 2 of the DQO process states how environmental data will be used in meeting objectives and solving the problem, identifies study questions or decision statement(s), and considers alternative outcomes or actions that can occur upon answering the question(s).

\section{A.4.1 Decision Statements}

\section{A.4.1.1 Primary Releases}

The Decision I statement for primary releases is: "Is any COC associated with the CAS present in environmental media (dose exceeding 25 mrem/yr)?”

- Any plot for which the 95 percent upper confidence limit (UCL) of the mean TED exceeds $25 \mathrm{mrem} / \mathrm{yr}$ will be defined as containing a COC.

- If a COC is present, then Decision II must be resolved. If a COC is not present, the investigation for that release is complete.

The Decision II statement for primary releases is: "Is the extent of the area that provides a dose exceeding 25 mrem/yr defined?”

Sufficient information is defined as identifying the area of media (where the TED exceeds $25 \mathrm{mrem} / \mathrm{yr})$.

\section{A.4.1.2 Other Releases}

The Decision I statement for other releases is: "Is any COC associated with the CAS present in environmental media?”

To resolve the Decision I, any analytical result for a COPC above the FAL will result in that COPC being designated as a COC.

A corrective action will be determined for any site containing a COC. The evaluation of the need for corrective action will include the potential for wastes that are present at a site to cause the future contamination of site environmental media, if the wastes were to be released. 
A COC may also be defined as a contaminant that, in combination with other like contaminants, is determined to jointly pose an unacceptable risk based on a multiple contaminant analysis (NNSA/NSO, 2006). If a COC is detected, then Decision II must be resolved. If a COC is not detected, then the investigation at that release is complete.

The Decision II statement for other releases is: "If a COC is present, is sufficient information available to evaluate potential corrective action alternatives?” Sufficient information is defined to include the:

- Lateral and vertical extent of COC contamination.

- Information needed to determine potential remediation waste types.

- Information needed to evaluate the feasibility of remediation alternatives.

If sufficient information is not available to evaluate potential corrective action alternatives then site conditions will be re-evaluated and additional samples will be collected (as long as the scope of the investigation is not exceeded and any CSM assumption has not been shown to be incorrect).

\section{A.4.2 Alternative Actions to the Decisions}

This section identifies actions that may be taken to solve the problem depending on the possible outcomes of the investigation.

\section{A.4.2.1 Alternative Actions to Decision I}

If no COC associated with a release from the CAS is detected, then further assessment of the CAS is not required. If a COC associated with a release from the CAS is detected, then the extent of COC contamination will be determined, and additional information required to evaluate potential corrective action alternatives will be collected.

\section{A.4.2.2 Alternative Actions to Decision II}

If sufficient information is available to evaluate potential corrective action alternatives, then further assessment of the CAS is not required. If sufficient information is not available to evaluate potential corrective action alternatives, then additional samples will be collected. 


\section{A.5.0 Step 3 - Identify Information Inputs}

Step 3 of the DQO process identifies the information needed, determines sources for information, and identifies sampling and analysis methods that will allow reliable comparisons with FALs.

\section{A.5.1 Information Needs}

\section{A.5.1.1 Primary Releases}

To resolve Decision I at the primary releases (determine whether a COC associated with the CAS is present [dose exceeding $25 \mathrm{mrem} / \mathrm{yr}$ ]), samples will be collected and analyzed following these two criteria:

- Samples must be collected in plots located in an area most likely to exceed a $25 \mathrm{mrem} / \mathrm{yr}$ dose rate, and samples must accurately represent contamination within the plots (probabilistic sampling).

- The analytical methods and in situ measurements must be sufficient to detect a $25 \mathrm{mrem} / \mathrm{yr}$ dose.

To resolve Decision II, dose measurements from bounding plots need to be collected and analyzed to meet the following criterion:

- A decreasing trend of TED rates from more than 25 mrem/yr to less than 25 mrem/yr along each vector needs to be established sufficiently to determine a boundary area that encompasses the area exceeding the FAL.

\section{A.5.1.2 Other Releases}

To resolve Decision I at other releases (determine whether a COC associated with the CAS is present), samples need to be collected and analyzed according to the following criteria:

- Samples must be collected in areas most likely to contain a COC (judgmental sampling).

- The analytical suite selected must be sufficient to identify any COCs present in the samples. 
To resolve Decision II (determine whether sufficient information is available to evaluate potential corrective action alternatives at each CAS), samples need to be collected and analyzed to meet the following criteria:

- Samples must be collected in areas contiguous to the COC contamination but where contaminant concentrations are below FALs.

- Samples of the waste or environmental media must provide sufficient information to determine potential remediation waste types.

- The analytical suites selected must be sufficient to detect contaminants at concentrations equal to or less than their corresponding FALs.

\section{A.5.2 Sources of Information}

Information to satisfy Decision I and Decision II will be generated by collecting environmental samples using randomized composite sampling, grab sampling, hand auguring, backhoe excavation, or other appropriate sampling methods. These samples will be submitted to analytical laboratories meeting the quality criteria stipulated in the Industrial Sites QAPP (NNSA/NV, 2002a). Screening levels/nonvalidated data (e.g., radiological surveys and visual surveys) will be used to guide the detailed sampling; however, only validated data from analytical laboratories will be used to support DQO decisions. Sample collection and handling activities will follow standard procedures.

Data collected will estimate the TED at each plot. The TED will be determined by summing the internal and external dose components. For internal dose, sample results will be used to calculate internal dose using RESRAD. External dose will be determined by collecting in situ measurements using TLDs. Decision criteria is based on the 95 percent UCL of the average TED estimates. Information on decreasing TED rate trends will be generated by calculating TED rates from plots, and correlating the dose with distance from the point of release, as described in Section A.9.0.

\section{A.5.2.1 Sample Locations}

Design of the sampling approaches for CAU 371 must ensure that the data collected are sufficient for selection and evaluation of the corrective action alternatives (EPA, 2002). To meet this objective, the samples collected from each site should be either from locations (or plots) that most likely contain a COC, if present, and/or from locations that represent contamination at the plot (primary releases). 
Therefore, these sample locations will be selected by a combination of judgmental sampling and probabilistic sampling.

\section{A.5.2.1.1 Primary Releases}

An investigation of contamination from the primary releases will be implemented through a combination of judgmental and probabilistic sampling. The establishment of sample plots will be conducted judgmentally. The selection of sample locations within sample plots will be conducted probabilistically.

The plot locations will be determined based upon the results of the radiological walkover surveys. The Decision I plot will be established at the highest reading detected in the radiological survey at each CAS (Figures A.9-1 and A.9-2).

For Decision II at CAS 11-23-05, if the results of the Decision I sample plot at CAS 11-23-05 show contamination present that exceeds the FALs, then a Decision II sampling strategy will be presented and agreed upon by the stakeholders.

For Decision II at CAS 18-45-01, three additional sample plots will be located (based upon the 1994 flyover radiological survey [Figure A.9-4]), along three sampling vectors, outward from GZ (Section A.9.0). For each sampling vector, at least one sample plot will be placed at a location where the TED is less than the 25-mrem/yr-dose FAL.

\section{Sample Collection Scheme}

The data needed to make DQO decisions requires the measurement of TED at several discreet areas throughout the CAS. To accomplish this, sample plots were established to represent what is essentially a $100 \mathrm{~m}^{2}$ exposure unit. This is a conservative estimate of exposure as it is not reasonable to assume that any worker would be assigned to work exclusively in such a small area. The size of this area was chosen to be congruent with RIDP estimates and also to provide an integrated estimate of radioactivity within this area. Therefore, the objective is to obtain dose measurements that accurately represent the true dose of each sample plot. To meet this objective, the samples collected 
from the plots must be representative of the entire $100 \mathrm{~m}^{2}$ area. This can be accomplished in two ways:

1. Simple Random Sampling - The area is represented through multiple samples that individually represent discrete locations within the area. The results from the individual locations are then averaged to generate a value representative of the area. The statistics (e.g., UCLs) generated samples is based on the variability between samples. The variability between simple random samples is a combination of the spatial variability within the plot area, and the variability associated with sampling and measurement errors. With the simple random sampling approach, these two sources of variability cannot be distinguished.

2. Composite Sampling - Composite samples represent the area through physical averaging of multiple individual aliquots collected across the area. Each aliquot must contribute equally to the total sample without bias. To accomplish this, equal size aliquots were collected size from random locations that were constrained to an evenly spaced grid that covered the plot (i.e., random start, systematic grid). Each sample, which is comprised of several aliquots, represents the area. The only inherent difference between samples is associated with sampling and measurement errors (i.e., does not include spatial variability).

A summary of the differences between simple random and composite sampling are provided in Table A.5-1.

The major difference between simple random and composite sampling schemes is that:

- Spatial variability and the variability from sampling and measurement errors cannot be distinguished using a simple random sampling scheme.

- Spatial variability is virtually eliminated and the resulting variability between samples is largely only attributable to sampling and measurement error using a composite sampling scheme.

Information on the spatial variability (i.e., true sub-exposure unit variability) of dose is not important as the DQO decisions are made at the exposure unit level. Sub-exposure unit variability can be significant as soil contamination from radionuclides is generally not homogenous. This is especially true for the actinides, which exhibit very small, insoluble particle sizes of high specific activity. 
Table A.5-1

Characteristics of Composite and Simple Random Sampling

\begin{tabular}{||c|c|c||}
\hline Characteristic & Composite Sampling & Simple Random Sampling \\
\hline \hline Representativeness & Represents the population average. & $\begin{array}{c}\text { Represents the sample collection } \\
\text { location. }\end{array}$ \\
\hline Population Mean & $\begin{array}{c}\text { Because the compositing physically averages the } \\
\text { individual samples, averaging the analytical } \\
\text { results of a few composites can produce an } \\
\text { estimated mean that is as precise as a mean } \\
\text { based on many more individual sample results. }\end{array}$ & $\begin{array}{c}\text { Estimate variability within the } \\
\text { population. Ability to estimate mean is } \\
\text { related to the number of samples. }\end{array}$ \\
\hline Variability & $\begin{array}{c}\text { Minimizes effects of within-population spatial } \\
\text { variability. Variability primarily due to } \\
\text { measurement error. }\end{array}$ & $\begin{array}{c}\text { Includes information on } \\
\text { within-population spatial variability. } \\
\text { Variability due to measurement error } \\
\text { as well as spatial variability. }\end{array}$ \\
\hline Cost & $\begin{array}{c}\text { Achieves approximately the same precision of an } \\
\text { estimated mean at a lower cost or provides more } \\
\text { coverage (better representation) of the population } \\
\text { at the same cost. }\end{array}$ & $\begin{array}{c}\text { More samples (analyses) are required } \\
\text { to provide comparable results. }\end{array}$ \\
\hline
\end{tabular}

This distinction is important because the variability between samples is used to calculate the 95 percent UCL of the average dose at each plot necessary to resolve the DQO decisions. The objective of the investigation is to generate a measurement of TED representative of the true average dose of the area at each plot (i.e., the exposure unit). The variability associated with sampling and measurement error is the important component of variability in establishing the confidence in the TED measurements.

Composite sampling, therefore, minimizes the effects of spatial variability and more accurately represents the variability associated with sampling and measurement errors. It was chosen as the preferred sampling scheme for CAU 371 (4 samples with 9 aliquots per sample) to be used for each plot and provides an estimate of the average characteristics of the plot equivalent to collecting and analyzing 36 simple random samples.

\section{Computation of Minimum Sample Size}

The minimum number of samples required to compute a UCL will be calculated from the TED measurements within each plot to verify that sufficient samples were collected. The minimum sample sizes will be calculated. 
The input parameters to be used in calculating the minimum sample size are:

- A confidence level that a false negative error will not occur will be set at 95 percent.

- A confidence level that a false positive error will not occur will be set at 80 percent.

- A gray region width of 50 percent of the FAL (12.5 mrem/yr).

- The standard deviation of the TED.

The location of subsamples within the plot will be determined using a triangular grid pattern, based on a starting location that is chosen randomly. If it is determined that additional samples need to be collected based on the determination of minimum sample size using actual sample results, additional sample(s) will be collected using the same methodology. An example of subsample locations within a plot is presented in Section A.9.0.

\section{A.5.2.1.2 Other Releases}

Decision I sample locations for other releases will be determined based upon the likelihood of the soil containing a COC, if present at the CAS. These locations will be selected based on field-screening techniques, biasing factors, the CSM, and existing information. Analytical suites for Decision I samples will be based on existing site information and site conditions discovered during the investigation. The following factors will be considered in selecting locations for analytical samples at CAU 371:

- Documented process knowledge on source and location of release (e.g., volume of release).

- Stains: Any spot or area on the soil surface that may indicate the presence of a potentially hazardous liquid. Typically, stains indicate an organic liquid (e.g., an oil) has reached the soil, and may have spread out vertically and horizontally.

- Elevated radiation: Any location identified during radiological walkover surveys that had alpha/beta/gamma levels significantly higher than surrounding background soil.

- Drums, containers, equipment, or debris: Materials of interest that may have been used at, or added to, a location, and that may have contained or come in contact with hazardous or radioactive substances at some point during use.

- Visual indicators such as discoloration, textural discontinuities, disturbance of native soils, or any other indication of potential contamination.

- $\quad$ Presence of potential source material. 
- Physical and chemical characteristics of contaminants.

- Other biasing factors: Factors not previously defined for the CAI that become evident once the investigation of the site is in progress.

Decision II sample step-out locations will be selected based on the CSM, biasing factors, and existing data. Analytical suites will include those parameters that exceeded FALs (i.e., COCs) in prior samples. Biasing factors to support Decision II sample locations include Decision I biasing factors plus available analytical results.

\section{A.5.2.2 Analytical Methods}

Analytical methods are available to provide the data needed to resolve the decision statements. The analytical methods and laboratory requirements (e.g., detection limits, precision, and accuracy) are provided in Tables 3-2 and 3-3. 


\section{A.6.0 Step 4 - Define the Boundaries of the Study}

Step 4 of the DQO process defines the target population of interest and its relevant spatial boundaries, specifies temporal and other practical constraints associated with sample/data collection, and defines the sampling units on which decisions or estimates will be made.

\section{A.6.1 Target Populations of Interest}

\section{A.6.1.1 Primary Releases}

The population of interest to resolve Decision I ("Is any COC associated with the CAS present in environmental media?”) is any area within the release where the TED exceeds the FAL. The populations of interest to resolve Decision II ("Is the extent of the area that provides a dose exceeding 25 mrem/yr defined?”) are:

- Areas within the release where the TED is less than the FAL along each sampling vector.

- Investigation waste and potential remediation waste.

\section{A.6.1.2 Other Releases}

The population of interest to resolve Decision I ("Is any COC associated with the CAS present in environmental media?”) is any location within the CAS that contains contaminant concentrations exceeding a FAL. The populations of interest to resolve Decision II ("If a COC is present, is sufficient information available to evaluate potential corrective action alternatives?”) are:

- Each one of a set of locations bounding contamination in lateral and vertical directions.

- Investigation waste and potential remediation waste.

\section{A.6.2 Spatial Boundaries}

Spatial boundaries are the maximum lateral and vertical extent of expected contamination supported by the CSM at each CAS, as shown in Table A.6-1. Contamination found beyond these boundaries may indicate a flaw in the CSM and may require re-evaluation of the CSM before the investigation could continue. Each CAS is considered geographically independent, and intrusive activities are not intended to extend into the boundaries of neighboring CASs. 
Table A.6-1

Spatial Boundaries of CAU 371 CASs

\begin{tabular}{|c|l|}
\hline CAS & \multicolumn{1}{|c|}{ Spatial Boundaries } \\
\hline \hline $11-23-05$ & $\begin{array}{l}\text { Vertical boundary is } 2 \mathrm{ft} \text { bgs for primary releases and } 15 \mathrm{ft} \text { bgs for other releases. The horizontal } \\
\text { boundary is } 1 \text { mile downgradient. }\end{array}$ \\
\hline $18-45-01$ & \\
\hline
\end{tabular}

\section{A.6.3 Practical Constraints}

Practical constraints for CAU 371 are:

- Underground utilities (active and inactive).

- $\quad$ Pin Stripe crater not currently approved to enter (no stability study).

- Access restrictions due to NTS activities.

- Conducting work on steep Johnnie Boy crater slopes.

\section{A.6.4 Define the Sampling Units}

The scale of decision-making in Decision I is defined as the CAS. Any COC detected at any location within the CAS will cause the determination that the CAS is contaminated and needs further evaluation. The scale of decision-making for Decision II is defined as a contiguous area contaminated with any COC originating from the CAS. Resolution of Decision II requires this contiguous area to be bounded. 


\section{A.7.0 Step 5 - Develop the Analytic Approach}

Step 5 of the DQO process specifies appropriate population parameters for making decisions, defines action levels, and generates an "If ... then ... else" decision rule that involves it.

\section{A.7.1 Population Parameters}

\section{A.7.1.1 Primary Releases}

For probabilistic sampling results (used for the primary releases), the population parameter is the true average TED of the plot. Resolution of the DQO Decision statements associated with the probabilistic sampling design requires determining, with a specified degree of confidence, whether the true average TED at the plot exceeds the FAL. Because the average TED from the plot measurements is an estimate of the true (unknown) average TED, it is uncertain how well the TED estimate represents the true TED at the plot. If the measured estimate of the TED was compared directly to the FAL, a significant difference between the estimated TED and the true TED could lead to making a decision error. To reduce the probability of making a false negative decision error (while increasing the probability of making a false positive decision error), a conservative estimate of the true TED will be used to compare to the FAL. This conservative estimate (overestimation) of the true TED will be calculated as the 95 percent UCL of the estimated TED. By definition, there will be a 95 percent probability that the true TED is less than the 95 percent UCL of the estimated TED.

The computation of appropriate UCLs depends upon the data distribution, the number of samples, the variability of the dataset, and the skewness associated with the dataset. A statistical package will be used to determine the appropriate probability distribution (e.g., normal, lognormal, gamma) and/or a suitable nonparametric distribution-free method will be defined and then used to compute appropriate UCLs.

Computation of an appropriate UCL for the TED requires that:

- A minimum number of samples be collected from random locations at each site.

- The data originate from a symmetric, but not necessarily normally distributed, population. 
For CAS 18-45-01, the population parameter for Decision II will be the location along each vector that corresponds to the estimated 95 percent UCL of the 25-mrem/yr dose, based on regression analyses of the TED as a function of distance along each vector.

\section{A.7.1.2 Other Releases}

For judgmental sampling results (used for other releases), the population parameter is the observed concentration of each contaminant from each individual analytical sample. Each sample result will be compared to the FALs to determine the appropriate resolution to Decision I and Decision II.

\section{A.7.2 Action Levels}

The PALs presented in this section are to be used for site screening purposes. They are not necessarily intended to be used as cleanup action levels or FALs. However, they are useful in screening out contaminants that are not present in sufficient concentrations to warrant further evaluation and, therefore, streamline the consideration of remedial alternatives. The RBCA process used to establish FALs is described in the Industrial Sites Project Establishment of Final Action Levels (NNSA/NSO, 2006). This process conforms with NAC Section 445A.227, which lists the requirements for sites with soil contamination (NAC, 2006a). For the evaluation of corrective actions, NAC Section 445A.22705 (NAC, 2006b) requires the use of ASTM Method E 1739-95 (ASTM, 1995) to "conduct an evaluation of the site, based on the risk it poses to public health and the environment, to determine the necessary remediation standards (i.e., FALs) or to establish that corrective action is not necessary."

This RBCA process defines three tiers (or levels) of evaluation involving increasingly sophisticated analyses:

- Tier 1 evaluation - Sample results from source areas (highest concentrations) are compared to action levels based on generic (non-site-specific) conditions (i.e., the PALs established in the CAIP). The FALs may then be established as the Tier 1 action levels, or the FALs may be calculated using a Tier 2 evaluation.

- Tier 2 evaluation - Conducted by calculating Tier 2 SSTLs using site-specific information as inputs to the same or similar methodology used to calculate Tier 1 action levels. The Tier 2 SSTLs are then compared to individual sample results from reasonable points of exposure (as opposed to the source areas as is done in Tier 1) on a point-by-point basis. Total TPH concentrations will not be used for risk-based decisions under Tier 2 or Tier 3. Rather, the individual chemicals of concern will be compared to the SSTLS. 
- Tier 3 evaluation - Conducted by calculating Tier 3 SSTLs on the basis of more sophisticated risk analyses using methodologies described in Method E 1739-95 that consider site-, pathway-, and receptor-specific parameters.

The comparison of laboratory results to FALs and the evaluation of potential corrective actions will be included in the CADD. The FALs will be defined (along with the basis for their definition) in the CADD.

\section{A.7.2.1 Chemical PALs}

Except as noted herein, the chemical PALs are defined as the EPA Region 9 Preliminary Remediation Goals (PRGs) for chemical contaminants in industrial soils (EPA, 2008). Background concentrations for RCRA metals and zinc will be used instead of PRGs when natural background concentrations exceed the PRG, as is often the case with arsenic on the NTS. Background is considered the average concentration plus two standard deviations of the average concentration for sediment samples collected by the Nevada Bureau of Mines and Geology throughout the Nevada Test and Training Range (formerly the Nellis Air Force Range) (NBMG, 1998; Moore, 1999). For detected chemical COPCs without established PRGs, the protocol used by the EPA Region 9 in establishing PRGs (or similar) will be used to establish PALs. If used, this process will be documented in the CADD.

\section{A.7.2.2 Total Petroleum Hydrocarbon PALs}

The PAL for TPH is $100 \mathrm{mg} / \mathrm{kg}$ as listed in NAC 445A.2272 (NAC, 2006c).

\section{A.7.2.3 Radionuclide PALs}

The radiological PAL for the primary releases is established as the 25-mrem/yr TED based on the industrial area exposure scenario.

The PALs for radiological contaminants for the other releases are based on the NCRP Report No. 129 recommended screening limits for construction, commercial, industrial land-use scenarios (NCRP, 1999) scaled to $25 \mathrm{mrem} / \mathrm{yr}$ dose constraint (Murphy, 2004) and the generic guidelines for residual concentration of radionuclides in DOE Order 5400.5 (DOE, 1993). These PALs are based on the construction, commercial, and industrial land-use scenario provided in the guidance and are appropriate for the NTS based on future land-use scenarios as presented in Section A.3.2. 


\section{A.7.3 Decision Rules}

The decision rule applicable to both Decision I and Decision II is:

- If COC contamination is inconsistent with the CSM or extends beyond the spatial boundaries identified in Section A.6.2, then work will be suspended and the investigation strategy will be reconsidered, else the decision will be to continue sampling.

The decision rules for Decision I are:

- If the population parameter of any COPC in the Decision I population of interest (defined in Step 4) exceeds the corresponding FAL, then that contaminant is identified as a COC, and Decision II samples will be collected, else no further investigation is needed for that COPC in that population.

- If a COC exists at any CAS, then a corrective action will be determined, else no further action will be necessary.

- If a waste is present that, if released, has the potential to cause the future contamination of site environmental media, then a corrective action will be determined, else no further action will be necessary.

The decision rule for Decision II (primary releases) is:

- If a radiation survey isopleth exists that bounds all locations determined to exceed the 95 percent UCL of the 25-mrem/yr TED, then the isopleth will be established as the corrective action boundary, else the radiation survey area will be increased until that boundary is defined.

The decision rule for Decision II (other releases) is:

- If the population parameter (the observed concentration of any COC) in the Decision II population of interest (defined in Step 4) exceeds the corresponding FAL in any bounding direction, or potential remediation waste types have not been adequately defined, then additional samples will be collected to complete the Decision II evaluation, else the extent of the COC contamination has been defined. 


\section{A.8.0 Step 6 - Specify Performance or Acceptance Criteria}

Step 6 of the DQO process defines the decision hypotheses, specifies controls against false rejection and false acceptance decision errors, examines consequences of making incorrect decisions from the test, and places acceptable limits on the likelihood of making decision errors.

\section{A.8.1 Decision Hypotheses}

The baseline condition (i.e., null hypothesis) and alternative condition for Decision I are:

- $\quad$ Baseline condition - A COC is present.

- Alternative condition - A COC is not present.

The baseline condition (i.e., null hypothesis) and alternative condition for Decision II are as follows:

- $\quad$ Baseline condition - The extent of a COC has not been defined.

- Alternative condition - The extent of a COC has been defined.

Decisions and/or criteria have false negative or false positive errors associated with their determination. The impact of these decision errors and the methods that will be used to control these errors are discussed in the following subsections. In general terms, confidence in DQO decisions based on judgmental sampling results will be established qualitatively by:

- The development and concurrence of the CSM (based on process knowledge) by stakeholder participants during the DQO process

- Validity testing of the CSM based on investigation results

- Evaluation of the data quality based on DQI parameters

\section{A.8.2 False Negative Decision Error}

The false negative decision error would mean deciding that a COC is not present when it actually is (Decision I), or deciding that the extent of a COC has been defined when it has not (Decision II). In both cases, the potential consequence is an increased risk to human health and environment. 


\section{A.8.2.1 False Negative Decision Error for Judgmental Sampling}

In judgmental sampling, the selection of the number and location of samples is based on knowledge of the feature or condition under investigation and on professional judgment (EPA, 2002).

Judgmental sampling conclusions about the target population depend upon the validity and accuracy of professional judgment.

The false negative decision error (where consequences are more severe) for judgmental sampling designs is controlled by meeting these criteria:

1. For Decision I, having a high degree of confidence that the sample locations selected will identify COCs if present anywhere within the CAS. For Decision II, having a high degree of confidence that the sample locations selected will identify the extent of COCs.

2. Having a high degree of confidence that analyses conducted will be sufficient to detect any COCs present in the samples.

3. Having a high degree of confidence that the dataset is of sufficient quality and completeness.

To satisfy the first criterion, Decision I samples must be collected in areas most likely to be contaminated by COCs (supplemented by random samples where appropriate). Decision II samples must be collected in areas that represent the lateral and vertical extent of contamination (above FALs). The following characteristics must be considered to control decision errors for the first criterion:

- Source and location of release

- Chemical nature and fate properties

- Physical transport pathways and properties

- Hydrologic drivers

These characteristics were considered during the development of the CSM and selection of sampling locations. The field-screening methods and biasing factors listed in Section A.5.2.1 will be used to further ensure that appropriate sampling locations are selected to meet these criteria. Radiological survey instruments and field-screening equipment will be calibrated and checked in accordance with the manufacturer's instructions and approved procedures. The CADD will present an assessment on 
the DQI of representativeness that samples were collected from those locations that best represent the populations of interest as defined in Section A.6.1.

To satisfy the second criterion, Decision I samples will be analyzed for the chemical and radiological parameters listed in Section 3.2. Decision II samples will be analyzed for those chemical and radiological parameters that identified unbounded COCs. The DQI of sensitivity will be assessed for all analytical results to ensure that all sample analyses had measurement sensitivities (detection limits) that were less than or equal to the corresponding FALs. If this criterion is not achieved, the affected data will be assessed (for usability and potential impacts on meeting site characterization objectives) in the CADD.

To satisfy the third criterion, the entire dataset, as well as individual sample results, will be assessed against the DQIs of precision, accuracy, comparability, and completeness as defined in the Industrial Sites QAPP (NNSA/NV, 2002a) and in Section 6.2.2. The DQIs of precision and accuracy will be used to assess overall analytical method performance as well as to assess the need to potentially "flag" (qualify) individual contaminant results when corresponding QC sample results are not within the established control limits for precision and accuracy. Data qualified as estimated for reasons of precision or accuracy may be considered to meet the analyte performance criteria based on an assessment of the data. The DQI for completeness will be assessed to ensure that all data needs identified in the DQO have been met. The DQI of comparability will be assessed to ensure that all analytical methods used are equivalent to standard EPA methods so that results will be comparable to regulatory action levels that have been established using those procedures. Strict adherence to established procedures and QA/QC protocol protects against false negatives. Site-specific DQIs are discussed in more detail in Section 6.2.2.

To provide information for the assessment of the DQIs of precision and accuracy, the following QC samples will be collected for radiological samples as required by the Industrial Sites QAPP (NNSA/NV, 2002a):

- Field duplicates (minimum of 1 per matrix per 20 environmental samples)

- Laboratory QC samples (minimum of 1 per matrix per 20 environmental samples or 1 per CAS per matrix, if less than 20 collected) 


\section{A.8.2.2 False Negative Decision Error for Probabilistic Sampling}

The false negative error rate was established by the DQO meeting participants at 0.05 (or 5 percent probability). Upon validation of the analytical results, statistical parameters will be calculated for each COC identified at each site. Maintenance of a false negative error rate of 0.05 is contingent upon:

- Population distribution

- Sample size

- Actual variability

- Measurement error

Control of the false negative decision error for probabilistic sampling designs, therefore, is accomplished by ensuring that:

- The population distributions fit the applied UCL determination method.

- A sufficient sample size was collected.

- The actual standard deviation is calculated.

- Analyses conducted were sufficient to detect any COCs present in samples.

If these criteria cannot be met, the false negative decision error also may be controlled by assuming that COCs exist at the CAS.

\section{A.8.3 False Positive Decision Error}

The false positive decision error would mean deciding that a COC is present when it is not, or a COC is unbounded when it is not, resulting in increased costs for unnecessary sampling and analysis.

False positive results are typically attributed to laboratory and/or sampling/handling errors that could cause cross contamination. To control against cross contamination, decontamination of sampling equipment will be conducted according to established and approved procedures, and only clean sample containers will be used. To determine whether a false positive analytical result may have occurred, the following QC samples will be collected as required by the Industrial Sites QAPP (NNSA/NV, 2002a) for chemical samples only (if collected):

- Trip blanks (1 per sample cooler containing VOC environmental samples)

- Equipment blanks (1 per sampling event for each type of decontamination procedure)

- Source blanks (1 per source lot per sampling event) 
- Field blanks (minimum of 1 per CAS, additional if field conditions change)

- Field duplicates (minimum of 1 per matrix per 20 environmental samples)

For probabilistic sampling, false positive decision error was established by the DQO meeting participants at 0.20 (or 20 percent probability). Protection against this decision error is also afforded by the controls listed in Section A.8.2 for probabilistic sampling designs. 


\section{A.9.0 Step 7 - Develop the Plan for Obtaining Data}

Step 7 of the DQO process selects and documents a design that will yield data that will best achieve performance or acceptance criteria. Judgmental sampling schemes will be implemented to select the sample plot locations for the primary releases. Probabilistic sampling schemes will be implemented to select nine sample locations for each of four composite samples within each sample plot.

Judgmental sampling will also be used to investigate any other releases based on site biasing factors (staining, historical knowledge, debris). Sections A.9.1 through A.9.2.2 contain general information about collecting samples under judgmental and probabilistic sampling designs, and Decision II sampling.

\section{A.9.1 Sampling of Primary Releases}

A combination of judgmental and probabilistic sampling approaches will be implemented for the investigation of the annular distribution of contamination at both CAU 371 CASs.

The location of sample plots is judgmental because placement of the:

- Decision I sample plots at CASs 11-23-05 and 18-45-01 will be biased to the areas of highest radiological reading detected during the walkover surveys.

- Decision II sample plots at CAS 11-23-05, if needed, will also be biased, with the biasing factors that one plot will have a dose greater than $25 \mathrm{mrem} / \mathrm{yr}$, and one plot will have a dose less than $25 \mathrm{mrem} / \mathrm{yr}$.

- Decision II sample plots at CAS 18-45-01 will be biased so that there is a minimum of three plots along each of three vectors.

The collection and evaluation of samples within each plot is probabilistic because:

- Aliquot (i.e., subsample) locations within each plot for each composite sample will be determined using a random start, triangular grid pattern, thereby giving an unbiased selection of sampled locations.

- $\quad$ Statistics (i.e., average, standard deviation, and 95 percent UCL of the average) from the data will be used to evaluate the results. 


\section{A.9.1.1 Decision I Sampling}

A combination of judgmental and probabilistic sampling approaches will be implemented for the Decision I investigation of the primary releases of contamination. Data collected will estimate the TED at each plot. The TED will be determined by summing the internal and external dose components. For internal dose, sample results will be used to calculate internal dose using RESRAD. External dose will be determined by collecting in situ measurements using TLDs or other dose measurement devices. Dose measurements will be taken at the approximate center of the sample plot at a height of $1 \mathrm{~m}$.

Radiological surveys will be used for biasing sample plot locations. The radiological surveys will include the 1994 aerial radiological survey and GPS-assisted gamma walkover surveys to determine patterns of contaminant distribution. The surveys will encompass the plume footprint and potential areas of migration (i.e., drainages). One sample plot will be established judgmentally at the highest reading detected during the radiological surveys at each CAS. See Figures A.9-1 and A.9-2 for an example of the Decision I sampling approaches for CASs 11-23-05 and 18-45-01.

Within each sample plot, each sample will be a composite sample from nine predetermined locations, determined under a probabilistic sampling scheme. If a predetermined location cannot feasibly be sampled (e.g., rock, caliche or concrete), the Site Supervisor will establish an alternate sampling location at the nearest place that can be sampled.

For the probabilistic sampling approach at the sample plots:

- Each composite sample will be comprised of nine randomly selected aliquots taken from random locations within each plot. These locations will be predetermined using a random start with a triangular grid pattern.

- Samples will be screened to eliminate material greater than 0.25 in.

- The entire volume of the composited material collected will be submitted to the laboratory for analysis.

A minimum number of samples (i.e., composite samples) is required to compute a UCL. This number will be calculated based on the TED results (comprised of individual internal dose rates associated with each of the four composite samples added to the external dose rates from each plot). 


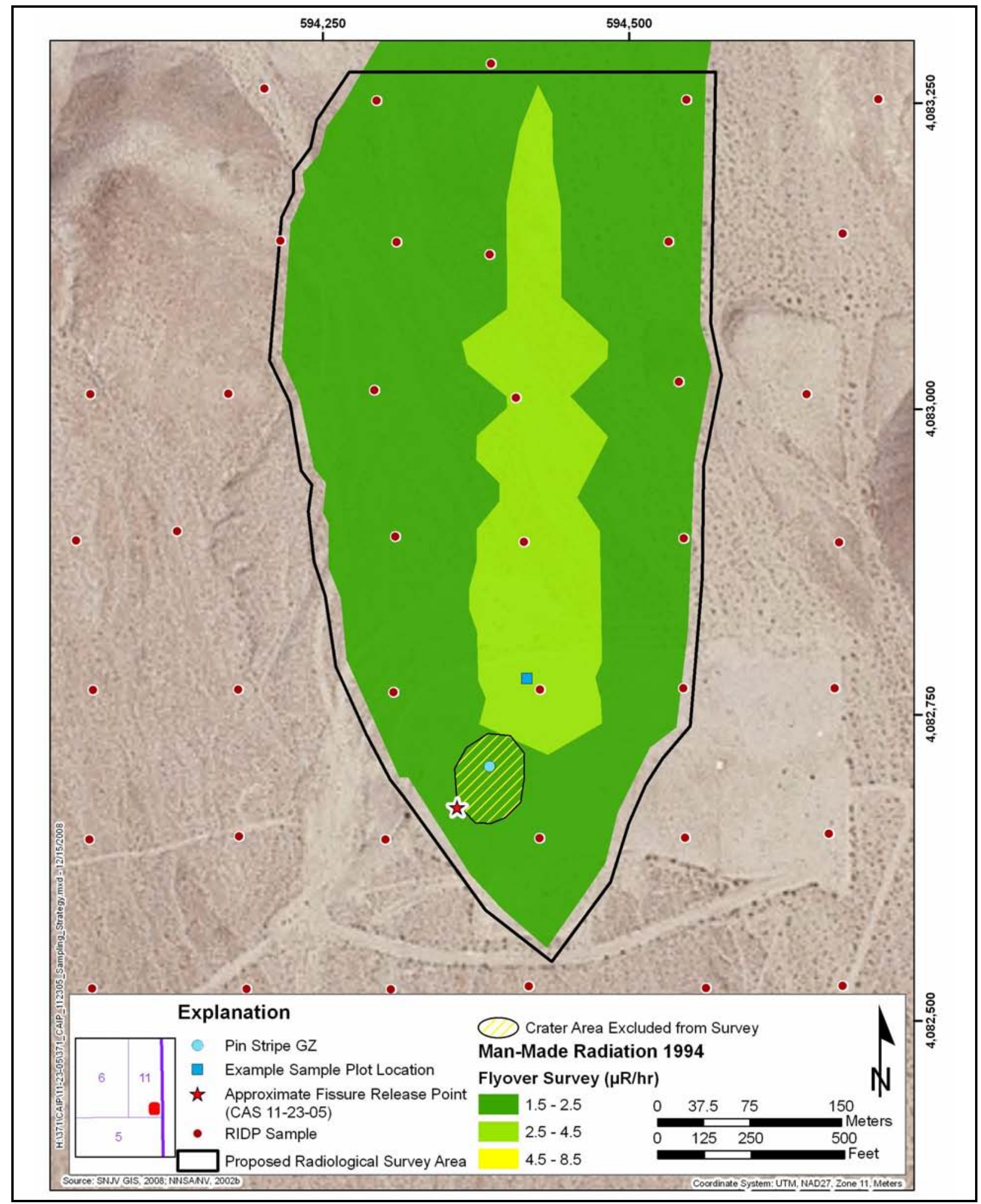

Figure A.9-1

Proposed Sample Locations at CAS 11-23-05 


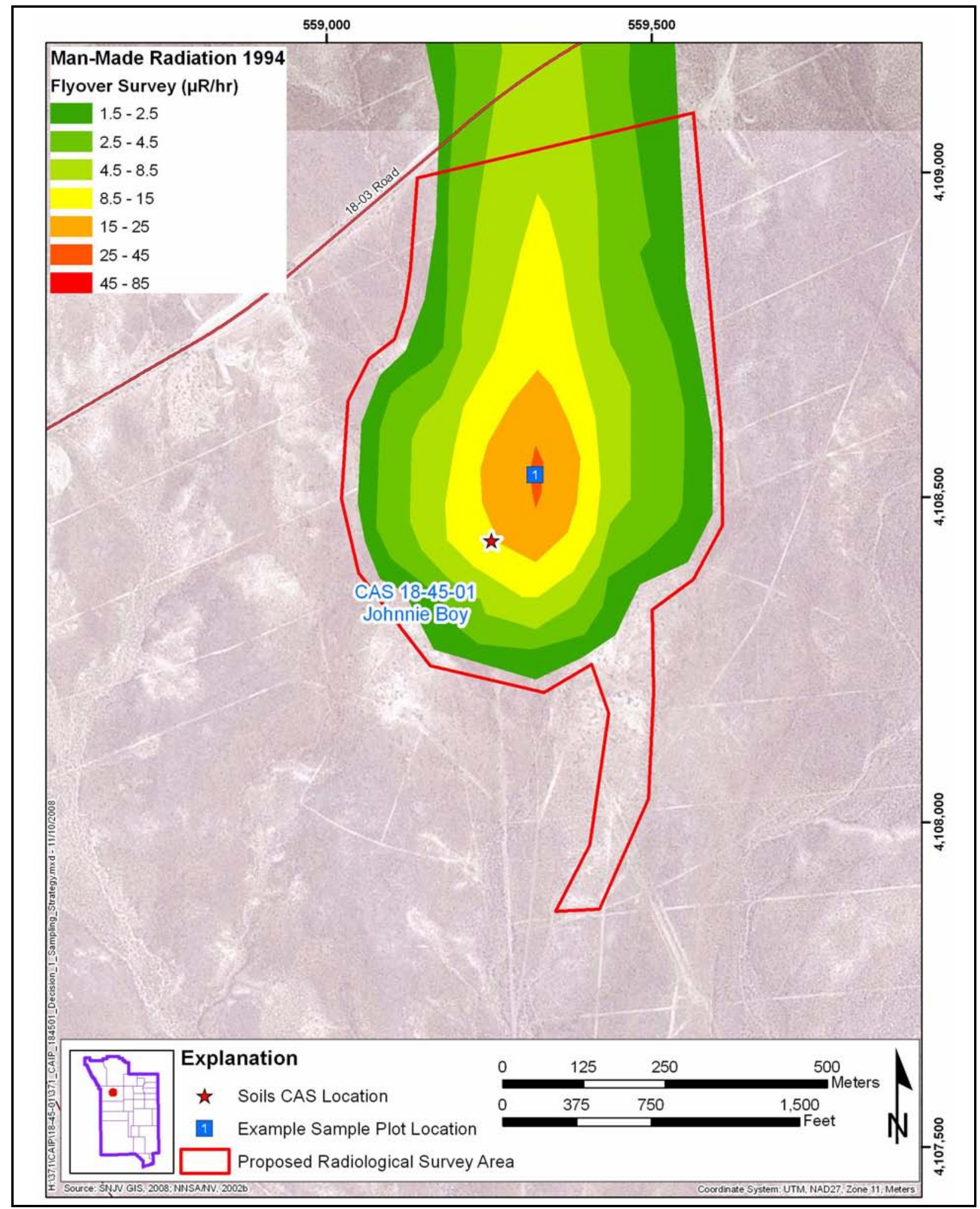

Figure A.9-2

Proposed Decision I Sampling for CAS 18-45-01 
Determination of the minimum sample size cannot be determined until after the data has been generated. However, based on the input parameters below, and the variability of the data from CAU 370, a minimum of three samples would be required. After the evaluation of the data for CAU 371 is complete and the required number of samples is calculated, additional samples will be collected, if necessary.

The input parameters to be used in calculating the minimum sample size are:

- A confidence level that a false negative error will not occur will be set at 95 percent.

- A confidence level that a false positive error will not occur will be set at 80 percent.

- A gray region width equal to 50 percent of the FAL (12.5 mrem/yr).

- The standard deviation of the TEDs at each plot.

If the criteria established in this section results in a determination that the minimum sample size was not met for a plot, one of the following actions may be taken:

- Additional composite sample(s) may be collected.

- Conservatively assume that the average TED for the plot exceeds the FAL.

Justification for use of the resulting average TED without meeting the criteria will be made in the CADD.

An example of the four composite samples and nine locations per sample, at the sample plots for CASs 11-23-05 and 18-45-01, is shown in Figure A.9-3.

Values/settings used for the computation of the composite sample locations for the plot are listed in Table A.9-1.

\section{A.9.1.2 Decision II Sampling}

For Decision II at CAS 11-23-05, if the results of the Decision I sample plot show contamination present that exceeds the FALs, then a Decision II sampling strategy will be presented and agreed upon by the stakeholders.

For Decision II at CAS 18-45-01, three additional $100 \mathrm{~m}^{2}$ sample plots will be established along each of three vectors. The approximate proposed sampling vectors and sample plots are shown in 


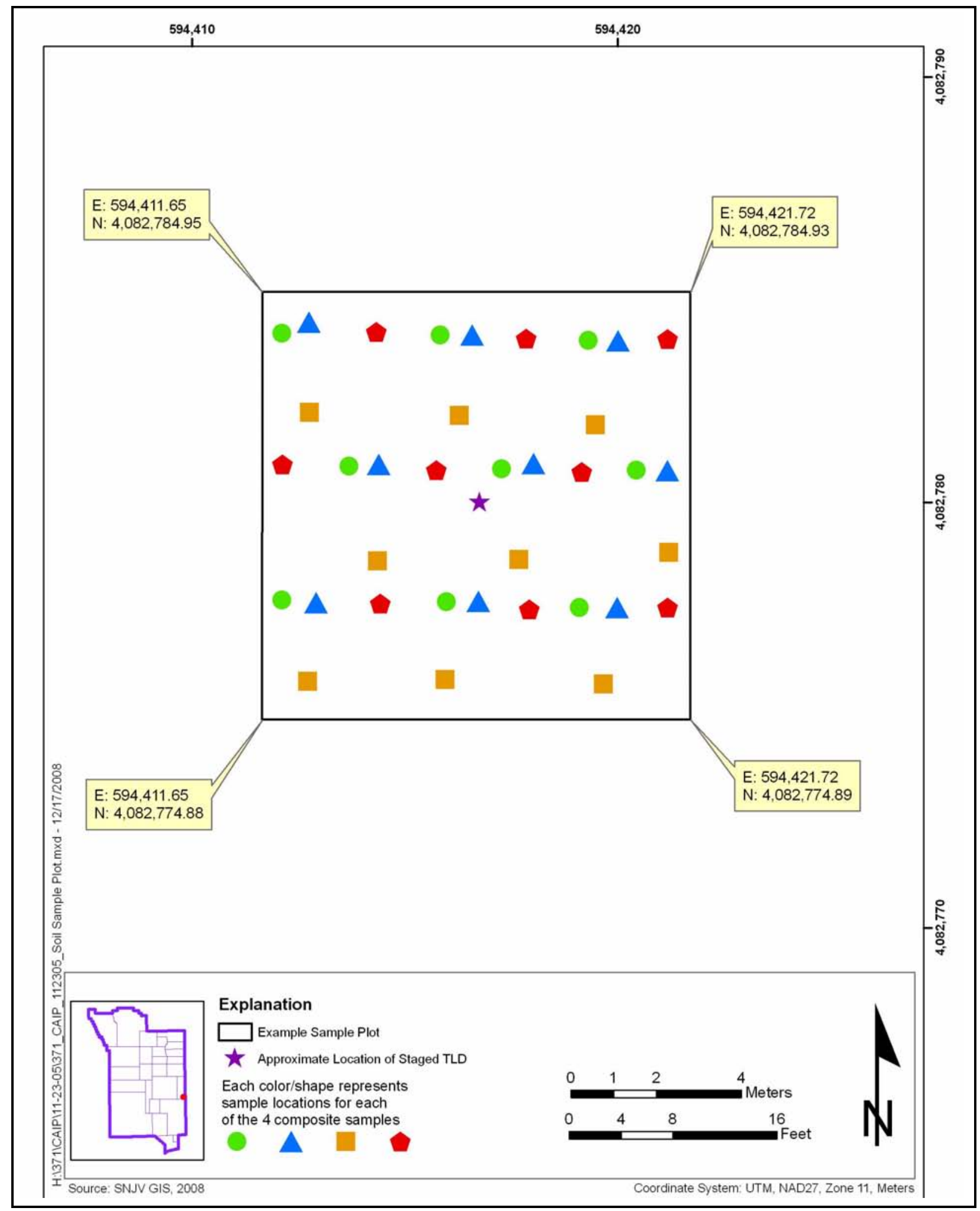

Figure A.9-3

Sample Plot Example for CASs 11-23-05 and 18-45-01 
Table A.9-1

Placement of Random Composite Sample Locations

\begin{tabular}{|c|c|}
\hline Type of sampling design & Ordinary - predetermined number of samples \\
\hline \hline Sample aliquot placement (location) in the field & Systematic with a random start location \\
\hline Estimated initial number of sample aliquots & 9 \\
\hline Size of sample plot & $100 \mathrm{~m}^{2}$ \\
\hline Grid pattern & Triangular \\
\hline
\end{tabular}

Figure A.9-4. Because there is high confidence that the FAL will be exceeded at the Decision I sample plot, Decision II sample plots will be located and sampled at CAS 18-45-01 during the initial field effort.

The area exceeding the FAL will be calculated using the 95 percent UCL TEDs from each plot along each vector. A trend of the 95 percent UCL TEDs along each vector will determine a point along each vector where the 95 percent UCL TED is equivalent to $25 \mathrm{mrem} / \mathrm{yr}$. This will be established based on a correlation of the 95 percent UCL TEDs with distance along each vector.

An isopleth from a radiological survey will be chosen to bound the area of the CAS that exceeds a 25-mrem/yr-dose rate based on the following criterion:

- The area encompasses the estimated points along each vector that correspond to a 25-mrem/yr average TED.

\section{A.9.2 Other Releases}

\section{A.9.2.1 Decision I}

A judgmental sampling approach will be implemented for the Decision I investigation of other releases at both CAU 371 CASs.

The investigation of other releases includes locations of potential chemical contamination identified during the CAI (i.e., debris, brick, stains, roadway) at all CASs. 


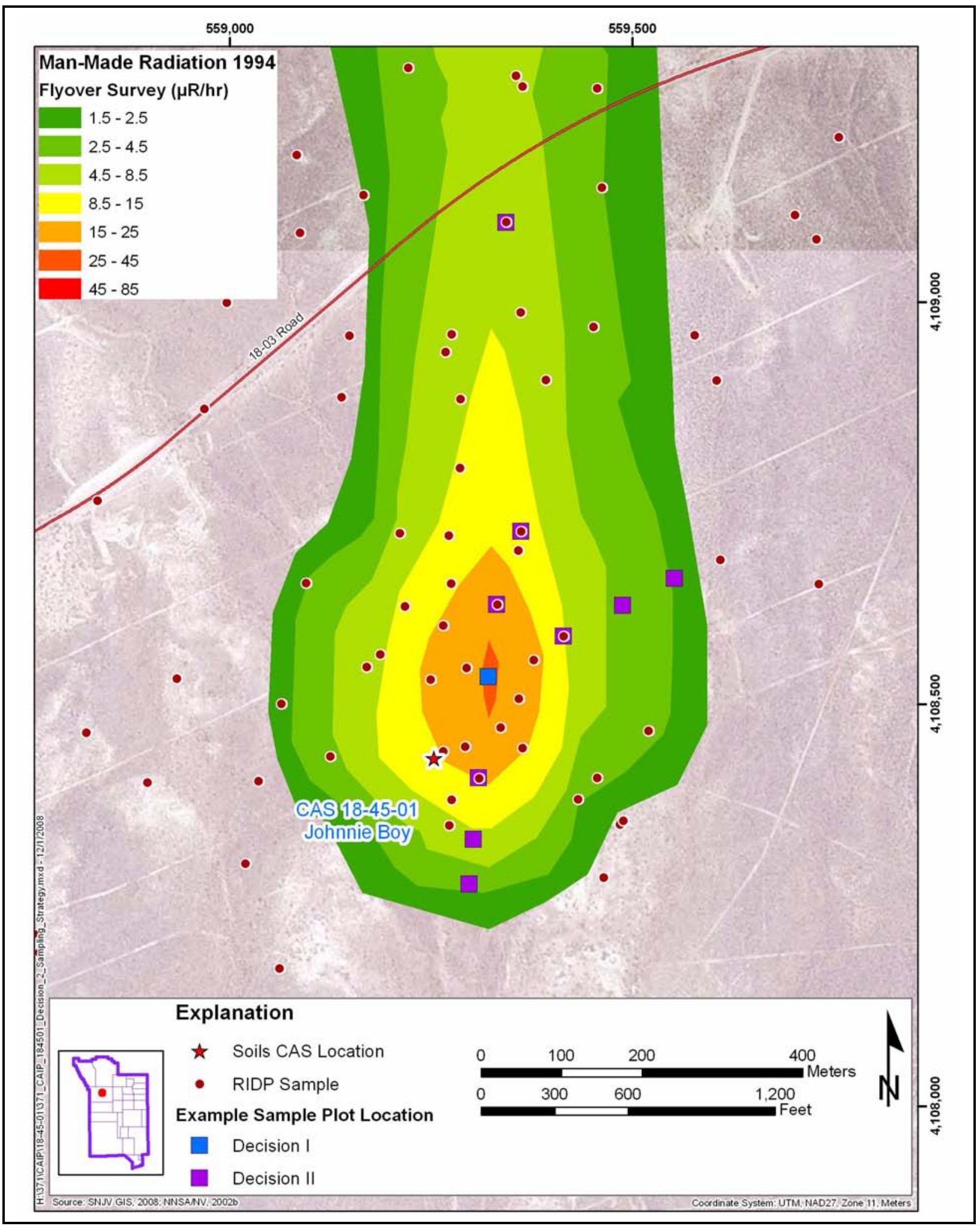

Figure A.9-4

Proposed Decision II Sampling for CAS 18-45-01 
If potential chemical contamination is identified, grab samples will be collected and submitted to the laboratory for analysis based on existing site information and site conditions discovered during the investigation. The following factors will be considered in selecting locations for analytical samples at CAU 371:

- Documented process knowledge on source and location of release (e.g., volume of release).

- Stains: Spots or areas on the soil surface that may indicate the presence of a potentially hazardous liquid. Typically, stains indicate an organic liquid (e.g., an oil) has reached the soil, and may have spread out vertically and horizontally.

- Elevated radiation: Locations identified during radiological walkover surveys that had alpha/beta/gamma levels significantly higher than surrounding background soil.

- Drums, containers, equipment, or debris: Materials of interest that may have been used at, or added to, a location, and that may have contained or come in contact with hazardous or radioactive substances at some point during their use.

- Visual indicators such as discoloration, textural discontinuities, disturbance of native soils, or other indications of potential contamination.

- Presence of potential source material.

- Physical and chemical characteristics of contaminants.

- Other biasing factors: Factors not previously defined for the CAI that become evident once the investigation of the site is in progress.

\section{A.9.2.2 Decision II}

To meet the DQI of representativeness, Decision II samples will be collected from locations that represent the population of interest as defined in Section A.6.1. Judgmental sampling locations at each CAS will be selected based on locations where COCs were detected, the CSM, and other field-screening and biasing factors listed in Section A.5.2. In general, sample locations will be arranged in a triangular pattern around the area containing COCs at distances based on site conditions, process knowledge, and biasing factors. If COCs extend beyond the initial step-outs, Decision II samples will be collected from incremental step-outs. Initial step-outs will be at least as deep as the vertical extent of contamination defined at the Decision I location, and the depth of the incremental step-outs will be based on the deepest contamination observed at all locations. A clean 
sample (i.e., COCs less than FALs) collected from each step-out direction (lateral or vertical) will define extent of contamination in that direction. The number, location, and spacing of step-outs may be modified by the Site Supervisor, as warranted by site conditions, but only if the modified locations meet the decision needs and criteria stipulated in this DQO. 


\section{A.10.0 References}

ARL/SORD, see Air Resources Laboratory/Special Operations and Research Division.

ASTM, see American Society for Testing and Materials.

Air Resources Laboratory/Special Operations and Research Division. 2009. NTS Climatological Rain Gauge Data. As accessed at http://www.sord.nv.goe/home_climate_rain.htm on 12 February.

American Society for Testing and Materials. 1995. Standard Guide for Risk-Based Corrective Action Applied at Petroleum Release Sites, ASTM E 1739-95 (Reapproved 2002). Philadelphia, PA.

BN, see Bechtel Nevada.

Bechtel Nevada. 1999. An Aerial Radiological Survey of the Nevada Test Site, DOE/NV/11718--324. Prepared for U.S. Department of Energy, Nevada Operations Office. Las Vegas, NV: Remote Sensing Laboratory.

DOE, see U.S. Department of Energy.

DOE/NV, see U.S. Department of Energy, Nevada Operations Office.

DRI, see Desert Research Institute.

Desert Research Institute. 1983. Radionuclide Inventory and Distribution Program: The Galileo Area. Desert Research Institute, University of Nevada System, Water Resources Center. December. DOE/NV/10162-14. Las Vegas, NV.

Desert Research Institute. 1985. Nevada Test Site Radionuclide Inventory and Distribution Program Report \#2. Areas 2 and 4, Publication \#45041. Las Vegas, NV.

EPA, see U.S. Environmental Protection Agency.

GE, see General Electric Company-TEMPO.

General Electric Company-TEMPO. 1979. Compilation of Local Fallout Data from Test Detonations 1945-1962 Extracted from DASA 1251, Volume I, DNA 1251-1-EX. 1 May. Prepared for Defense Nuclear Agency. Santa Barbara, CA: DASIAC. 
Gilbert, R.O., Essington, E.H., Brady, D.N., Doctor, P.G., and Eberhardt, L.L. 1977. Statistical Activities During 1976 and the Design and Initial Analysis of Nuclear Site Studies. In: Transuranics in Desert Ecosystems. Nevada Applied Ecology Group. November. U.S. DOE, Nevada Operations Office, Las Vegas, Nevada. NVO-181.

Gray, K.J., D.S. Shafer, K. Self, C. Martin, and R. McCarthur. 2007. Radionuclide Inventory and Distribution Program (RIDP) Database, Rev. 2. April. Las Vegas, NV.

Moore, J., Science Applications International Corporation. 1999. Memorandum to M Todd (SAIC) entitled, "Background Concentrations for NTS and TTR Soil Samples,” 3 February. Las Vegas, NV: IT Corporation.

Murphy, T., Bureau of Federal Facilities. 2004. Letter to R. Bangerter (NNSA/NSO) entitled, "Review of Industrial Sites Project Document Guidance for Calculating Industrial Sites Project Remediation Goals for Radionuclides in Soil Using the Residual Radiation (RESRAD) Computer Code,” 19 November. Las Vegas, NV.

NAC, see Nevada Administrative Code.

NBMG, see Nevada Bureau of Mines and Geology.

NCRP, see National Council on Radiation Protection and Measurements.

NNSA/NSO, see U.S. Department of Energy, National Nuclear Security Administration Nevada Site Office.

NNSA/NV, see U.S. Department of Energy, National Nuclear Security Administration Nevada Operations Office.

National Council on Radiation Protection and Measurements. 1999. Recommended Screening Limits for Contaminated Surface Soil and Review of Factors Relevant to Site-Specific Studies, NCRP Report No. 129. Bethesda, MD.

Nevada Administrative Code. 2006a. NAC 445A.227, “Contamination of Soil: Order by Director for Corrective Action; Factors To Be Considered in Determining Whether Corrective Action Required.” Carson City, NV. As accessed at http://www.leg.state.nv.us/nac on 3 December.

Nevada Administrative Code. 2006b. NAC 445A.22705, “Contamination of Soil: Evaluation of Site by Owner or Operator; Review of Evaluation by Division.” Carson City, NV. As accessed at http://www.leg.state.nv.us/nac on 3 December.

Nevada Administrative Code. 2006c. NAC 445A.2272, "Contamination of Soil: Establishment of Action Levels.” Carson City, NV. As accessed at http://www.leg.state.nv.us/nac on 3 December. 
Nevada Bureau of Mines and Geology. 1998. Mineral and Energy Resource Assessment of the Nellis Air Force Range, Open-File Report 98-1. Reno, NV.

RSL, Remote Sensing Laboratory.

Remote Sensing Laboratory. 1974. Aerial Photograph “672-81,” 4 April. Las Vegas, NV.

Sandia, see Sandia Corporation.

SNJV GIS, see Stoller-Navarro Joint Venture Geographic Information Systems.

Sandia Corporation. 1966. Letter to W.W. Allaire (U.S. Atomic Energy Commission) entitled, “Scientific Advisor’s Report of Pin Stripe.” 19 May. Open Net Accession Number 77515. Sandia Base, Albuquerque, NM.

Stoller-Navarro Joint Venture Geographic Information Systems. 2008. ESRI ArcGIS Software.

Tamura, T. 1977. Plutonium Distribution in a Desert Pavement-Desert Mound Soil System in Area 11. In: Environmental Plutonium on the Nevada Test Site and Environs. June. Nevada Applied Ecology Group. U.S. Energy Research and Development Administration, Las Vegas, Nevada. NVO-171.

USGS, see U.S. Geological Survey.

U.S. Department of Energy. 1993. Radiation Protection of the Public and the Environment, DOE Order 5400.5, Change 2. Washington, DC: U.S. Government Printing Office.

U.S. Department of Energy, National Nuclear Security Administration Nevada Operations Office. 2002a. Industrial Sites Quality Assurance Project Plan, Nevada Test Site, Nevada, Rev. 3, DOE/NV--372. Las Vegas, NV.

U.S. Department of Energy, National Nuclear Security Administration Nevada Operations Office. 2002b. Nevada Test Site Orthophoto Site Atlas, DOE/NV/11718--604. Prepared by Bechtel Nevada. Las Vegas, NV.

U.S. Department of Energy, National Nuclear Security Administration Nevada Site Office. 2006. Industrial Sites Project Establishment of Final Action Levels, Rev. 0, DOE/NV--1107. Las Vegas, NV.

U.S. Department of Energy, Nevada Operations Office. 1992. Remedial Investigation and Feasibility Study for the Plutonium Contaminated Soils at Nevada Test Site, Nellis Air Force Range and Tonopah Test Range. April. Las Vegas, NV. 
U.S. Department of Energy, Nevada Operations Office. 1996a. Final Environmental Impact Statement for the Nevada Test Site and Off-Site Locations in the State of Nevada, DOE/EIS 0243. Las Vegas, NV.

U.S. Department of Energy, Nevada Operations Office. 1996b. Radiological Effluents Released From U.S. Continental Tests 1961 Through 1992, DOE/NV-317 (Rev 1) UC-702. August. Las Vegas, NV.

U.S. Department of Energy, Nevada Operations Office. 2000a. Nevada Test Site Contaminated Land Areas Report, Volume I, DOE/NV/11718-481-VOL 1. Las Vegas, NV.

U.S. Department of Energy, Nevada Operations Office. 2000b. United States Nuclear Tests, July 1945 through September 1992, DOE/NV--209-Rev 15. Las Vegas, NV.

U.S. Environmental Protection Agency. 2002. Guidance for Quality Assurance Project Plans, EPA QA/G5. Washington, DC.

U.S. Environmental Protection Agency. 2006. Guidance on Systematic Planning Using the Data Quality Objectives Process, EPA QA/G-4. Washington, DC.

U.S. Environmental Protection Agency. 2008. Region 9: Superfund, Preliminary Remediation Goals, Screening Levels for Chemical Contaminants. As accessed at http://www.epa.gov/region09/waste/sfund/prg/index.html on November 5. Prepared by EPA Office of Superfund and Oak Ridge National Laboratory.

U.S. Geological Survey. 1966. Letter to J.E. Reeves (U.S. Atomic Energy Commission) entitled, "Technical Letter: NTS-91, Supplement 2i, Surface Effects from an Underground Explosion at the U11b Site, Nevada Test Site.” 10 June. Opennet Accession Number 127423. U.S. Department of the Interior, Federal Center, Denver, CO. 


\section{Appendix B}

\section{Project Organization}




\section{B.1.0 Project Organization}

The NNSA/NSO Acting Federal Sub-Project Director is Kevin Cabble. He can be contacted at (702) 295-5000.

The identification of the project Health and Safety Officer and the Quality Assurance Officer can be found in the appropriate plan. However, personnel are subject to change and it is suggested that the DOE Federal Sub-Project Director be contacted for further information. The Task Manager will be identified in the FFACO Monthly Activity Report before the start of field activities. 


\section{Appendix C}

\section{Nevada Division of Environmental Protection Comment Responses}

(3 Pages) 


\section{NEVADA ENVIRONMENTAL RESTORATION PROJECT \\ DOCUMENT REVIEW SHEET}

\begin{tabular}{|l|l|}
\hline $\begin{array}{l}\text { 1. Document Title/Number: Draft Corrective Action Investigation Plan for Corrective Action Unit 371: Johnnie } \\
\text { Boy Crater and Pin Stripe, Nevada Test Site, Nevada }\end{array}$ & 2. Document Date: 12/22/2008 \\
\hline 3. Revision Number: 0 & 4. Originator/Organization: Stoller-Navarro \\
\hline 5. Responsible NNSA/NV ERP Project Manager: Kevin J. Cabble & 6. Date Comments Due: 01/21/2009 \\
\hline 7. Review Criteria: Full & \\
\hline 8. Reviewer/Organization/Phone No: Jeff MacDougall, John Wong, NDEP, 486-2850 & 9. Reviewer's Signature: \\
\hline
\end{tabular}

\begin{tabular}{|c|c|c|c|c|}
\hline $\begin{array}{l}\text { 10. Comment } \\
\text { Number/Location }\end{array}$ & 11. Type ${ }^{\star}$ & 12. Comment & 13. Comment Response & 14. Accept \\
\hline $\begin{array}{l}\text { 1.) General } \\
\text { Comment }\end{array}$ & Mandatory & $\begin{array}{l}\text { Present data from individual RIDP points associated } \\
\text { with each CAS and include conversion to exposure } \\
\text { data, if possible. }\end{array}$ & $\begin{array}{l}\text { We believe that it is premature to use RIDP data for } \\
\text { making CAI decisions as we do not yet have } \\
\text { consensus among stakeholders as to how the RIDP } \\
\text { data can be used. Therefore, while the RIDP data is } \\
\text { acknowledged in the CAIP under the identification of } \\
\text { previous investigations, it is not proposed to use this } \\
\text { data in decision making. Significant data will be } \\
\text { generated during the CAU } 371 \text { investigation that will } \\
\text { add to data generated from other Soils investigations } \\
\text { that will be valuable in determining the usefulness of } \\
\text { the RIDP data for future Soils investigations. } \\
\text { Therefore, we suggest that the data from the RIDP } \\
\text { points and the associated conversions not be included } \\
\text { in the CAIP as this data is not used in CAU } 371 \\
\text { decisions. The reference to RIDP data being used to } \\
\text { locate sample plots in Section } 4.2 .2 \text { is misleading and } \\
\text { was deleted, and the sentence was changed to read, } \\
\text { "...based upon the } 1994 \text { flyover radiological survey." } \\
\text { However, if a RIDP location meets the criteria defined } \\
\text { for locating a sample plot, then the sample plot may be } \\
\text { established at that location to further knowledge on the } \\
\text { RIDP data set. }\end{array}$ & \\
\hline $\begin{array}{l}\text { 2.) Sections } 2.1 .1 \\
\text { and } 2.1 .2, \text { Pages } 8 \\
-9\end{array}$ & Mandatory & $\begin{array}{l}\text { Provide the upper and lower range of rainfall with the } \\
\text { mean value and the } 95 \% \text { data value range of the } \\
\text { potential evapotransportation with the average. These } \\
\text { range values should be presented at least once in all } \\
\text { documents, after which averages may then be used } \\
\text { throughout the remainder of the document. }\end{array}$ & $\begin{array}{l}\text { This information regarding rainfall and PET has been } \\
\text { included in Sections 2.1.1 and 2.1.2. }\end{array}$ & \\
\hline
\end{tabular}

\section{UNCONTROLLED When Printed}




\section{NEVADA ENVIRONMENTAL RESTORATION PROJECT \\ DOCUMENT REVIEW SHEET}

\begin{tabular}{|c|c|c|c|c|}
\hline \\
\hline \begin{tabular}{|l|} 
10. Comment \\
Number/Location
\end{tabular} & 11. Type* & 12. Comment & 13. Comment Response & 14. Accept \\
\hline $\begin{array}{l}\text { 3.) Section 2.2.1, } \\
\text { Page } 10\end{array}$ & Mandatory & $\begin{array}{l}\text { Has the fissure associated with CAS 11-23-05 (Pin } \\
\text { Stripe) been located? Provide additional pertinent } \\
\text { information and discussion. }\end{array}$ & $\begin{array}{l}\text { The following text was added as a second sentence in } \\
\text { Section 2.2.1 of the CAIP: "Venting occurred from a } \\
\text { fissure approximately } 30 \text { to } 46 \mathrm{~m} \text { southwest of ground } \\
\text { zero." Site visits have been conducted to the Pin Stripe } \\
\text { area, and the fissure has not been physically located. } \\
\text { No additional information regarding the fissure has } \\
\text { been found. }\end{array}$ & \\
\hline $\begin{array}{l}\text { 4.) Section 2.4, } \\
\text { Page } 11\end{array}$ & Mandatory & $\begin{array}{l}\text { Provide information, references, and/or data that } \\
\text { supports the statement that "...there has been no } \\
\text { known migration of contaminants ...beyond surface } \\
\text { soil..." (how has contaminant migration been studied or } \\
\text { evaluated?). If there is neither information nor data to } \\
\text { support the statement, remove or modify the statement } \\
\text { to accurately reflect what is known or not known about } \\
\text { the releases associated with each CAS. Also, when } \\
\text { referring to surface soil and shallow subsurface soil, } \\
\text { define by depth, at least initially. }\end{array}$ & $\begin{array}{l}\text { The statement is misleading and has been removed } \\
\text { from the document. In addition, beginning in Section } \\
1.1 .2 \text {, the text has been modified to describe that the } \\
\text { release of radioactive materials is to the soil surface. } \\
\text { In Section } 4.2 .3 \text {, the document describes that the } \\
\text { surface soil sample will be collected at } 0 \text { to } 5 \mathrm{~cm} \text {. }\end{array}$ & \\
\hline $\begin{array}{l}\text { 5.) Figure } 3-2 \text {, } \\
\text { Pages } 16-17\end{array}$ & Mandatory & $\begin{array}{l}\text { Should the fissure associated with CAS } 11-23-05 \text { (Pin } \\
\text { Stripe) be included as part of the CSM? Explain why } \\
\text { or why not. }\end{array}$ & $\begin{array}{l}\text { Yes, the fissure is the point of release. The } \\
\text { explanations of the isopleths and atmospheric } \\
\text { deposition have been edited in Figure 3-2 to better } \\
\text { reflect the release from the fissure. }\end{array}$ & \\
\hline $\begin{array}{l}\text { 6.) Sections } 2.5 .1 \\
\text { and 2.5.2, Page } 12\end{array}$ & Mandatory & $\begin{array}{l}\text { Clearly state what "background/natural background" } \\
\text { levels are and provide information as to how this } \\
\text { exposure rate, level, or application concentration was } \\
\text { determined or established. }\end{array}$ & $\begin{array}{l}\text { The references to background/natural background } \\
\text { have been removed from Sections } 2.5 .1 \text { and } 2.5 .2 \text {. } \\
\text { The sentence in Section 2.5.1 was changed to read, } \\
\text { "The exposure rate at Pin Stripe ranged from } 18 \text { to } 24 \\
\text { microroentgens per hour (uR/hr) (BN, 1999)." The } \\
\text { sentence in Section } 2.5 .2 \text { was changed to read, "The } \\
\text { exposure rate at Johnnie Boy ranged from } 39 \text { to } 50 \\
\text { uR/hr." The sentences were edited because in the } \\
\text { context of the referenced sections of the proposed } \\
\text { CAIP, "background/natural background" refers to } \\
\text { exposure rates and associated land areas in the } 1994 \\
\text { aerial radiological survey that are respresentative of } \\
\text { the native areas of the NTS and do not appear to be } \\
\text { affected (on a large scale) by activities on the NTS. }\end{array}$ & \\
\hline
\end{tabular}




\section{NEVADA ENVIRONMENTAL RESTORATION PROJECT \\ DOCUMENT REVIEW SHEET}

\begin{tabular}{|c|c|c|c|c|}
\hline $\begin{array}{l}\text { 10. Comment } \\
\text { Number/Location }\end{array}$ & 11. Type* & 12. Comment & 13. Comment Response & 14. Accept \\
\hline $\begin{array}{l}\text { 7.) Section } 3.3 \text { and } \\
\text { Section } 6.2 .1 \\
\text { Pages } 24,44\end{array}$ & Mandatory & $\begin{array}{l}\text { Reference is made to an "investigation report;" clearly } \\
\text { define/specify where the results of the data } \\
\text { assessment/evaluation will be documented (i.e., in the } \\
\text { subsequent CADD, a separate report). }\end{array}$ & $\begin{array}{l}\text { Reference to the "investigation report" in } 18 \text { locations } \\
\text { within the document have been changed to read, } \\
\text { "CADD." }\end{array}$ & \\
\hline $\begin{array}{l}\text { 8.) Section A.9.1.1 } \\
\text { and Figure A.9-3, } \\
\text { Pages A-37 to A- } \\
42\end{array}$ & Mandatory & $\begin{array}{l}\text { The description and illustration of the sampling } \\
\text { strategy is confusing at best. Clarify, and include an } \\
\text { explanation as to why composite sampling is being } \\
\text { performed (versus regular probabilistic sampling); } \\
\text { include a description of the advantages/disadvantages, } \\
\text { etc., of one sampling strategy compared with the other } \\
\text { (s). }\end{array}$ & $\begin{array}{l}\text { Section A.9.1.1 was reorganized, with additional } \\
\text { explanatory information added. Information on the } \\
\text { judgmental location of sample plots and the } \\
\text { probabilistic location of samples has been inserted in } \\
\text { Section A.9.1. Information on the advantages and } \\
\text { disadvantages of composite samples versus simple } \\
\text { random samples (both under a probabilistic sampling } \\
\text { scheme) was inserted in Section A.5.2.1.1. }\end{array}$ & \\
\hline $\begin{array}{l}\text { 9.) Section 4.2.3, } \\
\text { Page } 34\end{array}$ & Mandatory & $\begin{array}{l}\text { Specify the criteria used for determining whether or not } \\
\text { background samples will be necessary. }\end{array}$ & $\begin{array}{l}\text { The CAIP text in Section } 4.2 .3 \text { was changed to remove } \\
\text { the 4th bullet. The contaminants of potential concern } \\
\text { at CAU } 371 \text { generally do not occur in nature; therefore, } \\
\text { consideration of the contribution from natural } \\
\text { background is not necessary. Background samples will } \\
\text { not be necessary or collected. }\end{array}$ & \\
\hline $\begin{array}{l}\text { 10.) Section 8.0, } \\
\text { Page } 56\end{array}$ & Mandatory & $\begin{array}{l}\text { Modify the reference to document DOE/NV-325 to } \\
\text { reflect the current revision (Revision 7). }\end{array}$ & $\begin{array}{l}\text { The reference to document DOE/NV-325 has been } \\
\text { updated to reflect the current revision (Rev. 7). }\end{array}$ & \\
\hline $\begin{array}{l}\text { 11.) Section } \\
\text { A.9.1.1, Page A-40 }\end{array}$ & Mandatory & $\begin{array}{l}\text { Explain why/how the collection of four composite } \\
\text { samples satisfies the minimum sample size based on } \\
\text { the input parameters referenced in this section. }\end{array}$ & $\begin{array}{l}\text { A paragraph has been added in the CAIP text following } \\
\text { the paragraph which begins "A minimum number of } \\
\text { samples (i.e., composite samples)..." stating, } \\
\text { "Determination of the minimum sample size cannot be } \\
\text { determined until after the data has been generated. } \\
\text { However, based on the input parameters below and } \\
\text { the variability of the data from CAU } 370 \text {, a minimum of } \\
\text { three samples would be required. After the evaluation } \\
\text { of the data for CAU } 371 \text { is complete and the required } \\
\text { number of samples is calculated, additional samples } \\
\text { will be collected if necessary." }\end{array}$ & \\
\hline
\end{tabular}

\section{UNCONTROLLED When Printed}




\title{
Library Distribution List
}

\author{
$\underline{\text { Copies }}$ \\ U.S. Department of Energy \\ 1 (Uncontrolled, electronic copy) \\ National Nuclear Security Administration \\ Nevada Site Office \\ Technical Library \\ P.O. Box 98518, M/S 505 \\ Las Vegas, NV 89193-8518 \\ U.S. Department of Energy \\ Office of Scientific and Technical Information \\ 1 (Uncontrolled, electronic copy) \\ P.O. Box 62 \\ Oak Ridge, TN 37831-0062 \\ Southern Nevada Public Reading Facility \\ 2 (Uncontrolled, electronic copies) \\ c/o Nuclear Testing Archive \\ P.O. Box 98521, M/S 400 \\ Las Vegas, NV 89193-8521 \\ Manager, Northern Nevada FFACO \\ 1 (Uncontrolled, electronic copy) \\ Public Reading Facility \\ c/o Nevada State Library \& Archives \\ 100 N Stewart Street \\ Carson City, NV 89701-4285
}

